Carlos Alberto de Araújo Júnior

\title{
Metodologia de Determinação dos Níveis Metas para as Futuras Condições de Operação do Sistema Interligado Nacional
}

Dissertação apresentada como requisito parcial para obtenção do grau de Mestre pelo Programa de Pós-graduação em Engenharia Elétrica do Departamento de Engenharia Elétrica da PUC-Rio

Orientador: Prof. Alexandre Street de Aguiar 


\section{Metodologia de Determinação dos Níveis Metas para as Futuras Condições de Operação do Sistema Interligado Nacional}

Dissertação apresentada como requisito parcial para obtenção do grau de Mestre pelo Programa de Pós-graduação em Engenharia Elétrica do Departamento de Engenharia Elétrica do Centro Técnico Científico da PUC-Rio. Aprovada pela Comissão Examinadora abaixo assinada.

Prof. Alexandre Street de Aguiar Orientador

Departamento de Engenharia Elétrica - PUC-Rio

Prof. Delberis Araújo Lima Departamento de Engenharia Elétrica - PUC-Rio

Prof. André Luís Marques Marcato Universidade Federal de Juiz de Fora - UFJF

Dr. Alberto Sérgio Kligerman Operador Nacional do Sistema Elétrico - ONS

Prof. José Eugênio Leal Coordenador Setorial do Centro Técnico Científico - PUC-Rio 
Todos os direitos reservados. É proibida a reprodução total ou parcial do trabalho sem autorização da universidade, do autor e do orientador.

\section{Carlos Alberto de Araújo Júnior}

Graduou-se em Engenharia Elétrica na Universidade Federal de Juiz de Fora (Juiz de Fora, MG). Atualmente trabalha no Operador Nacional do Sistema Elétrico, onde atua na área de modelos de otimização para o planejamento da operação energética do Sistema Interligado Nacional.

Ficha Catalográfica

de Araújo Júnior, Carlos Alberto

Metodologia de Determinação dos Níveis Metas para as Futuras Condições de Operação do Sistema Interligado Nacional / Carlos Alberto de Araújo Júnior; orientador: Alexandre Street de Aguiar. - 2013.

78 f: il.(color) ; $30 \mathrm{~cm}$

1. Dissertação (mestrado) - Pontifícia Universidade Católica do Rio de Janeiro, Departamento de Engenharia Elétrica, 2013.

Inclui bibliografia.

1. Engenharia Elétrica - Tese. 2. Métodos de Apoio à Decisão; Otimização; Planejamento da Operação de Sistemas Hidrotérmicos. I. de Aguiar, Alexandre Street. II. Pontifícia Universidade Católica do Rio de Janeiro. Departamento de Engenharia Elétrica. III. Título. 


\section{Agradecimentos}

Dedico meus sinceros agradecimentos:

Inicialmente a Deus, pela vida e oportunidade constante de aprendizado.

Aos meus pais, Carlos Alberto e Sônia Maria, e irmãos, Priscilla, Nathália e Marcus, pelo apoio e incentivo em todos os instantes da minha vida.

Especialmente e carinhosamente à amiga Maria Cândida, pelos muitos momentos compartilhados de trabalho e estudo, fundamentais para a realização desta dissertação.

Ao meu orientador Alexandre Street, pela confiança e orientação neste trabalho.

Aos meus gestores no Operador Nacional do Sistema Elétrico, Alberto Kligerman e Roberto Fontoura, que me possibilitaram a realização deste trabalho, concedendo a oportunidade de cursar o mestrado.

Ao amigo Murilo Soares, pela amizade e ajuda sempre que precisei.

Aos membros da banca, Alberto Kligerman, André Marcato e Delberis Lima, e ao amigo Bruno Dias, pelas sugestões na revisão desta dissertação.

Aos amigos do Operador Nacional do Sistema Elétrico, em especial aos amigos da Gerência de Metodologias e Modelos Energéticos, pelo apoio e oportunidade de aprender a cada dia mais.

A PUC-Rio pelo apoio financeiro recebido durante a realização deste trabalho.

Aos amigos que fiz na PUC-Rio ao longo destes dois anos, que de alguma forma contribuíram para a realização deste trabalho. 


\section{Resumo}

de Araújo Júnior, Carlos Alberto; de Aguiar, Alexandre Street. Metodologia de Determinação dos Níveis Metas para as Futuras Condições de Operação do Sistema Interligado Nacional. Rio de Janeiro, 2013. 78p. Dissertação de Mestrado - Departamento de Engenharia Elétrica, Pontifícia Universidade Católica do Rio de Janeiro.

O Sistema Interligado Nacional Brasileiro (SIN) é um sistema hidrotérmico com forte predominância de geração hidráulica, caracterizado pela existência de reservatórios de grande porte com regularização plurianual. Contudo, com a perspectiva da entrada em operação na região Amazônica de novas usinas de grande porte quanto à capacidade de geração, mas de pequena capacidade de regularização, tem-se a perspectiva de mudanças no atual perfil de operação do SIN em função da região Amazônica possuir um forte ciclo sazonal e baixa complementariedade com as demais regiões do Brasil. Com isto, a metodologia atualmente utilizada, que minimiza o valor esperado do custo total de operação, tende a elevar o risco dos reservatórios do subsistema Sudeste atingirem níveis baixos no fim do período seco, supondo que com a importação de energia da região Amazônica no período úmido o armazenamento, em média, possa ser recuperado. O deplecionamento a níveis baixos dos reservatórios do subsistema Sudeste pode significar um aumento no risco de atendimento à demanda energética, caso venha a se configurar um cenário de afluência desfavorável no período úmido. Isso requer aprimoramentos metodológicos a fim de considerar este novo perfil de operação do SIN. Neste contexto, este trabalho propõe o desenvolvimento de uma modelagem utilizando métodos de apoio multicritério à decisão, que permite a consideração de múltiplos objetivos, para definição do nível mínimo de armazenamento do subsistema Sudeste ao final do período seco de forma a minimizar o valor esperado do custo, dado que se garanta a segurança energética do SIN. O desempenho da metodologia proposta foi avaliado por meio de estudos de casos aplicados ao SIN, para a condição atual e futura, nas quais as novas usinas da região Amazônica estão totalmente motorizadas, e os resultados obtidos, assim como as vantagens observadas ao se utilizar a metodologia multicritério, são discutidos ao longo do texto.

\section{Palavras-chave}

Métodos de Apoio à Decisão; Otimização; Planejamento da Operação de Sistemas Hidrotérmicos. 


\section{Abstract}

de Araújo Júnior, Carlos Alberto; de Aguiar, Alexandre Street (Advisor). Methodology for the Determination of Level Goals for Future Operating Conditions of the National Interconnected System. Rio de Janeiro, 2013. 78p. MSc. Dissertation - Departamento de Engenharia Elétrica, Pontifícia Universidade Católica do Rio de Janeiro.

The Brazilian National Interconnected System (SIN) is a large scale hydrothermal system with a strong predominance of hydro generation, characterized by large reservoirs with multi-annual regularization capabilities. However, with the prospect of entry in operation in the Amazon region of new large plants with high generation capacity but low inflows regularization capacity, methodological changes in the energy planning operations are expected due to Amazon's region strong seasonal cycle and low complementarity with other regions of Brazil. This way, the current methodology, which minimizes the expected value of the total operations cost, tends to raise the risk of the drawdown of the Southeast subsystem reservoirs reaching low levels at the end of the dry season, with the assumption that the reservoirs, on average, will be recovered by the energy imported from Amazon during the wet season. The low drawdown of Southeast subsystem reservoirs can pose a risk for dry scenarios, which may not be able to meet the energy demand. In this context, this work proposes the development of a model using multicriteria decision support methods, which allows consideration of multiple objectives, to define the minimum level of storage of the Southeast subsystem at the end of the dry season to minimize the expected value of cost, provided that it guarantees the energy security of the SIN during the next year. The performance of the proposed methodology has been evaluated by means of case studies applied to SIN, for both the current conditions and the expected future conditions. The results obtained, as well as the advantages observed when using the multicriteria methodology, are discussed throughout the text.

\section{Keywords}

Decision Support Methods; Optimization; Operation Planning of Hydrothermal Systems. 


\section{Sumário}

1 Introdução 11

1.1 Motivação do Trabalho 11

$\begin{array}{lll}1.2 & \text { Objetivo do Trabalho } & 12\end{array}$

1.3 Organização do Trabalho 12

2 Revisão Bibliográfica dos Métodos de Apoio Multicritério a

Decisão $\quad 14$

2.1 Introdução 14

2.2 Métodos de Decisão Multiatributo ou Multicritério 15

2.3 Métodos de Decisão Multiobjetivo 24

2.4 Aplicações dos Métodos de Apoio à Decisão 28

3 Planejamento da Operação de Sistemas Hidrotérmicos 31

3.1 Introdução 31

3.2 O Sistema Interligado Nacional 32

3.3 Histórico do Planejamento Energético no Brasil 33

3.4 Etapas do Planejamento 34

3.5 Metodologia de Segurança Operativa 36

4 Operação do SIN Frente à Entrada de Usinas a Fio D'água de Grande Porte na Região Amazônica $\quad 41$

4.1 Introdução $\quad 41$

4.2 Características da Região Amazônica 43

4.3 Análise da Operação Frente à Nova Configuração 45

5 Metodologia Proposta para a Determinação dos Níveis Metas $\quad 49$

5.1 Introdução 49

5.2 Sistema de Apoio à Decisão 49

5.3 Processo de Obtenção dos Dados para o Sistema de Apoio à Decisão 52

6 Estudos de Casos $\quad 56$

6.1 Introdução $\quad 56$

6.2 Primeiro Estudo de Caso: Condição Atual do Sistema 56

6.3 Segundo Estudo de Caso: Novas Usinas Motorizadas 60

6.4 Análise de Sensibilidade 64

7 Conclusões e Trabalhos Futuros $\quad \mathbf{7 2}$

$\begin{array}{lll}7.1 & \text { Conclusões } & 72\end{array}$

$\begin{array}{lll}7.2 & \text { Trabalhos Futuros } & 73\end{array}$ 


\section{Lista de Figuras}

2.1 Classificação dos Métodos de Apoio Multicritério à Decisão 15

2.2 Estrutura Hierárquica do Método AHP 18

2.3 Exemplo das Relações de Superação do Método ELECTRE I 20

2.4 Regras do Cálculo da Medida de Discordância e Concordância 21

2.5 Funções de Preferência Relativa 23

2.6 Exemplo do Método da Distância Mínima à Solução Ideal 25

3.1 Consequências Operativas das Decisões Adotadas 32

3.2 Repartição da Potência Instalada e da Energia Gerada 32

3.3 Cadeia de Modelos 35

3.4 Evolução do Armazenamento do Subsistema Sudeste 36

3.5 Objetivo da CAR 37

3.6 Determinação do Nível de Segurança 39

3.7 Metodologia Atual de Determinação dos Níveis Metas 40

4.1 Bacias Hidrográficas $\quad 41$

4.2 Potencial Hidroelétrico Brasileiro 42

4.3 Energia Afluente Média 44

4.4 Participação Regional na Capacidade Instalada do SIN 44

4.5 Motorização das Novas Usinas da Região Amazônica 46

4.6 Percentual de Séries Abaixo de $10 \%$ do Armazenamento e Motorização das Novas Usinas da Região Amazônica 47

4.7 Valor Médio das Séries Simuladas para o Sudeste, Bacia do Paraná 48

4.8 Valor Médio das Séries Simuladas para o Sudeste, Bacia do Paraná, e Sudeste, Menos Bacia do Paraná 48

5.1 Funções de Preferências Utilizadas $\quad 51$

5.2 Valores Percentuais dos Pesos 53

6.1 Pesos e Limiares Utilizados nos Estudos de Casos 57

6.2 Avaliações das Alternativas de Maior e Menor Armazenamento Caso: Novas Usinas Motorizadas $\quad 67$

6.3 Avaliação da Melhor Alternativa - Caso: Novas Usinas Motorizadas 68

6.4 Intervalos de Confiança para Variação dos Pesos sem Alteração da Melhor Alternativa - Caso: Novas Usinas Motorizadas

6.5 Intervalos de Confiança para Variação dos Pesos sem Alteração da Melhor Alternativa para a Etapa de Refinamento da Solução Caso: Novas Usinas Motorizadas

6.6 Curva de Pareto da Etapa 1 - Caso: Novas Usinas Motorizadas 70

6.7 Curva de Pareto da Etapa 2 - Caso: Novas Usinas Motorizadas 71 


\section{Lista de Tabelas}

$\begin{array}{lll}2.1 & \text { Escala Fundamental de Saaty } & 19\end{array}$

4.1 Potencial Hidrelétrico Brasileiro (MW) 43

4.2 Novas Principais Usinas da Região Amazônica 45

6.1 Variáveis Observadas - Caso: Condição Atual do Sistema 58

6.2 Ordem das Alternativas - Caso: Condição Atual do Sistema 59

6.3 Variáveis Observadas para a Etapa de Refinamento da Solução Caso: Condição Atual do Sistema

6.4 Ordem das Alternativas para a Etapa de Refinamento da Solução - Caso: Condição Atual do Sistema

6.5 Variáveis Observadas - Caso: Novas Usinas Motorizadas

6.6 Ordem das Alternativas - Caso: Novas Usinas Motorizadas

6.7 Variáveis Observadas para a Etapa de Refinamento da Solução Caso: Novas Usinas Motorizadas

6.8 Ordem das Alternativas para a Etapa de Refinamento da Solução - Caso: Novas Usinas Motorizadas

6.9 Resultados em Relação a Variação dos Pesos - Caso: Novas Usinas Motorizadas 
"Gravity explains the motions of the planets, but it cannot explain who set the planets in motion. God governs all things and knows all that is or can be done." ("A gravidade explica os movimentos dos planetas, mas não pode explicar quem colocou os planetas em movimento. Deus governa todas as coisas e sabe tudo que é ou que pode ser feito.")

Sir Isaac Newton 


\section{Introdução}

\section{1}

\section{Motivação do Trabalho}

O Sistema Interligado Nacional Brasileiro (SIN) é um sistema hidrotérmico com forte predominância de geração hidráulica [1, 2], caracterizado por reservatórios de grande porte com regularização plurianual. Com a perspectiva da entrada em operação na região Amazônica de novas usinas de grande porte quanto à capacidade de geração, mas de pequena capacidade de regularização [3], tem-se a perspectiva de mudanças metodológicas no planejamento da operação do SIN, uma vez que este, gradativamente, poderá se encaminhar ao longo dos próximos anos para um regime de regularização anual.

A região Amazônica possui um ciclo sazonal bem definido, com alta afluência no período úmido e baixa no período seco [3]. Com vistas a melhor utilizar esta característica hidrológica, a metodologia atual, que minimiza o valor esperado do custo total de operação (custo de geração termoelétrica mais penalidade por não suprimento da demanda), tende a elevar o risco dos reservatórios do subsistema Sudeste atingirem níveis baixos no fim do período seco. Isso porque o modelo supõe que o armazenamento do subsistema Sudeste será recuperado, em média, com a importação de energia da região Amazônica no período úmido. Há, portanto, dependência de transmissão de intenso fluxo de energia proveniente da região Amazônica neste período e o deplecionamento a níveis mínimos dos reservatórios do subsistema Sudeste pode significar um risco de atendimento à demanda energética caso venha a se configurar um cenário desfavorável. Isto leva à necessidade de ajustes de metodologias e critérios de operação, de forma a garantir a segurança energética com economicidade.

Atualmente os níveis mínimos estabelecidos para os subsistemas Sudeste/Centro-Oeste e Nordeste (níveis metas) são determinados através de cálculo recursivo utilizando a metodologia da Curva de Aversão a Risco (CAR) [4], contudo, com a nova configuração do Sistema Interligado Nacional (SIN), a determinação dos níveis metas com a metodologia atual pode vir se tornar difícil devido à:

- dificuldade no estabelecimento da série hidrológica crítica; 
- dificuldade em estabelecer premissas de intercâmbio, o que pode ser agravado com a perspectiva de aumento do número de subsistemas nos estudos de planejamento do SIN;

- necessidade de tratamento de outras condicionantes que não são consideradas na metodologia atual, tais como o custo para alcançar os níveis metas.

\section{2}

\section{Objetivo do Trabalho}

Nesta dissertação apresenta-se a proposta de desenvolvimento de uma modelagem para definição dos níveis mínimos de armazenamento ao final do período seco utilizando metodologia de apoio multicritério à decisão, que captura as preferências dos decisores, visando auxiliar o operador nos estudos de planejamento da operação energética frente à nova configuração do SIN e contornar as possíveis dificuldades apontadas em determinar os níveis metas utilizando a metodologia atual.

\section{3}

\section{Organização do Trabalho}

A dissertação está organizada em 7 capítulos, iniciados por esta introdução que contém a motivação, objetivo e organização do trabalho.

O Capítulo 2 apresenta os resultados da revisão bibliográfica realizada sobre métodos de apóio multicritério a decisão e aplicações existentes na literatura, principalmente no contexto de planejamento da operação energética.

O Capítulo 3 descreve as principais características do problema de planejamento da operação de sistemas hidrotérmicos, as principais características do SIN e as metodologias de segurança utilizadas atualmente nos estudos de planejamento da operação.

O Capítulo 4 descreve as principais características da operação do SIN frente à nova configuração, ou seja, após a entrada de usinas a fio d'água de grande porte na região Amazônica.

O Capítulo 5 descreve a metodologia proposta para especificação, construção e calibração do sistema de apoio à decisão que será utilizado para a definição dos níveis metas.

No Capítulo 6 são abordados estudos de casos onde a metodologia proposta é aplicada nos estudos de planejamento da operação do SIN, nas condições atual e futura, ou seja, após a total motorização das novas usinas da região Amazônica. 
O Capítulo 7 corresponde às conclusões e trabalhos futuros. Este capítulo realiza uma breve revisão do trabalho e lista as principais melhorias que podem ser incorporadas futuramente ao sistema de apoio multicritério à decisão desenvolvido. 


\section{Revisão Bibliográfica dos Métodos de Apoio Multicritério a Decisão}

\section{1 \\ Introdução}

Classicamente, os processos decisórios sempre buscaram a identificação da solução ótima, através da maximização ou minimização do valor de uma determinada função objetivo. Atualmente, com o surgimento de demandas sociais que exigem a consideração de múltiplos objetivos na condução de atividades, se tornou fundamental a participação humana na maioria das decisões. Neste contexto, buscar a solução ótima com a informação que a modelagem computacional é capaz de tratar, baseando-se em apenas um objetivo, se tornou insuficiente. Para suprir a necessidade de consideração de múltiplos objetivos, muitas vezes conflitantes, pode-se recorrer a um sistema de apoio à decisão, cujo principal objetivo é transformar toda a informação disponível em conhecimento à disposição do decisor, mesmo que não sejam consideradas explicitamente pelo modelo de otimização $[5,6]$.

Em um problema de otimização com múltiplos objetivos conflitantes, não existe uma única solução que seja ótima para todos os objetivos simultaneamente. Por isto, é importante a noção de dominância, que é básica para vários métodos de apoio à decisão. $\mathrm{O}$ conceito de dominância diz que: uma solução pertence ao conjunto de soluções dominantes se não existir uma outra solução que seja melhor do que ela simultaneamente em todos os objetivos, ou seja, a melhoria em um objetivo apenas pode ser alcançado por degradação de pelo menos um dos outros. Uma solução é considerada dominada se existir outra que seja melhor do que ela em pelo menos um objetivo, permanecendo inalterados os restantes [6].

O campo de conhecimento chamado de Apoio Multicritério a Decisão (AMD) envolve uma vasta gama de métodos que têm como princípio básico buscar o estabelecimento da estrutura de preferências relacionada às consequências da decisão e propiciar a avaliação das alternativas de ação que possam ser consideradas no problema em tratamento, ou seja, os métodos AMD auxiliam os decisores a compreender e explicitar suas preferências junto às alternativas [7]. 
Na literatura existem várias maneiras de classificação; neste trabalho será abordada a que diferencia as técnicas em Multiatributo (MADM) e Multiobjetivo (MODM) [7, 8], Figura 2.1.

\section{Métodos de Apoio multicritério a Decisão}

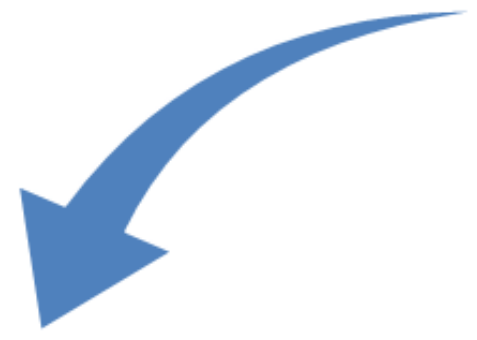

Multiatributo

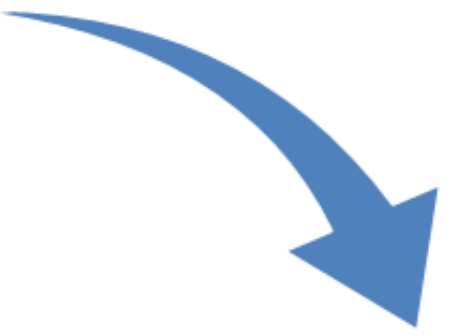

Multiobjetivo

Figura 2.1: Classificação dos Métodos de Apoio Multicritério à Decisão

- Decisão Multiatributo ou Multicritério: Esta categoria de métodos engloba os métodos de seleção, ordenação ou categorização de um número finito, ou seja, discreto, de alternativas. São os métodos MADM Multiple Attribute Decision Making.

- Decisão Multiobjetivo: Esta categoria de métodos engloba os métodos contínuos, ou seja, com um número infinito de alternativas. Também denominados métodos de otimização multicritério, compreendendo basicamente métodos de programação matemática com mais de uma função objetivo. São conhecidos por MODM - Multiple Objective Decision Making ou MOP - Multiple Objective Programming.

\section{2}

\section{Métodos de Decisão Multiatributo ou Multicritério}

Os métodos MADM podem ser organizados em duas classes [7, 8]:

- Métodos compensatórios ou de função única de síntese: Nesta classe de métodos, os critérios são agrupados em uma única função de forma compensatória.

- Métodos não compensatórios ou de sobreclassificação: Nesta classe de métodos, os critérios não são agrupados em uma única função, estes métodos utilizam a ideia de sobreclassificação, ou seja, dominância de uma alternativa em relação à outra. 


\subsection{1}

\section{Métodos Compensatórios ou de Função Única de Síntese}

O objetivo dos métodos pertencentes a esta classe é agregar os critérios de forma compensatória através de uma única função visando sintetizar o objetivo global [7].

\section{Método MAUT}

MAUT do Inglês Multi-Attribute Utility Theory é a sigla para Teoria da Utilidade Multiatributo, que foi derivada da teoria da utilidade para problemas envolvendo múltiplos critérios [7].

A Teoria da Utilidade [9] é a representação das preferências de um indivíduo entre os elementos de um conjunto, usando-se números para representá-los, ou seja, na teoria da utilidade a satisfação de um individuo é representada por uma função, denominada função utilidade, $u(x)$ que representa a satisfação do individuo com relação a determinado vetor de variável de decisão " $x$ ". A utilidade é uma expressão quantitativa do valor de satisfação associado a um resultado.

A Teoria da Utilidade Multiatributo parte da construção de funções utilidades individuais $u_{i}$ para cada critério " $i$ ", para em seguida agregar as diversas funções em uma única função utilidade. As diversas funções utilidades podem ser agregadas em uma única função utilidade na forma aditiva ou multilinear:

- Forma multilinear:

A forma multilinear é uma forma de agregação mais geral, com a vantagem de permitir dependência entre os critérios.

$$
U\left(x_{1}, x_{2}\right)=k_{1} u_{1}\left(x_{1}\right)+k_{2} u_{2}\left(x_{2}\right)+k_{12} u_{1}\left(x_{1}\right) u_{2}\left(x_{2}\right)
$$

- Forma aditiva:

A forma aditiva é uma simplificação da forma multilinear, esta propriedade pode facilitar bastante o trabalho de obtenção da utilidade total, mas só pode ser utilizada quando há independência entre os critérios.

$$
U\left(x_{1}, x_{2}\right)=k_{1} u_{1}\left(x_{1}\right)+k_{2} u_{2}\left(x_{2}\right)
$$

Após agregar as diversas funções utilidades em uma única função, as constantes de escala $k_{i}$ são definidas comparando os critérios dois a dois, de forma a atribuir maior valor ao critério mais importante para o decisor [7]. 


\section{Método SMART}

SMART do inglês Simple Multi-Attribute Rating Technique [10] é a sigla para Técnica de Simples Avaliação Multi-Atributo. SMART é uma simplificação do MAUT, onde as preferências são medidas em uma escala única, sendo que para conseguir obter os pesos para cada um dos critérios, é explorada a noção de que em um modelo aditivo os pesos representam a importância relativa de um atributo em relação aos outros, ou seja, o decisor julga o grau de importância de cada atributo em relação aos outros e estes julgamentos são colocados num conjunto de pesos normalizados, por exemplo, de 0 a 1 ficando a pior alternativa com 0 e a melhor com 1 e todos os valores intermediários proporcionalmente distribuídos entre 0 e 1 , deste modo o decisor expressa suas preferências de forma linear [11].

\section{Método MACBETH}

MACBETH do inglês Measuring Attractiveness by a categorical based Evaluation Technique [12]. É um método de julgamento semântico para atribuição dos pesos. Ao contrário dos outros métodos, onde o decisor estabelece valores quantitativos, neste método os critérios são avaliados por conceitos, ou seja, requer apenas julgamentos qualitativos sobre as diferenças de atratividade entre os critérios. Após a elaboração dos julgamentos o método transporta as avaliações verbais para uma escala numérica utilizando programação linear e aplica o modelo aditivo, apresentado no método MAUT [13].

\section{Método AHP}

Do inglês Analytic Hierarchy Process, é a sigla para Método da Análise Hierárquica [14]. No AHP o problema de decisão é dividido em níveis hierárquicos. No topo da estrutura é representado o problema geral e nos níveis inferiores sucessivamente são colocados os critérios que representam algum impacto no critério do nível acima em que está ligado, no último nível da estrutura estão as alternativas consideradas [7]. A Figura 2.2 apresenta a estrutura hierárquica do método AHP.

Depois de construída a estrutura hierárquica, é feita uma comparação par a par de cada critério, subcritério e alternativa, através de uma matriz de decisão quadrada, utilizando a Escala Fundamental de Saaty, Tabela 2.1 [7]. O objetivo desta etapa é expressar o grau de preferência do decisor.

Após definidas as preferências do decisor, são calculados os valores dos pesos para cada critério, subcritério e alternativa da estrutura. Para obter os valores finais, para cada alternativa deve-se multiplicar todos os pesos obtidos 


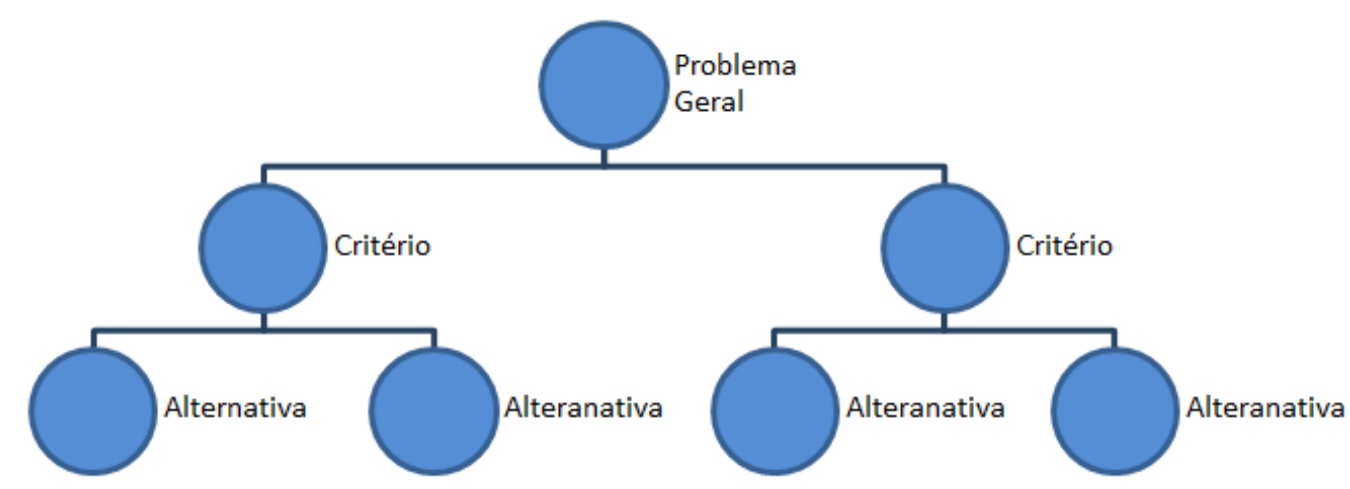

Figura 2.2: Estrutura Hierárquica do Método AHP

em cada passo e os resultados dos diferentes níveis hierárquicos devem ser somados [7].

\subsection{2}

\section{Métodos Não Compensatórios ou de Sobreclassificação}

Esta classe de métodos utiliza a ideia de sobreclassificação, ou seja, de dominância de uma alternativa em relação à outra. Os métodos que utilizam a ideia de sobreclassificação seguem duas etapas: Construção das relações de sobreclassificação, que consiste numa comparação par a par das alternativas levando em conta todos os critérios, e exploração das relações de sobreclassificação [7].

\section{Método ELECTRE I}

O método ELECTRE I, do francês Elimination et Choix Traduisant la Réalité [15], tem como objetivo definir o menor subconjunto possível com as melhores alternativas, denominado mínimo subconjunto dominante, onde toda alternativa pertencente ao subconjunto não é superada por nenhuma alternativa também pertencente a este subconjunto e, para toda alternativa não pertencente ao subconjunto, existe uma outra pertencente que a supera. Para isso são calculados os índices de concordância e discordância de cada alternativa [7]:

- Índice de concordância: é um índice calculado com base nos critérios nos quais a alternativa " $a$ " supera a alternativa " $b$ ".

- Índice de discordância: é um índice calculado com base nos critérios nos quais a alternativa " $a$ " é superada pela alternativa " $b$ ".

Os índices de concordância e discordância são comparados com tolerâncias pré-estabelecidas, limiar de concordância e o limiar de discordância. 
Tabela 2.1: Escala Fundamental de Saaty

\begin{tabular}{c|l|l}
\hline 1 & Igual importância & $\begin{array}{l}\text { As duas atividades contribuem igual- } \\
\text { mente para o objetivo. }\end{array}$ \\
\hline 3 & $\begin{array}{l}\text { Importância pequena } \\
\text { de uma a sobre outra }\end{array}$ & $\begin{array}{l}\text { A experiência e o julgamento favorecem } \\
\text { levemente uma atividade em relação à } \\
\text { outra. }\end{array}$ \\
\hline 5 & $\begin{array}{l}\text { Importância grande } \\
\text { ou essencial }\end{array}$ & $\begin{array}{l}\text { A experiência e o julgamento favorecem } \\
\text { fortemente uma atividade em relação à } \\
\text { outra. }\end{array}$ \\
\hline 7 & $\begin{array}{l}\text { Importância muito } \\
\text { grande ou demons- } \\
\text { trada }\end{array}$ & $\begin{array}{l}\text { Uma atividade é muito fortemente fa- } \\
\text { vorecida em relação à outra, sua do- } \\
\text { minação de importância é demonstrada } \\
\text { na prática. }\end{array}$ \\
\hline 9 & $\begin{array}{l}\text { Importância absoluta } \\
\text { A evidência favorece uma atividade em } \\
\text { relação à outra com o mais alto grau de } \\
\text { certeza. }\end{array}$ \\
\hline $2,4,6,8$ & Valores intermediários & $\begin{array}{l}\text { Quando se procura uma condição de } \\
\text { compromisso entre duas definições. }\end{array}$ \\
\hline
\end{tabular}

Desta forma, a alternativa " $a$ " só supera a alternativa "b" se, e somente se o índice de concordância for maior que o limiar de concordância e o índice de discordância for menor que o limiar de discordância.

Em seguida é feita uma análise das relações de superação através de um grafo, onde os vértices identificam as alternativas e os arcos as relações de superação $[7,16]$. A Figura 2.3 apresenta um exemplo onde as alternativas "3" e "4" são superadas pelas alternativas "1" e "2", e as alternativas "1" e "2" não superadas, formam o subconjunto de soluções dominantes [7].

\section{Método ELECTRE II}

O método ELECTRE II é o método ELECTRE I com o aprimoramento de ordenar as alternativas. Para isso são definidas, com base nas tolerâncias (limiares), duas relações de superação, uma forte (tolerâncias restritas) e uma fraca (tolerâncias menos restritas). A partir destas relações, são gerados dois grafos, sendo cada grafo gerado conforme apresentado no método ELECTRE I, e iniciado um processo iterativo, onde para as alternativas que são dominantes nos dois grafos é associado um grau de dominância maior e retiradas. O processo é repetido até que todas as alternativas sejam retiradas, cada vez é atribuindo graus de dominância menores, até que não reste nenhuma, então elas são ordenadas pelo seu grau de dominância [7]. 


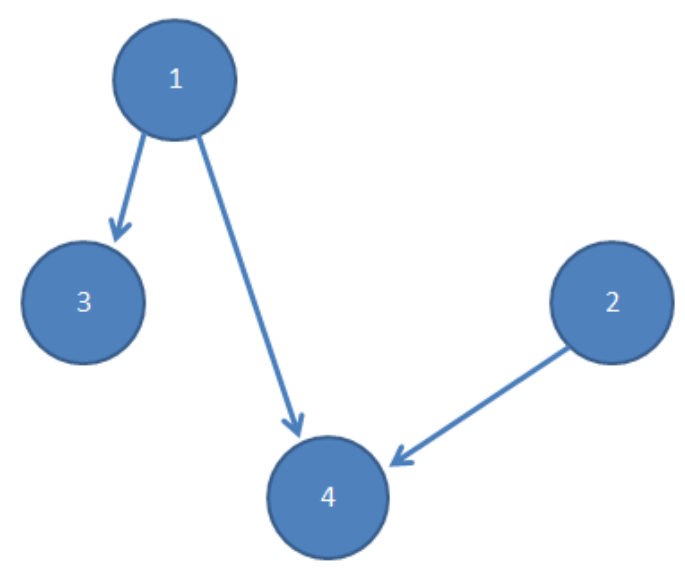

Figura 2.3: Exemplo das Relações de Superação do Método ELECTRE I

\section{Método ELECTRE III}

O método ELECTRE III, assim como o ELECTRE II, tem como objetivo classificar as diversas alternativas, com o aprimoramento de evitar que uma avaliação muito ruim em um determinado critério seja compensada com boas avaliações em outros critérios [17].

O método considera que ao comparar duas alternativas, "a" e "b", com base em um determinado critério " $j "$, o decisor pode optar por uma das relações [17]:

- Indiferença entre as alternativas: Uma alternativa é indiferente à outra se a diferença entre elas for inferior ao limite de indiferença $q_{j}$;

- Preferência fraca por uma alternativa em relação à outra: Uma alternativa é fracamente preferível à outra se a diferença entre elas for superior ao limite de indiferença $q_{j}$ e inferior ao limite de preferência $p_{j}$;

- Preferência estrita de uma alternativa em relação à outra: Uma alternativa é estritamente preferível à outra se a diferença entre elas for superior ao limite de preferência $p_{j}$ e inferior ao limite de veto $v_{j}$;

- Poder de veto de uma alternativa em relação à outra: Uma alternativa tem poder de veto sobre outra se a diferença entre elas for superior ao limite de veto $v_{j}$.

Com base nas relações acima, as alternativas são comparadas par a par e, para cada critério, é calculada uma medida que indica o quanto se aceita que a alternativa " $a$ " é tão boa quanto à " $b$ " e o quanto se rejeita que a alternativa " $a$ " é tão boa quanto à " $b$ ". A regra de cálculo desta medida é apresentada na Figura 2.4. 
A Figura 2.4 ilustra como são calculados, por critério, os índices de concordância e discordância. Considerando $Z_{j}$ a função de avaliação do critério " $j "$, tem-se que [17]:

Situações de concordância:

- se avaliação da alternativa " $a$ " $\left(Z_{j}(a)\right)$ for superior à avaliação da alternativa " $b$ " exceto pelo índice de indiferença $\left(Z_{j}(b)-q_{j}(b)\right)$, a concordância assume seu valor máximo 1 .

- se avaliação da alternativa " $a$ " $\left(Z_{j}(a)\right)$ for inferior à avaliação da alternativa "b" exceto pelo índice de indiferença $\left(Z_{j}(b)-q_{j}(b)\right)$ e superior a alternativa " $a$ " exceto pelo índice de preferência $\left(Z_{j}(b)-p_{j}(b)\right)$, a concordância assume valores entre 0 e 1.

- se avaliação da alternativa " $a$ " $\left(Z_{j}(a)\right)$ for inferior à avaliação da alternativa "b" exceto pelo índice de preferência $\left(Z_{j}(b)-p_{j}(b)\right)$, a concordância assume o valor mínimo 0 .

Situações de discordância:

- se avaliação da alternativa " $a$ " $\left(Z_{j}(a)\right)$ for superior à avaliação da alternativa " $b$ " exceto pelo índice de preferência $\left(Z_{j}(b)-p_{j}(b)\right)$, a discordância assume o valor mínimo 0.

- se avaliação da alternativa " $a$ " $\left(Z_{j}(a)\right)$ for inferior à avaliação da alternativa " $b$ " exceto pelo índice de preferência $\left(Z_{j}(b)-p_{j}(b)\right)$, e superior a alternativa " $b$ " exceto pelo índice de veto $\left(Z_{j}(b)-v_{j}(b)\right)$, a discordância assume valores entre 0 e 1 .

- se avaliação da alternativa " $a$ " $\left(Z_{j}(a)\right)$ for inferior à avaliação da alternativa " $b$ " exceto pelo limite de veto $\left(Z_{j}(b)-v_{j}(b)\right)$, a concordância assume seu valor máximo 1.

\section{Discordância}

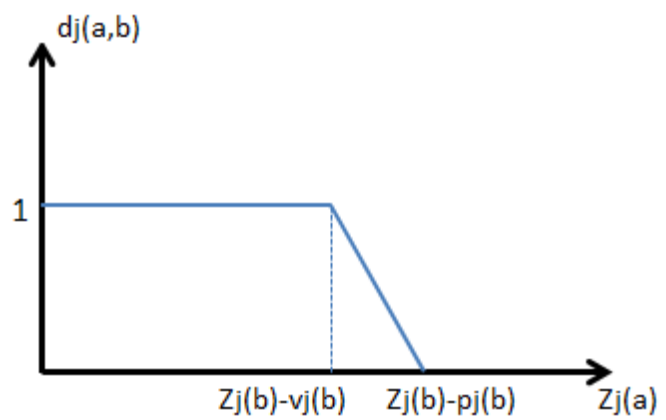

Concordância

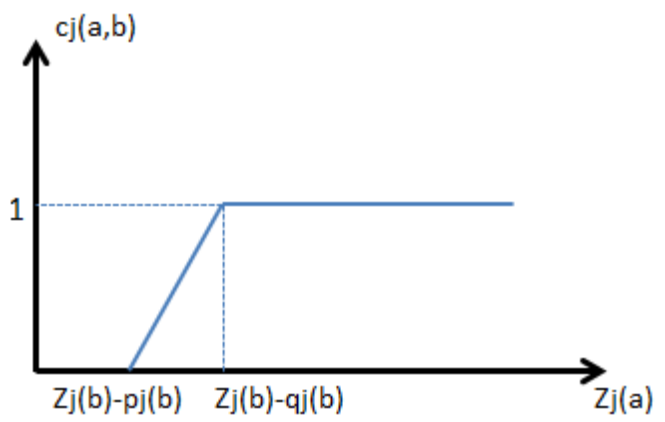

Figura 2.4: Regras do Cálculo da Medida de Discordância e Concordância 
Em seguida são calculados os índices de concordância para cada par de alternativas conforme equação:

$$
C(a, b)=\frac{1}{K} \times \sum_{j=1}^{n} k_{j} c_{j}(a, b)
$$

Sendo " $k$ " o somatório dos pesos de todos os critérios e " $n$ " o número de critérios.

Após o cálculo dos índices de concordância, são calculados os índices de credibilidade $S(a, b)$. Estes índices expressam quanto se admite que a alternativa " $a$ " subordina a alternativa " $b$ " utilizando a medida de discordância $d_{j}(a, b)$ para enfraquecer o índice de concordância $C(a, b)$, nos casos em que a medida de discordância seja superior ao índice de concordância em pelo menos um critério.

O passo seguinte é ordenar as alternativas com base nos valores dos índices de credibilidade, construindo uma matriz de subordinação T(a,b) composta de valores 0 ou 1 .

A seguir, as alternativas são ordenadas com base na totalização do número de vezes que a alternativa " $a$ " subordina as demais alternativas (valores 1 na matriz $T(a, b))$ menos o número de vezes que a alternativa " $a$ " é subordinada pelas demais (valores 0 da matriz $\mathrm{T}(\mathrm{a}, \mathrm{b})$ ) [17].

\section{Método PROMETHEE I}

O método PROMETHEE I, do inglês Preference Ranking Organization Method for Enrichment Evaluation [18], tem como objetivo obter uma ordem das alternativas. Para isso, calcula a preferência com base na diferença $\delta_{i k}$ para cada par de alternativas " $i$ " e " $k$ " em relação a cada critério " $j "$. Para expressar o grau de intensidade da preferência de uma alternativa em relação à outra, o método faz uso de seis funções de preferência relativa $[7,16,19]$. A Figura 2.5 apresenta estas funções, onde o limiar de preferência e indiferença são representados, respectivamente por " $p$ " e " $q$ ".

Para cada critério é definido uma função de preferência e os limiares de preferência e indiferença. Depois de calculado a preferência de uma alternativa em relação à outra para cada par de alternativas em relação a cada critério é calculado o índice geral da preferência $[7,16]$ :

$$
S_{i k}=\frac{\sum_{j} W_{j} P_{j}\left(\delta_{i k}\right)}{\sum_{j} W_{j}}
$$

Onde:

$W_{j}=$ peso do critério " $j$ ";

$P_{j}=$ função de preferência relativa do critério " $j$ "; 

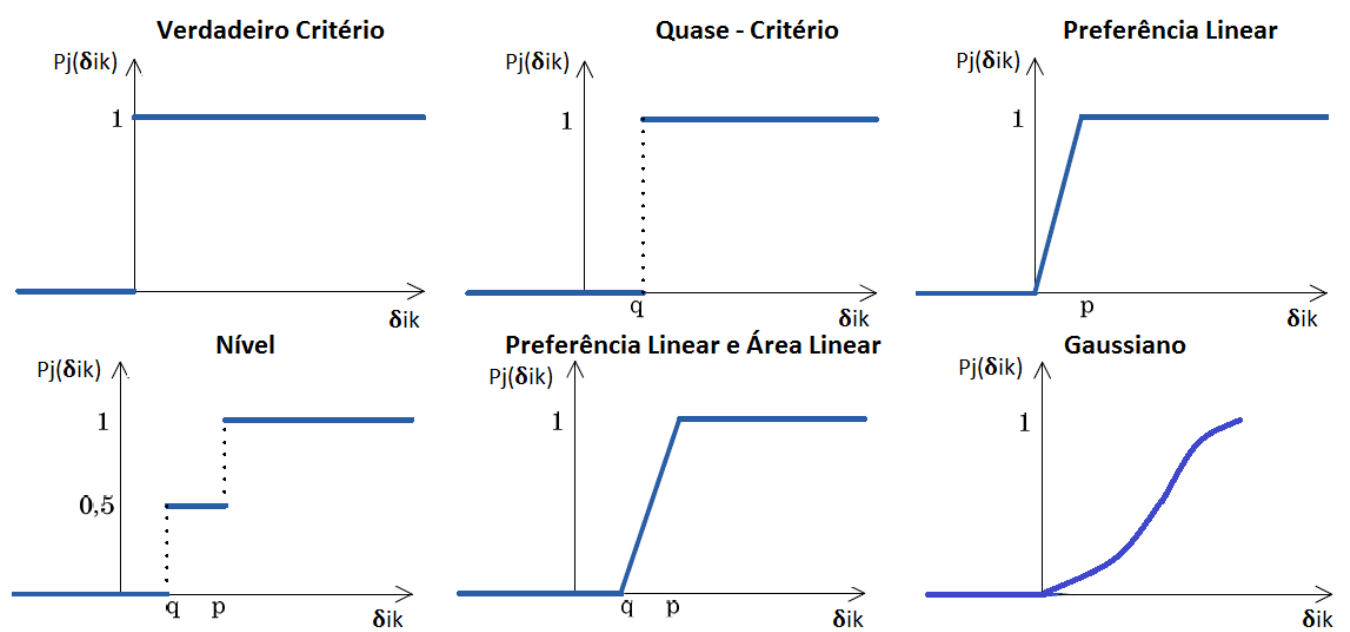

Figura 2.5: Funções de Preferência Relativa

$\delta_{i k}=$ diferença entre a alternativa " $i " \mathrm{e}$ " $k$ ".

Em seguida, são calculados os fluxos de superação positivos $\phi_{i}^{+}$e negativos $\phi_{i}^{-}$relativos à cada alternativa $(i)$. Estes fluxos têm como objetivo expressar como cada alternativa supera e é superada pelas demais $k_{n}$, sendo " $m$ " o número total de alternativas:

$$
\phi_{i}^{+}=\sum_{n=1}^{m-1} S_{i k_{n}} \quad \phi_{i}^{-}=\sum_{n=1}^{m-1} S_{k_{n} i}
$$

As alternativas são ordenadas através da comparação dos fluxos.

" $i$ " é indiferente de " $k$ " se:

$$
\phi_{i}^{+}=\phi_{k}^{+} \quad e \quad \phi_{i}^{-}=\phi_{k}^{-}
$$

"i" supera " $k$ " se:

$$
\phi_{i}^{+}>\phi_{k}^{+} \quad e \quad \phi_{i}^{-} \leq \phi_{k}^{-} \quad \text { ou } \quad \phi_{i}^{+} \geq \phi_{k}^{+} \quad \text { e } \quad \phi_{i}^{-}<\phi_{k}^{-}
$$

"i" é incomparável a " $k$ " se:

$$
\phi_{i}^{+}<\phi_{k}^{+} \quad e \quad \phi_{i}^{-}<\phi_{k}^{-} \quad \text { ou } \quad \phi_{i}^{+}>\phi_{k}^{+} \quad \text { e } \quad \phi_{i}^{-}>\phi_{k}^{-}
$$

No método PROMETHEE I, a ordenação é tida como uma ordenação parcial, porque podem ocorrer situações de incomparabilidade entre algumas alternativas $[5,7,16,18,19,20]$.

\section{Método PROMETHEE II}

O método PROMETHEE II é o método PROMETHEE I com o aprimoramento de ordenação total das alternativas. Para isso o método introduziu o 
conceito de fluxo de superação total, que consiste na diferença entre os fluxos de superação positivos $\phi_{i}^{+}$e negativos $\phi_{i}^{-}$relativos à alternativa " $i$ ":

$$
\phi_{i}=\phi_{i}^{+}-\phi_{i}^{-}
$$

Após os cálculos, as alternativas são ordenadas da mais eficiente (maior fluxo total) à menos eficiente (menor fluxo total) $[5,7,16,18,20]$.

\section{3}

\section{Métodos de Decisão Multiobjetivo}

Os Métodos de Decisão Multiobjetivo podem ser classificados pelo grau de intervenção do agente de decisão [6].

- Articulação a priori de preferências: são os métodos nos quais a agregação de preferências do decisor é definida no início, ou seja, antes da otimização.

- Articulação progressiva de preferências: são os métodos iterativos, em que há fases de cálculo de soluções eficientes e diálogo com o decisor para o cálculo de novas soluções eficientes.

- Articulação a posteriori de preferências: são os métodos em que as soluções eficientes são geradas, sendo a agregação de preferências do decisor feita a posteriori.

\subsection{1}

\section{Métodos de Articulação a Priori de Preferências}

\section{Método da Distância Mínima à Solução Ideal}

Um problema multiobjetivo consiste em várias funções a serem minimizadas simultaneamente, onde cada função representa um objetivo. Para cada função a ser minimizada existe um valor ótimo dentro do espaço de soluções viáveis, e chama-se solução ideal a composição de todas as soluções ótimas individuais, mas na maioria das vezes a solução ideal não faz parte do conjunto de soluções viáveis [6]. A Figura 2.6 mostra um exemplo com duas funções a serem minimizadas, onde a solução ideal não pertence ao conjunto de soluções viáveis.

O método propõe que a solução ideal passe a ser tratada como uma referência e a solução ótima uma solução viável que apresente a menor distância da solução ideal [6]. 


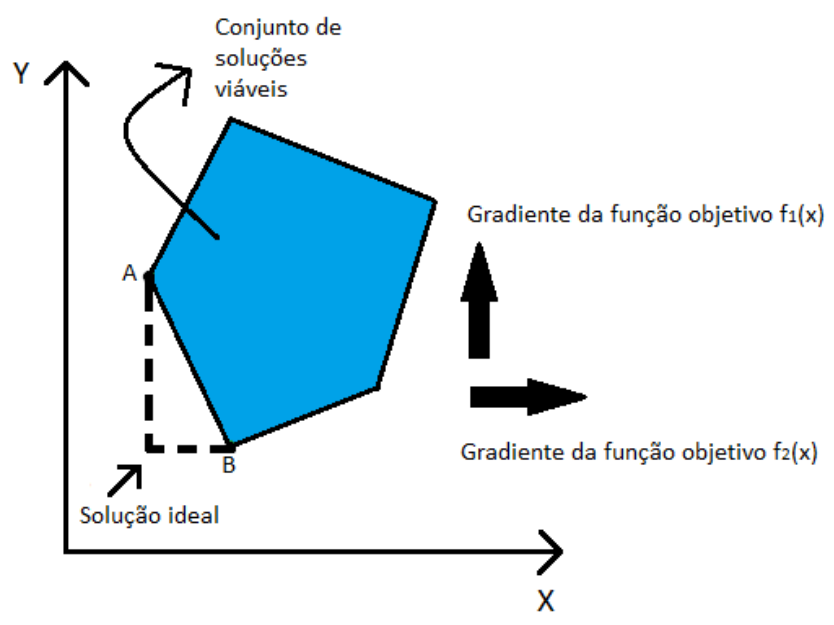

Figura 2.6: Exemplo do Método da Distância Mínima à Solução Ideal

\section{Método da Função Utilidade}

O método reúne todas as funções objetivo dos diversos critérios $Z_{i}(x)$ em uma única função utilidade $U\left[Z_{1}(x), Z_{2}(x), \ldots, Z_{n}(x)\right]$, onde os argumentos desta função são as funções objetivos dos critérios, para em seguida buscar a melhor solução, através de um processo de otimização, sendo o ótimo o ponto de tangência da função utilidade com o conjunto de soluções eficientes [6].

\section{Método Lexicográfico}

A palavra lexicografar significa dispor as opções por alguma ordem lógica de apresentação. Com base nesta ideia o método ordena as funções objetivo de acordo com as preferências do decisor, para em seguida otimizar de forma sequencial todas elas. Esta otimização é feita da seguinte forma: inicia-se otimizando a função objetivo mais importante e, a partir do resultado obtido e da função objetivo, é criada uma restrição de igualdade com uma folga que não seja maior que uma porcentagem definida a priori. Essa restrição que passa a fazer parte do problema de otimização seguinte, onde a segunda função objetivo é otimizada e assim sucessivamente até que todas as funções sejam otimizadas $[6]$.

\section{Programação por Metas}

O método Programação por Metas, do inglês Goal Programming, tem como objetivo minimizar o desvio em relação às metas estabelecidas pelo decisor, ou seja, o decisor estabelece metas para cada objetivo e a solução ótima é a que minimiza o desvio em relação a tais metas. É importante ressaltar que deve-se ter cuidado ao definir as metas, para não conduzir a uma solução dominada [6]. 


\subsection{2}

\section{Métodos de Articulação Progressiva de Preferências}

\section{Método STEM}

STEM, do inglês Step Method [21], é um método iterativo que funciona da seguinte maneira:

O primeiro passo é otimizar individualmente todas as " $n$ " funções objetivos $\left(Z_{n}\right)$ dentro da região admissível. Com estes resultados é construída uma tabela de ótimos individuais. A combinação de todas as soluções individuais chama-se solução ideal, que na maioria dos casos não é uma solução viável.

O segundo passo é a partir da tabela de ótimos individuais calcular os pesos para cada função objetivo $\left(\alpha_{n}\right)$, que serão usados no cálculo da solução eficiente, sendo a solução eficiente a que minimiza a distância ponderada ${ }^{1}$ à solução ideal.

O terceiro passo é resolver o problema de minimização da distância ponderada à solução ideal, dentro da região admissível.

O resultado é apresentado para o decisor, que poderá considerá-lo satisfatório ou não. Se considerar satisfatório, o problema termina. Se não, o decisor tem que indicar qual função objetivo já está satisfeito, com o resultado e estar disposto a sacrificar em uma certa quantidade, para tentar melhorar o resultado das que considera insuficiente. Por exemplo: se estiver satisfeito com a função objetivo $Z_{1}$, e disposto a sacrificá-la em $\Delta_{1}$, será adicionado na região admissível uma restrição $Z_{1}^{*} \geq Z_{1}-\Delta_{1}$, e o peso da função objetivo $Z_{1}$ será zerado $\left(\alpha_{1}=0\right)$.

Em seguida, retorna-se ao terceiro passo. O processo iterativo continua até que o decisor julgue o resultado satisfatório [6].

\section{Método de ZIONTS e WALLENIUS}

O método, que leva o nome dos criadores [22], tem como objetivo a redução das possíveis combinações dos pesos associados às alternativas do problema (redução do espaço de pesos). Esta redução é feita progressivamente através da participação do decisor após cada iteração.

Em cada iteração é otimizada, pela resolução de um problema de programação linear, uma soma ponderada das funções objetivo, onde o vetor de pesos inicial é o ponto central do espaço dos pesos original.

\footnotetext{
${ }^{1} \mathrm{~A}$ distância utilizada neste método é à distância de Tchebycheff, que é definida por um espaço vetorial em que a distância entre dois vetores é o valor máximo da diferença das suas coordenadas.
} 
A partir da solução obtida pelo problema de otimização original, com a variação de variáveis adjacentes (substituição de variáveis básicas por não básicas), são obtidas outras soluções chamadas de soluções adjacentes. As soluções adjacentes são comparadas, uma a uma com a solução original e o decisor expressa sua preferência. Com base nas respostas do decisor sobre as comparações entre pares de soluções, são introduzidas restrições no espaço dos pesos. Então, um novo vetor de pesos é selecionado respeitando as restrições inseridas no espaço de pesos original.

O processo termina quando o espaço dos pesos for reduzido a uma região pequena o suficiente para se identificar uma solução final ou quando no processo de informação de preferência pelo decisor, o decisor indicar que a solução atual é a mais interessante [6].

\section{Método TRIMAP}

O TRIMAP [23] é um ambiente computacional iterativo que tem como objetivo apoiar o decisor na pesquisa de soluções eficientes em problemas de programação linear com três funções objetivo (tri-critério), através de procedimentos que possibilitam uma pesquisa com base em uma aprendizagem progressiva, com redução do espaço dos pesos. O decisor pode especificar limitações para os valores das funções objetivo e impor restrições no espaço dos pesos.

O primeiro passo é otimizar individualmente cada uma das três funções objetivo dentro da região admissível, e calcular a região de indiferença no espaço dos pesos para cada resultado obtido, sendo a região de indiferença aquela em que variações nos pesos não provoca variação no resultado. Em seguida, é desenhado um triângulo com os pesos e suas respectivas zonas de indiferença preenchidas. Então é definido, com a participação do decisor, um vetor de pesos de uma zona do triângulo não preenchida, para a realização de uma nova otimização e preenchimento de respectiva região de indiferença.

A partir das informações obtidas, o decisor pode especificar limitações para os valores das funções objetivo e adicionar restrições no espaço dos pesos para reduzir a região admissível, com o objetivo de progressivamente eliminar os subconjuntos de soluções eficientes que não lhe parecem interessantes.

A iteração continua até o decisor conhecer o conjunto de soluções eficientes o suficiente para escolher uma solução final. O método tem como objetivo ajudar o decisor a eliminar progressivamente os subconjuntos de soluções eficientes que não lhe parecem interessantes, e não a de apenas assegurar a convergência para uma solução de compromisso ótima [6] 


\subsection{3}

\section{Métodos de Articulação de Preferências a Posteriori}

\section{Método dos Pesos}

O método consiste em transformar o problema multiobjetivo (várias funções objetivo) em um problema monobjetivo (única função objetivo), através da união de todas as funções objetivo em uma única função formada pela soma ponderada das "n" funções originais.

As soluções que otimizam a função formada pela soma ponderada das funções originais formam o conjunto de soluções eficientes; estas soluções são obtidas através da variação dos pesos das funções objetivo [6]

\section{Método das Restrições}

O método consiste em reduzir o problema multiobjetivo em um problema monobjetivo, considerando o restante das funções objetivo como restrições, conforme equação abaixo, onde $Z_{i}(x)$ é a função a ser minimizada e $Z_{1}(x)$ a $Z_{(n-1)}(x)$ funções consideradas como restrições.

$$
\operatorname{Max}=Z_{i}(x)
$$

Sujeito a:

$$
\left\{\begin{array}{c}
Z_{1}(x) \geq w_{1} \\
\cdots \\
Z_{(n-1)}(x) \geq w_{(n-1)}
\end{array}\right.
$$

As soluções são obtidas variando os valores dos $w_{i}[6]$

\section{4}

\section{Aplicações dos Métodos de Apoio à Decisão}

\subsection{1}

\section{Algumas Aplicações no Contexto Geral}

Os Métodos de Apoio à Decisão tem sido aplicados, em diversas áreas, para resolver problemas que envolvem objetivos conflitantes. O que segue são alguns dos trabalhos encontrados na literatura durante a revisão bibliográfica realizada.

Mladineo, Margeta, Brans e Mareschal [24] apresentam um trabalho sobre classificação de locais alternativos para pequenas centrais hidrelétricas utilizando métodos de apoio multicritério a decisão. 
Brans [25] aborda que a tomada de decisão requer três pólos de influência, o racional, o subjetivo e o ético. Aborda que a maioria dos modelos básicos de pesquisa operacional consideram apenas o pólo racional, sendo que nenhuma liberdade é deixada para o tomador de decisões e não são considerados os aspectos éticos. Mostram que, se bem especificado, o método de apoio multicritério à decisão PROMETHEE pode fornecer soluções equilibradas entre subjetividade, racionalidade e ética.

Meza, Yildirim, e Masud [26] apresentam uma aplicação no planejamento da expansão da geração de energia de sistemas elétricos através da otimização simultânea de vários objetivos, minimização de custos, impacto ambiental, combustível importado e os riscos relacionados aos preços dos combustíveis. Com isso é decidido a localização das unidades de geração.

Cavalcante e Almeida [27] apresentam um trabalho de desenvolvimento de um modelo de planejamento de manutenções preventivas, controlando falhas no contexto específico de quebra de equipamento. São abordados os critérios de custo, confiabilidade e peculiaridades de diferentes contextos em que ocorrem as atividades de manutenção. O modelo visa ajudar o tomador de decisão no planejamento de manutenção preventiva levando em conta as incertezas.

Albadvi, Chaharsooghi e Esfahanipour [28] apresentam uma aplicação do método PROMETHEE na negociação de ações na bolsa de valores. $O$ trabalho teve como objetivo desenvolver um modelo de tomada de decisão para selecionar o melhor investimento entre um número finito de alternativas, considerando vários critérios conflitantes. O método PROMETHEE é usado para resolver o problema e uma pesquisa com os especialistas foi realizada a fim de determinar os critérios e pesos utilizados no método.

Heldemarcio [29] apresenta um estudo sobre a localização de reservas técnicas para transformadores de potência em subestações de uma concessionária de energia elétrica. O problema é abordado mediante uma metodologia multicritério de apoio à decisão para a obtenção de soluções eficientes. É proposta uma série de modelos de localização a fim de contemplar diferentes cenários para reservas únicas ou múltiplas. Permite incorporar aspectos específicos do sistema de produção, tais como, arranjo das subestações, propensão à falha dos equipamentos, capacidade e raio de cobertura das reservas técnicas. Indicando soluções que refletem o melhor compromisso entre o conjunto de objetivos previamente estabelecidos para o atendimento global do sistema de produção abordado.

Passos [30] apresenta um trabalho que desenvolve um método construído através da fusão do Método de Análise Hierárquica (AHP) e Técnicas de Amortecimento Exponencial com a finalidade de criar um índice de qualidade para 
distribuidoras de energia elétrica, onde é possível avaliar uma distribuidora levando em conta múltiplos critérios e seus diversos índices passados.

Brucker, Macharis, e Verbeke [31] apresentam um trabalho de aplicação de multicritério na resolução de problemas de desenvolvimento sustentável na tomada de decisões, através da avaliação de projetos complexos que envolvem múltiplos objetivos e grupos de interesse múltiplos. Tais avaliações são normalmente voltadas para satisfazer simultaneamente metas privadas, econômicas, sociais e ambientais.

Abedi, Torabi, Norouzi, Hamzeh e Elyasi [32] apresentam uma aplicação do método PROMETHEE II, para explorar reservas de cobre. O método é aplicado para produzir o mapeamento de prospectividade mineral desejado, através da seleção da área a ser explorada, com o objetivo de reduzir o custo de perfuração exploratória. O método tem como base critérios relacionados a dados geológicos, geoquímicos e geofísicos.

\subsection{2}

\section{Aplicações no Contexto de Planejamento da Operação Energética}

Na literatura existem, pelo menos, três trabalhos relevantes de aplicação de Métodos de Apoio à Decisão no planejamento da operação energética de sistemas hidrotérmicos de grande porte.

Um dos trabalhos é Campello de Souza [33], intitulado de "Procedimentos para a Aplicação da Teoria da Decisão". A autora aplica os conceitos de teoria da utilidade de von Neumann-Morgenstern-Wald para edução da função utilidade de diversos profissionais do setor elétrico, para aplicação em um problema de decisão no planejamento da operação do sistema elétrico brasileiro, envolvendo o déficit de energia e o custo operacional das usinas térmicas.

Outro trabalho é Kligerman [5], intitulado de "Um Sistema de Apoio à Decisão Bicritério para o Planejamento da Operação Energética". O autor propõe um sistema de apoio à decisão, utilizando o método PROMETHEE II, para ordenação das possíveis alternativas de operação, sendo cada alternativa uma possibilidade de operação obtida através de otimização determinística utilizando o modelo DECOMP. São gerados cenários hidrológicos e estes cenários são simulados através do modelo para gerar as múltiplas alternativas.

Outro trabalho é Silva Duarte [34], intitulado de "Teoria da Decisão Aplicada ao Planejamento da Operação do Sistema Hidroelétrico Brasileiro". O autor propõe um sistema de apoio à decisão, utilizando Teoria da Decisão, para seleção de uma determinada alternativa de operação. As diversas alternativas são geradas com a variação da Função de Custo de Deficit. 


\section{Planejamento da Operação de Sistemas Hidrotérmicos}

\section{1}

\section{Introdução}

No planejamento energético de sistemas puramente térmicos ou com predominância de geração termoelétrica, a disponibilidade dos recursos energéticos praticamente não está sujeita à aleatoriedade. As eventuais limitações de recursos se devem às falhas de equipamentos, sendo que este tipo de aleatoriedade não causa impactos por mais de um mês ao longo do horizonte. Tem-se, portanto, um problema de planejamento sujeito a baixa aleatoriedade e de horizonte de apenas algumas semanas [35].

No entanto, diferentemente do que ocorre em sistemas puramente térmicos ou com predominância de geração termoelétrica, em sistemas hidrotérmicos com predominância de geração hidroelétrica, a cada intervalo de tempo é necessário decidir o nível adequado de geração térmica, intercâmbios com outros subsistemas e geração hidráulica, levando em conta a utilização dos reservatórios, o que prolonga o horizonte de influência de cada decisão, devido ao fato de que uma decisão de deplecionamento dos reservatórios no presente pode ter consequências por um longo período. Deve-se também considerar que a disponibilidade de geração hidráulica depende das condições hidrológicas, ou seja, é de natureza estocástica [36].

O problema do planejamento hidrotérmico pode ser visto na Figura 3.1, onde se observa que, caso o operador decida utilizar a água dos reservatórios no estágio atual, obtendo um custo imediato baixo, poderá ter no estágio seguinte uma operação econômica, caso a afluência que se configure seja alta; porém, terá um custo elevado, devido a um alto volume de geração térmica e até mesmo de um possível déficit, se no estágio seguinte a afluência que se configurar for baixa. Por outro lado se resolver estocar a água no estágio atual, atendendo a carga com geração térmica, terá um custo imediato alto, obtendo uma operação econômica no caso de se configurar uma afluência baixa; mas tendo que verter água, que representa uma perda econômica, dado que esta água vertida poderia ter sido usada para atender a demanda economizando geração térmica, no caso de se configurar uma afluência alta [37]. 


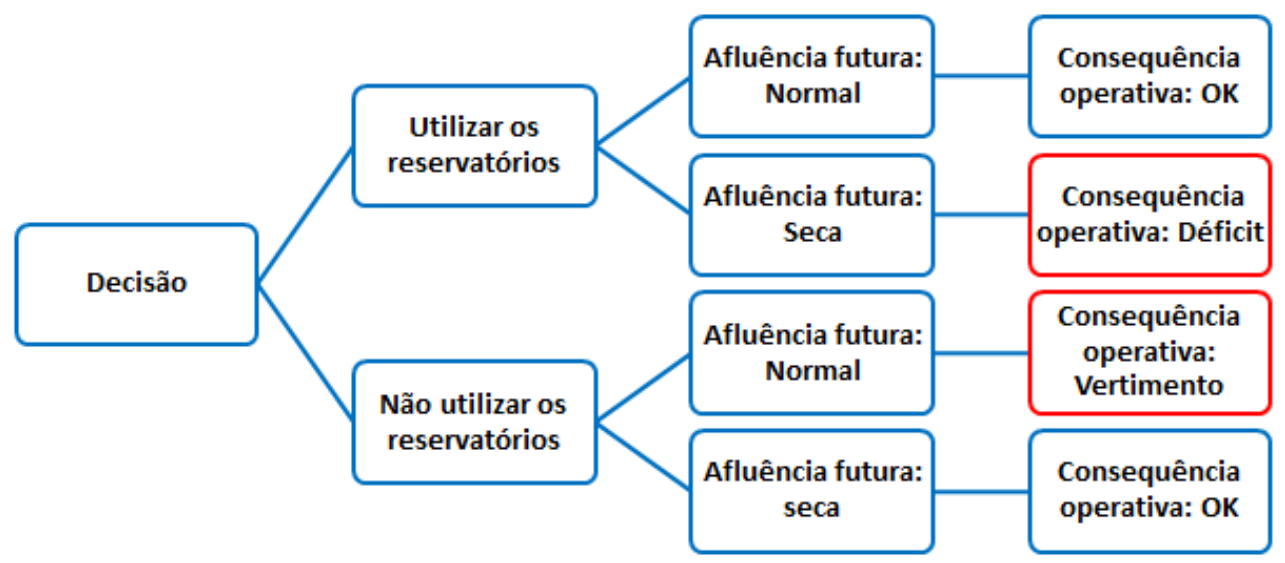

Figura 3.1: Consequências Operativas das Decisões Adotadas

Consequentemente, constitui parte importante no planejamento da operação de sistemas hidroelétricos com predominância de geração hidráulica a simulação da operação do sistema, a qual é obtida por meio de uma cadeia de modelos matemáticos.

\section{2}

\section{O Sistema Interligado Nacional}

A existência de várias bacias interligadas e a necessidade de avaliação das consequências do uso da água para os anos futuros levam ao emprego de um período longo de estudo, tornando o planejamento da operação do Sistema Interligado Nacional (SIN) um problema complexo e de grande porte.

No ano de 2012, o SIN atendeu o mercado com $85.87 \%$ de sua energia gerada por hidroelétricas [1], relacionado ao seu grande potencial hidráulico (78.70\% da potência instalada [38]), como ilustra a Figura $3.2[1,38]$. O SIN se destaca pela predominância da geração hidráulica, o que o torna dependente das condições hidrológicas, aumentando a complexidade da operação.

\section{Geração de Energia}

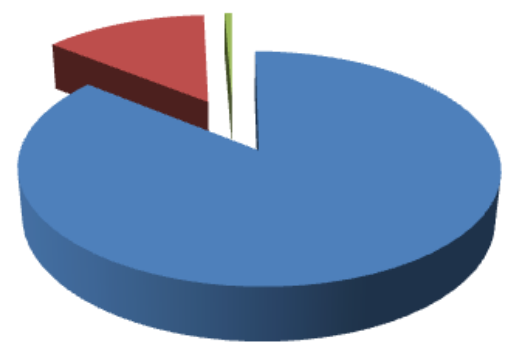

- Hidráulica $85.9 \%$ - Térmica $13.5 \%$ Eólica $0.6 \%$

\section{Capacidade Instalada}

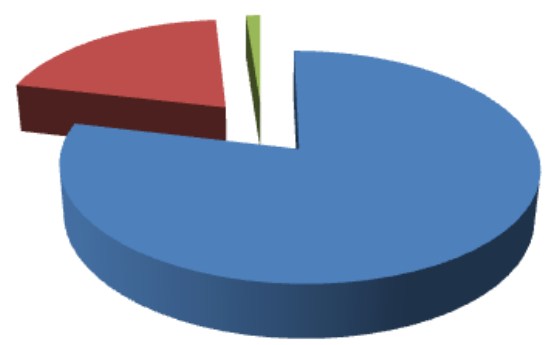

- Hidráulica $78.7 \%$ Térmica 20.1\% Eólica 1.2\%

Figura 3.2: Repartição da Potência Instalada e da Energia Gerada 
Resumidamente o SIN possui as seguintes características:

- estocasticidade: em função das incertezas em relação às afluências futuras, que se tornam mais significativas quanto maior for o horizonte do planejamento;

- acoplamento espacial: as usinas hidráulicas estão dispostas em cascata, o que faz com que a operação de uma usina à montante interfira na operação das usinas à jusante, diferentemente das usinas térmicas que apresentam a operação independente;

- acoplamento temporal: a decisão da utilização dos recursos hídricos em um mês ocasiona efeitos nos meses subsequentes.

\section{3}

\section{Histórico do Planejamento Energético no Brasil}

O planejamento energético brasileiro teve início na década de 70 , com a criação de grandes troncos de interligação entre os subsistemas Sudeste/Centro-Oeste e o subsistema Sul e com a construção das grandes usinas hidroelétricas existentes atualmente. Para planejar e operar este sistema foi criado o Grupo Coordenador da Operação Interligada (GCOI), coordenado pela Eletrobras [2, 5].

O planejamento era realizado utilizando como referência o pior cenário do histórico de vazões, que data deste janeiro de 1931, e a estratégia era estabelecer uma curva limite, ou seja, um limite mínimo que os reservatórios poderiam ser deplecionados de forma que se garantisse o atendimento da carga mesmo ocorrendo o cenário de afluência do período crítico [5].

No final da década de 70 , este modelo foi substituído por um modelo baseado em programação dinâmica estocástica (PDE) [39], que tinha como objetivo a minimização do custo total esperado. A estratégia era gerar um conjunto de cenários de vazões, com base nos índices estatísticos do histórico de vazões (média, desvio padrão, correlação temporal) e determinar a geração térmica e hidráulica de forma a minimizar o valor esperado em todo o horizonte de planejamento, sendo as usinas representadas por sistemas equivalentes.

Com a interligação das regiões Norte e Nordeste com o Sudeste/CentroOeste e Sul, a metodologia da PDE passou a se tornar computacionalmente inviável, devido ao problema da dimensionalidade, e na década de 80 foi proposta a Programação Dinâmica Dual Estocástica (PDDE) [40], que resolve o problema da dimensionalidade trabalhando com um número muito menor de estados que a PDE. 
No final da década de 90 foi criado o Operador Nacional do Sistema Elétrico (ONS), para suceder o GCOI. O ONS é, atualmente, o responsável pelo planejamento e operação do SIN e, para isso utiliza a metodologia da PDDE. O planejamento realizado pelo ONS é composto de três etapas, descritas na próxima seção [2, 41, 42].

\section{4}

\section{Etapas do Planejamento}

O objetivo do planejamento da operação de um sistema hidrotérmico é determinar, para cada etapa do horizonte de planejamento, as metas de geração para cada usina que atendam a demanda e minimizem o valor esperado do custo total de operação ao longo de todo horizonte. A operação do Sistema Elétrico Brasileiro é dividida em três etapas, onde em cada uma delas é adotado um horizonte.

O planejamento da operação de médio prazo tem um horizonte de cinco anos com discretização mensal. Nos estudos desta etapa é feita uma representação do processo estocástico de vazões afluentes por simulação de Monte Carlo (árvore incompleta) e as hidrelétricas são representadas por sistemas equivalentes.

Nos estudos de planejamento da operação energética de médio prazo do Sistema Interligado Nacional Brasileiro é utilizado o modelo NEWAVE [43], desenvolvido pelo Centro de Pesquisas de Engenharia Elétrica (CEPEL). O Modelo NEWAVE foi desenvolvido para o planejamento da operação de médio e longo prazo (horizonte máximo de 30 anos). Ele calcula a alocação ótima de recursos de geração hidroelétrica e termoelétrica com o objetivo de minimizar o custo total esperado de operação. O modelo utiliza como método de solução do problema de otimização a Programação Dinâmica Dual Estocástica (PDDE) e os reservatórios são agrupados em sistemas equivalentes.

O planejamento da operação de curto prazo tem um horizonte de dois meses com discretização semanal no primeiro mês e mensal no segundo, sendo feita uma representação determinística para as vazões afluentes nas semanas que compõem o primeiro mês e detalhada do processo estocástico de vazões afluentes aos reservatórios (árvore completa) no segundo mês. Neste horizonte de planejamento as hidrelétricas são representadas de forma individual.

No planejamento da operação energética de curto prazo do Sistema Interligado Nacional Brasileiro é utilizado o modelo DECOMP [44], desenvolvido pelo Centro de Pesquisas de Engenharia Elétrica (CEPEL). O Modelo DECOMP foi desenvolvido para o planejamento da operação de curto prazo (horizonte máximo de 1 ano). Ele determina a meta de geração semanal para 
cada usina com o objetivo de minimizar o custo total esperado de operação. O modelo utiliza como método de solução do problema de otimização o método L-SHAPED [45] e as usinas são representadas de forma individualizada.

O planejamento da operação de curtíssimo prazo tem um horizonte de uma semana com discretização de meia em meia hora, onde são consideradas restrições detalhadas das usinas hidrelétricas e representação da rede de transmissão.

No planejamento da operação energética de curto prazo do Sistema Interligado Nacional Brasileiro está em processo de aprovação a utilização do modelo DESSEM-PAT [46], como ferramenta de apoio na determinação da programação diária da operação. Desenvolvido pelo Centro de Pesquisas de Engenharia Elétrica (CEPEL), o Modelo DESSEM-PAT determina o despacho hidrotérmico de mínimo custo operativo para um período de até 2 semanas e com discretização de até 5 períodos diários, com representação do fluxo de potência linearizado da rede de transmissão.

A Figura 3.3 apresenta a cadeia de modelos desenvolvidos pelo CEPEL para o planejamento e a operação do SIN, juntamente com suas principais características.

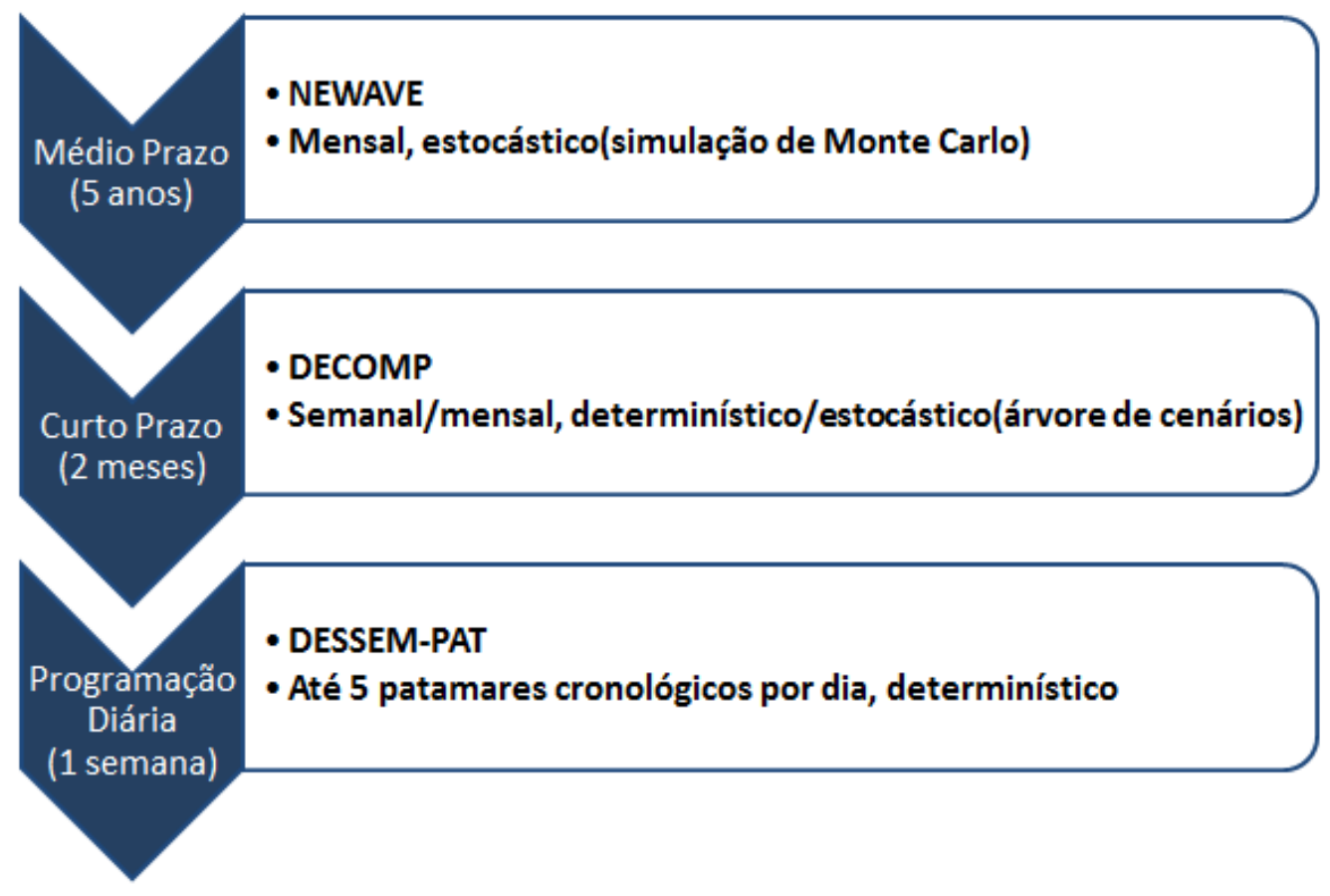

Figura 3.3: Cadeia de Modelos 


\section{5}

\section{Metodologia de Segurança Operativa}

\subsection{1}

\section{Histórico}

O planejamento da operação energética do Sistema Interligado Nacional é realizado por meio de uma cadeia de modelos matemáticos que consiste em minimizar o valor esperado do custo total de operação ao longo do período de planejamento. No entanto, o racionamento de energia ocorrido em meados de 2001 tornou evidente a necessidade de discussão e revisão do critério de otimização, neutro ao risco, implementado até então nos modelos usados no planejamento da operação. Consequentemente, o desenvolvimento de uma formulação capaz de incorporar aspectos de segurança à otimização econômica se tornou necessário, e em 2002 foi desenvolvida a Curva de Aversão a Risco (CAR) [47], que posteriormente foi incorporada ao modelo de médio prazo.

A Figura 3.4 [48] ilustra a evolução do armazenamento do subsistema Sudeste de janeiro de 1997 a janeiro de 2012, onde observa-se o baixo nível de armazenamento no período de racionamento.

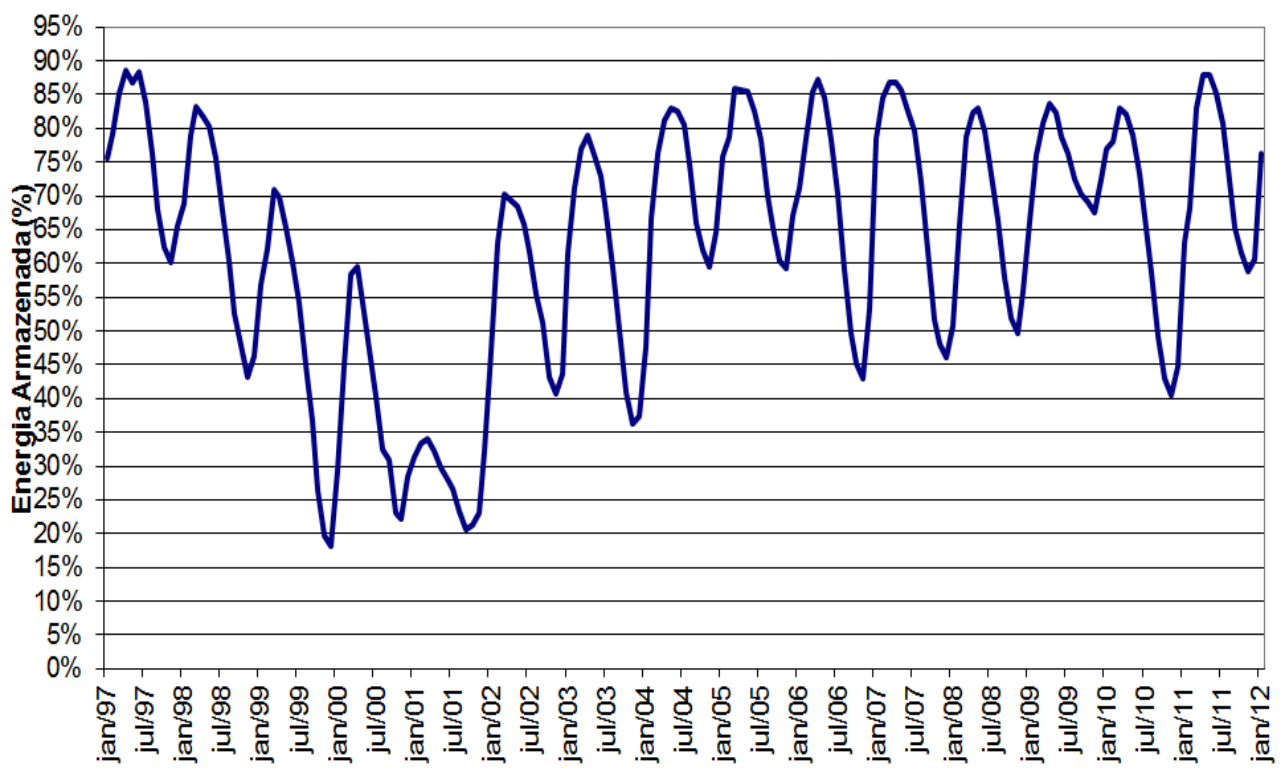

Figura 3.4: Evolução do Armazenamento do Subsistema Sudeste

Posteriormente, em 2008, com o objetivo de proteger o SIN contra o atraso da estação chuvosa e preservar os estoques dos reservatórios, foi desenvolvido um novo mecanismo de segurança chamado de Procedimento Operativo de Curto Prazo (POCP) [4]. 


\subsection{2}

\section{Curva de Aversão a Risco (CAR)}

O objetivo da Curva de Aversão a Risco (CAR) [47, 49] é estabelecer um nível de armazenamento mínimo que evite o esvaziamento dos reservatórios de cada subsistema até o final do próximo ano, considerando severas condições hidrológicas.

A CAR é calculada partindo do nível de segurança ao final do período seco, novembro do segundo ano, com os reservatórios no armazenamento mínimo aceitável pelo ONS, 10\% da capacidade. Calcula-se recursivamente, através da equação de balanço hídrico, o armazenamento mínimo do mês anterior, necessário para atingir o armazenamento do mês seguinte, com todas as usinas térmicas despachadas na capacidade máxima. No cálculo são consideradas premissas de intercâmbio e definido um cenário de afluência crítico para cada subsistema. O processo recursivo é repetido mês a mês até o início do estudo. Com isto tem-se a curva de armazenamentos mínimos para cada mês e subsistema, chamada de Curva de Aversão a Risco (CAR).

Sua inserção no modelo NEWAVE funciona da seguinte forma: caso algum subsistema esteja abaixo da CAR, seu valor da água é acrescido de uma penalidade que torna o valor da água um pouco maior que o custo do gerador térmico mais caro, como mostra a Figura 3.5 [49]. Com isto, o modelo de otimização, que tem como função objetivo a minimização do custo total de operação, despacha os geradores térmicos por ordem de mérito e recolhe geração hidráulica, evitando o esvaziamento dos reservatórios.

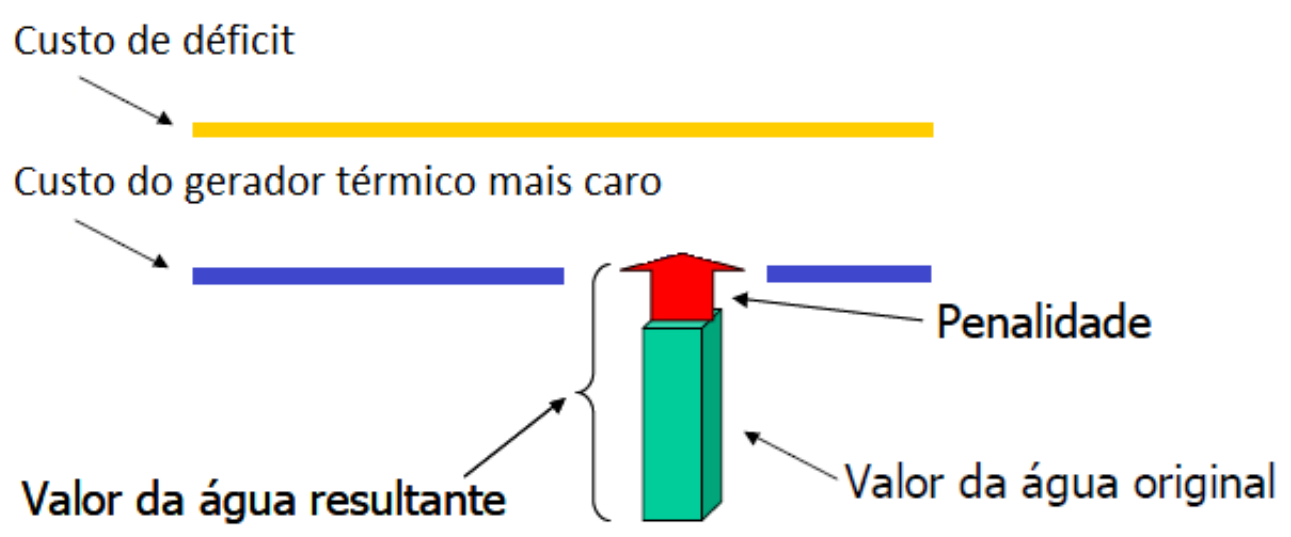

Figura 3.5: Objetivo da CAR 


\subsection{3}

\section{Procedimentos Operativos de Curto Prazo (POCP)}

O objetivo dos Procedimentos Operativos de Curto Prazo (POCP) [4] é proteger o SIN contra o atraso da estação chuvosa e preservar os estoques dos reservatórios, aumentando a garantia do atendimento energético nos dois primeiros anos do horizonte de cinco anos do planejamento da operação, através do despacho de geração térmica de forma antecipada e complementar ao sinal econômico dos modelos de otimização e da gestão dos intercâmbios de energia entre regiões. Os POCP são aplicados de abril a novembro de cada ano, e funcionam da seguinte forma:

- Primeiramente são estabelecidos os níveis metas para os subsistemas Sudeste/Centro-Oeste (SE/CO) e Nordeste (NE) ao final da estação seca do primeiro ano, que tem como objetivo garantir o atendimento no segundo ano.

- Em seguida são determinados para as regiões SE/CO e NE, através de uma simulação determinística no modelo DECOMP, os níveis de segurança ao final do primeiro mês do PMO com uso do valor esperado da previsão de vazões (VE) aplicando um fator de segurança (FS) a partir do mês PMO até novembro, em estágios mensais, Figura 3.6 [50].

- O passo seguinte é, através do modelo DECOMP, simulando a operação com o deck oficial do Programa Mensal de Operação (PMO), definir as políticas de intercâmbio e o despacho de geração térmica por ordem de mérito.

- Se os níveis de segurança no mês de estudo para as regiões SE/CO ou NE foram atingidos, esta deverá ser a política para a operação hidrotérmica na semana.

- Se os níveis de segurança no mês de estudo em qualquer uma das regiões SE/CO ou NE não foram atingidos, há a necessidade de se rever as políticas de intercâmbio de energia e o despacho térmico.

- As políticas de operação semanais continuam a ser definidas pelo modelo DECOMP, através da simulação do deck do PMO, porém com a restrição adicional de atingir os níveis de segurança mensais das regiões SE/CO e NE. Assim, o resultado deste processo de otimização é que irá definir a política de operação semanal e o despacho térmico total. O despacho térmico obtido pelos POCP terá remuneração através de Encargos de Serviços do Sistema ${ }^{1}$ [50]. 


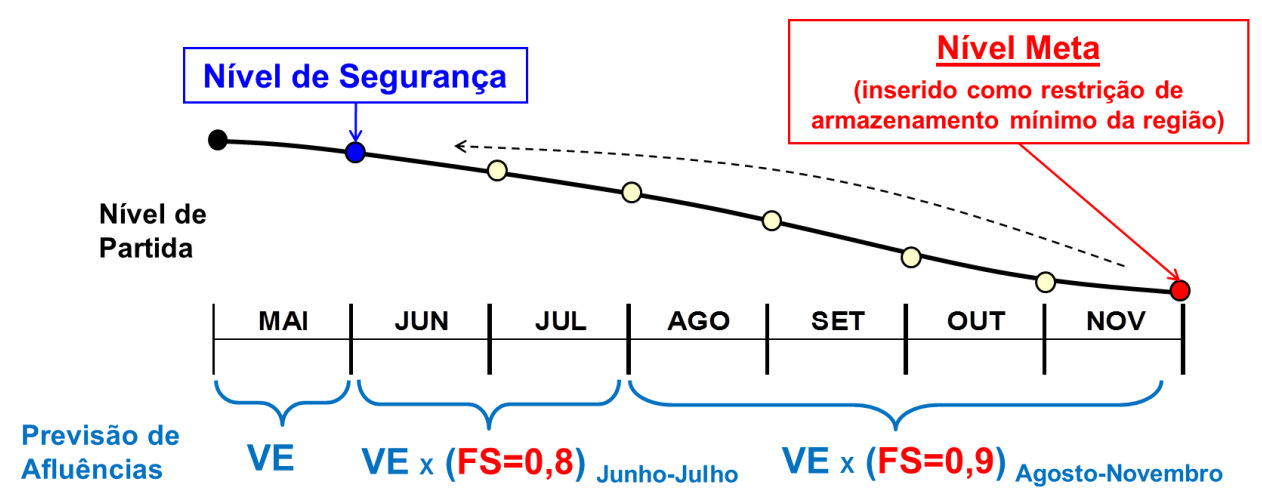

Figura 3.6: Determinação do Nível de Segurança

Logo, quando se aplicam os POCP, o bloco de geração térmica necessário para o atendimento ao critério de segurança é definido por este procedimento, o qual, atualmente, é revisto semanalmente. A revisão semanal dos POCP objetiva capturar as tendências hidrológicas que se verificam ao longo do mês, ajustando o despacho térmico por POCP às mesmas, tendo como meta o atingimento dos níveis de segurança mensais, os quais, uma vez atingidos mensalmente, garantem o atingimento do nível meta em novembro [50].

\subsection{4}

\section{Metodologia Atual de Determinação dos Níveis Metas}

Atualmente os níveis metas estabelecidos para os subsistemas Sudeste/Centro-Oeste e Nordeste são determinados através de cálculo recursivo utilizando a metodologia da Curva de Aversão a Risco (CAR), da seguinte forma:

- Considera-se o nível ao final de abril do segundo ano determinado pela Curva de Aversão a Risco, como o Nível de Segurança ao Final do Período Úmido (NSPU).

- Partindo de abril do segundo ano, com os reservatórios no nível de armazenamento NSPU. Calcula-se recursivamente, através da equação de balanço hídrico, o armazenamento mínimo do mês anterior, necessário para atingir o armazenamento do mês seguinte, com todas as usinas térmicas despachadas na capacidade máxima. No cálculo são consideradas premissas de intercâmbio e definido um cenário de afluência para o grau de segurança desejado, um dos cinco mais críticos do histórico, para cada subsistema. O processo recursivo é repetido mês a mês até novembro do primeiro ano.

\footnotetext{
${ }^{1}$ Encargos de Serviços do Sistema são valores destinados ao ressarcimento dos agentes de geração dos custos incorridos na manutenção da confiabilidade e da estabilidade do SIN e são pagos por todos os agentes de consumo.
} 
A Figura 3.7 ilustra o procedimento de determinação dos níveis metas utilizando a metodologia atual [50].

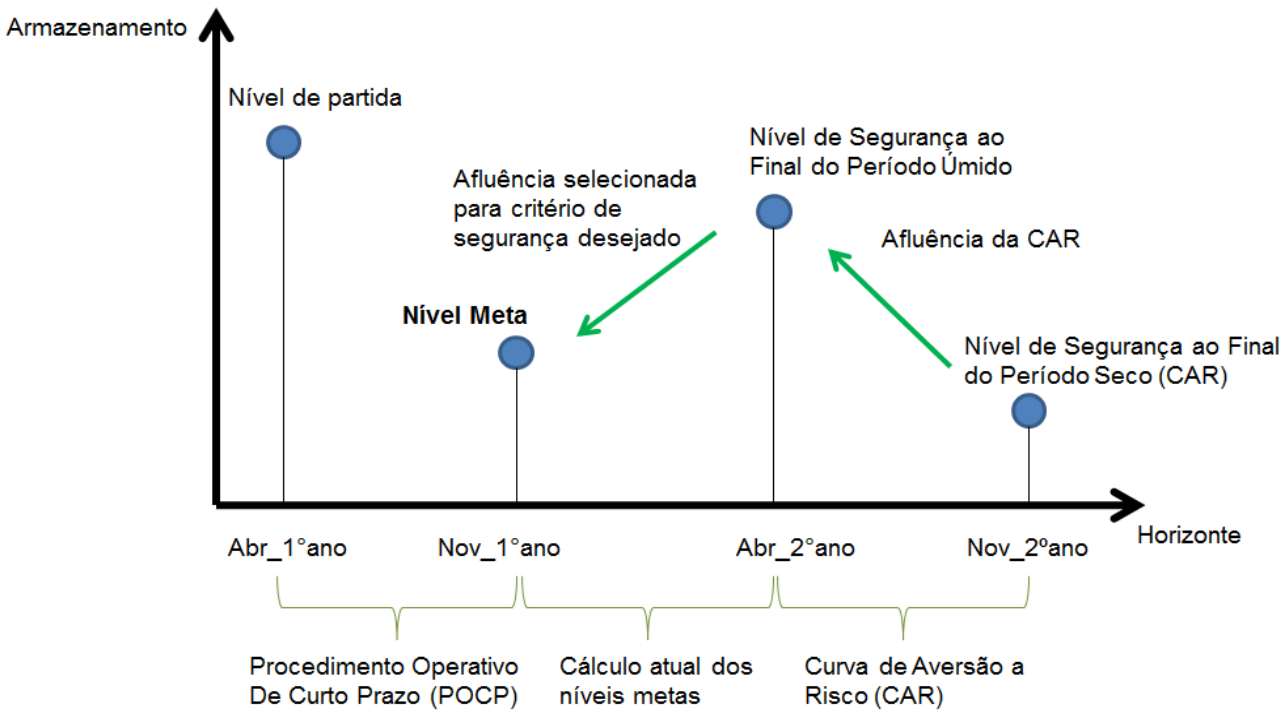

Figura 3.7: Metodologia Atual de Determinação dos Níveis Metas

Contudo, com a nova configuração do SIN, entrada de usinas a fio d'água de grande porte na região Amazônica, a determinação dos níveis metas com a metodologia atual pode vir se tornar difícil devido à: dificuldade no estabelecimento da série hidrológica crítica; dificuldade em estabelecer premissas de intercâmbio, o que pode ser agravado com a perspectiva de aumento do número de subsistemas; e necessidade de tratamento de outras condicionantes que não são consideradas na metodologia atual, tais como o custo para alcançar os níveis metas. 


\section{Operação do SIN Frente à Entrada de Usinas a Fio D'água de Grande Porte na Região Amazônica}

\section{1 \\ Introdução}

As bacias hidrográficas consistem numa porção da superfície terrestre drenada por um rio principal, seus afluentes e subafluentes. O Brasil é dotado de uma vasta e densa rede hidrográfica, sendo composto por 12 bacias. Dentre elas destaca-se a bacia Amazônica, por possuir 6.11 milhões de $K \mathrm{~m}^{2}$, sendo a maior bacia hidrográfica do mundo. No Brasil, ela compreende uma área de 3.85 milhões de $K \mathrm{~m}^{2}$, estando presente nos estados do Acre, Amapá, Amazonas, Roraima, Rondônia, Mato Grosso e Pará [51]. A Figura 4.1 [52] apresenta as bacias hidrográficas brasileiras.

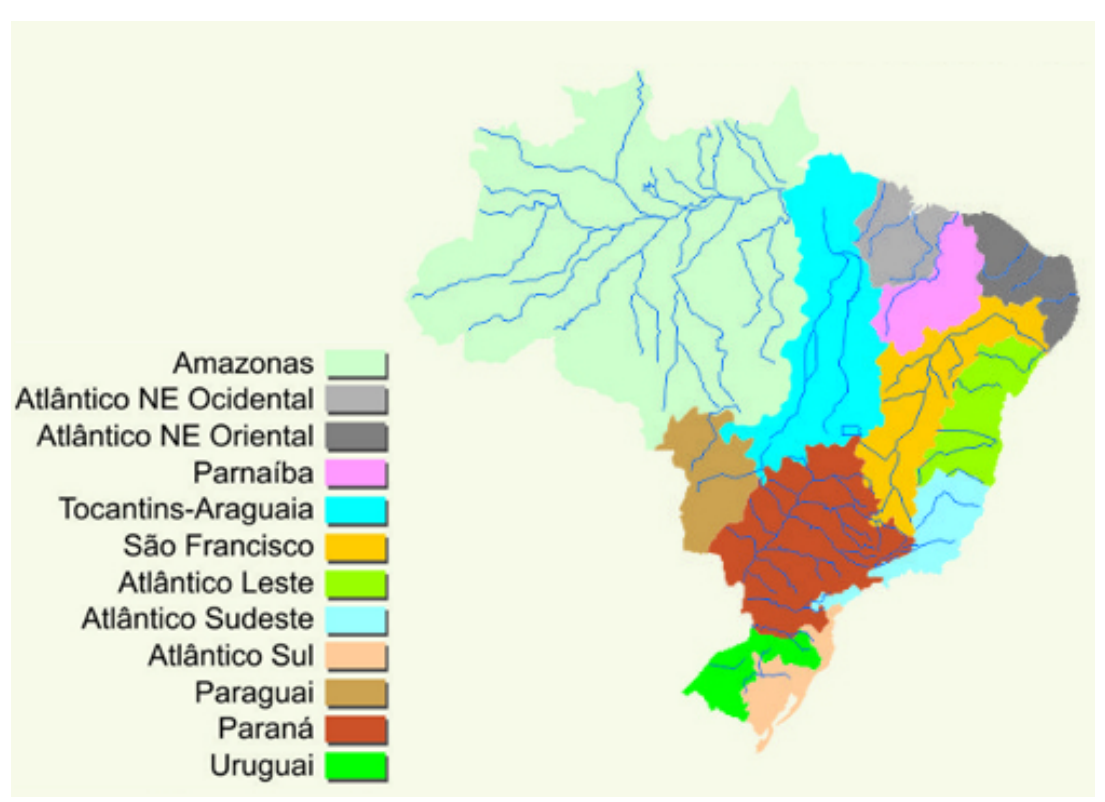

Figura 4.1: Bacias Hidrográficas

O potencial hidroelétrico brasileiro, distribuído por bacias e classificado de acordo com o nível de utilização de seus aproveitamentos, é apresentado na Figura 4.2 [53] e na Tabela 4.1 [54], onde observa-se que a região Amazônica detém pouco menos de $1 \%$ do potencial em operação, e possui mais de $60 \%$ do potencial a ser explorado, enquanto que o grande potencial hidrelétrico 
disponível nas demais regiões já foi basicamente explorado, embora ainda remanesça um potencial a explorar [54].

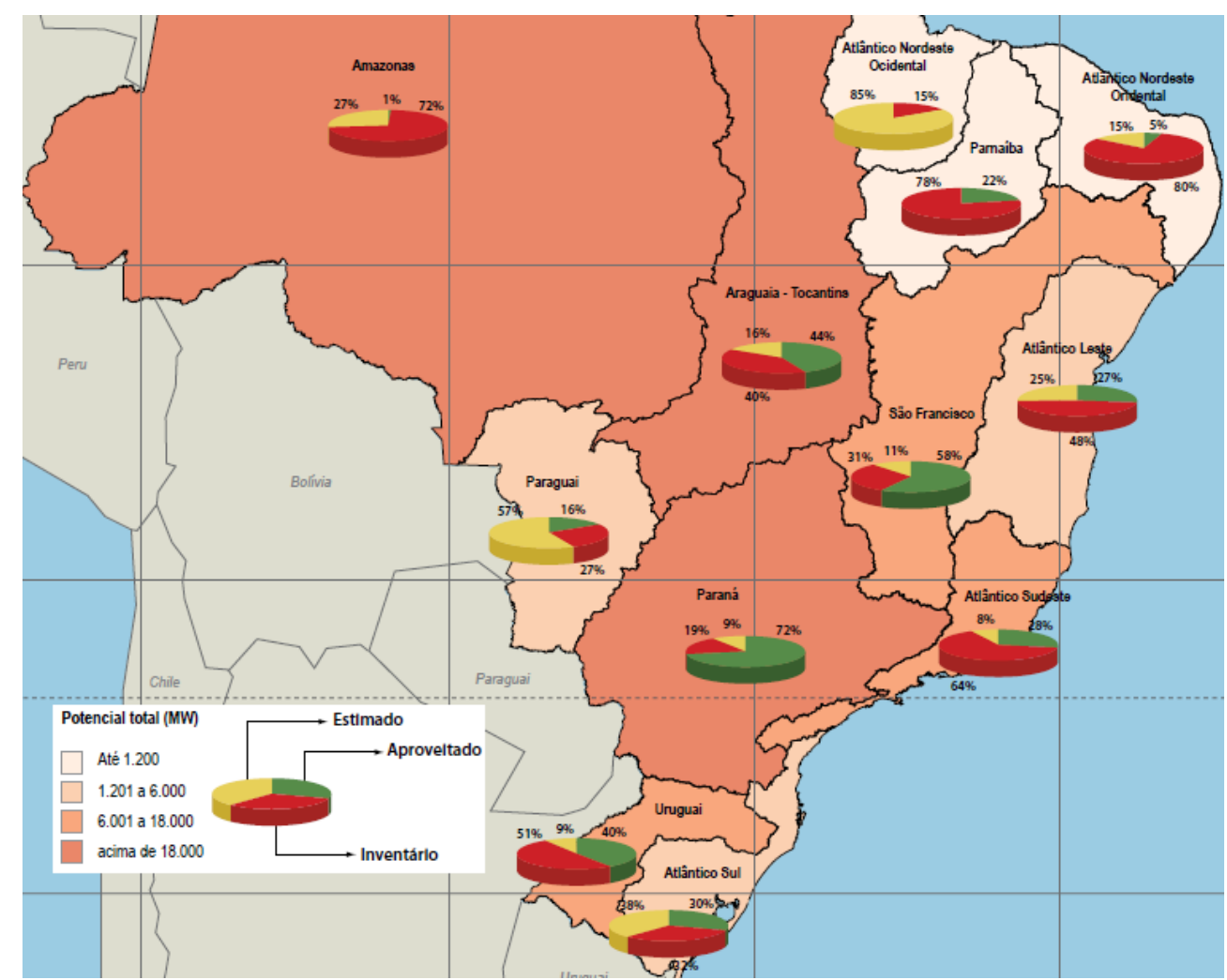

Figura 4.2: Potencial Hidroelétrico Brasileiro

Entretanto, explorar o potencial da região Amazônica tem sido bastante complicado, por causa de questões ambientais que vêm assumindo grande importância nos critérios de decisão do setor elétrico. Grupos ambientalistas nacionais e internacionais questionam empreendimentos na região Amazônica, em razão do potencial hidrelétrico estar localizado em áreas de condições socioambientais delicadas, por suas interferências sobre territórios indígenas, áreas de preservação e recursos florestais. Isso provoca entraves jurídicos que dificultam o licenciamento ambiental de usinas de fonte hidráulica nesta região.

A solução encontrada para minimizar os impactos ambientais e tornar viável a construção de usinas hidroelétricas tem sido a construção de usinas a fio d'água, ou seja, usinas que dispõe de uma capacidade de armazenamento muito pequena e só podem gerar energia com a vazão natural do rio, sem a possibilidade de acumular água na época das cheias para uso na época de estiagem. Esta configuração do sistema gera consequências diversas, dentre as quais a impossibilidade de controle de cheias, maior exigência das atuais usinas do sistema com capacidade de regularização, gerando alterações de nível dos reservatórios ao longo dos ciclos hidrológicos e maior despacho térmico para atender às exigências sazonais da carga [3, 53]. 
Capítulo 4. Operação do SIN Frente à Entrada de Usinas a Fio D'água de Grande Porte na Região Amazônica

Tabela 4.1: Potencial Hidrelétrico Brasileiro (MW)

\begin{tabular}{r|r|r|r||r|r}
\hline Bacia & Aproveitado & Inventário & Estimado & Total & \% \\
\hline Amazonas & 835 & 77.058 & 28.256 & 106.149 & 42,2 \\
\hline Paraná & 41.696 & 10.742 & 5.363 & 57.801 & 23,0 \\
\hline Tocantins/Araguaia & 12.198 & 11.297 & 4.540 & 28.035 & 11,2 \\
\hline São Francisco & 10.290 & 5.550 & 1.917 & 17.757 & 7,1 \\
\hline Atlântico Sudeste & 4.107 & 9.501 & 1.120 & 14.728 & 5,9 \\
\hline Uruguai & 5.182 & 6.482 & 1.152 & 12.816 & 5,1 \\
\hline Atlântico Sul & 1.637 & 1.734 & 2.066 & 5.437 & 2,2 \\
\hline Atlântico Leste & 1.100 & 1.950 & 1.037 & 4.087 & 1,6 \\
\hline Paraguai & 499 & 846 & 1.757 & 3.102 & 1,2 \\
\hline Parnaíba & 225 & 819 & 0 & 1.044 & 0,4 \\
\hline Atlântico NE Oc. & 0 & 58 & 318 & 376 & 0,1 \\
\hline \hline Atlântico NE Or. & 8 & 127 & 23 & 158 & $<0,1$ \\
\hline Total & 77.777 & 126.164 & 47.549 & 251.490 & 100,0 \\
\hline$\%$ & 30,9 & 50,2 & 18,9 & 100,0 & 100,0 \\
\hline
\end{tabular}

\section{2}

\section{Características da Região Amazônica}

A região Amazônica possui uma forte sazonalidade, ou seja, um ciclo sazonal bem definido, com alta afluência no período úmido e baixa no período seco e forte simultaneidade com o regime hidrológico do Sudeste [3]. A Figura 4.3 apresenta uma comparação da energia afluente média entre a região Amazônica (Acre Rondônia, Teles Pires e Belo Monte) e o subsistema Sudeste, considerando a bacia do Paraná.

Outro dado importante a ser observado sobre a região Amazônica é a estimativa de elevação da participação na expansão de projetos de geração de energia elétrica, passando de 10\%, em dezembro de 2010, para $23 \%$ da capacidade instalada do SIN, em dezembro de 2020, totalizando 28.209 MW de expansão. Enquanto no subsistema Sudeste há uma estimativa de redução de $60 \%$ para $46 \%$ na participação na oferta total do sistema, conforme mostra a Figura $4.4[3]$. 
Capítulo 4. Operação do SIN Frente à Entrada de Usinas a Fio D'água de Grande Porte na Região Amazônica

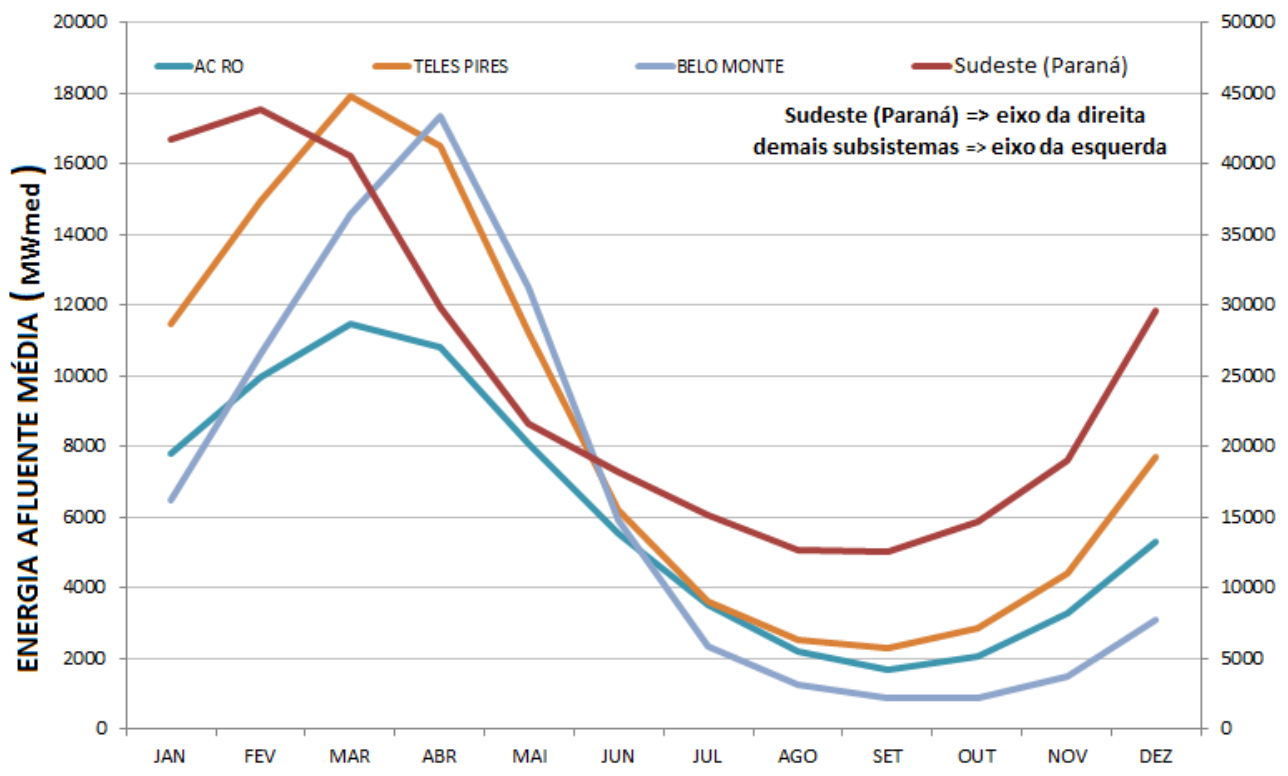

Figura 4.3: Energia Afluente Média

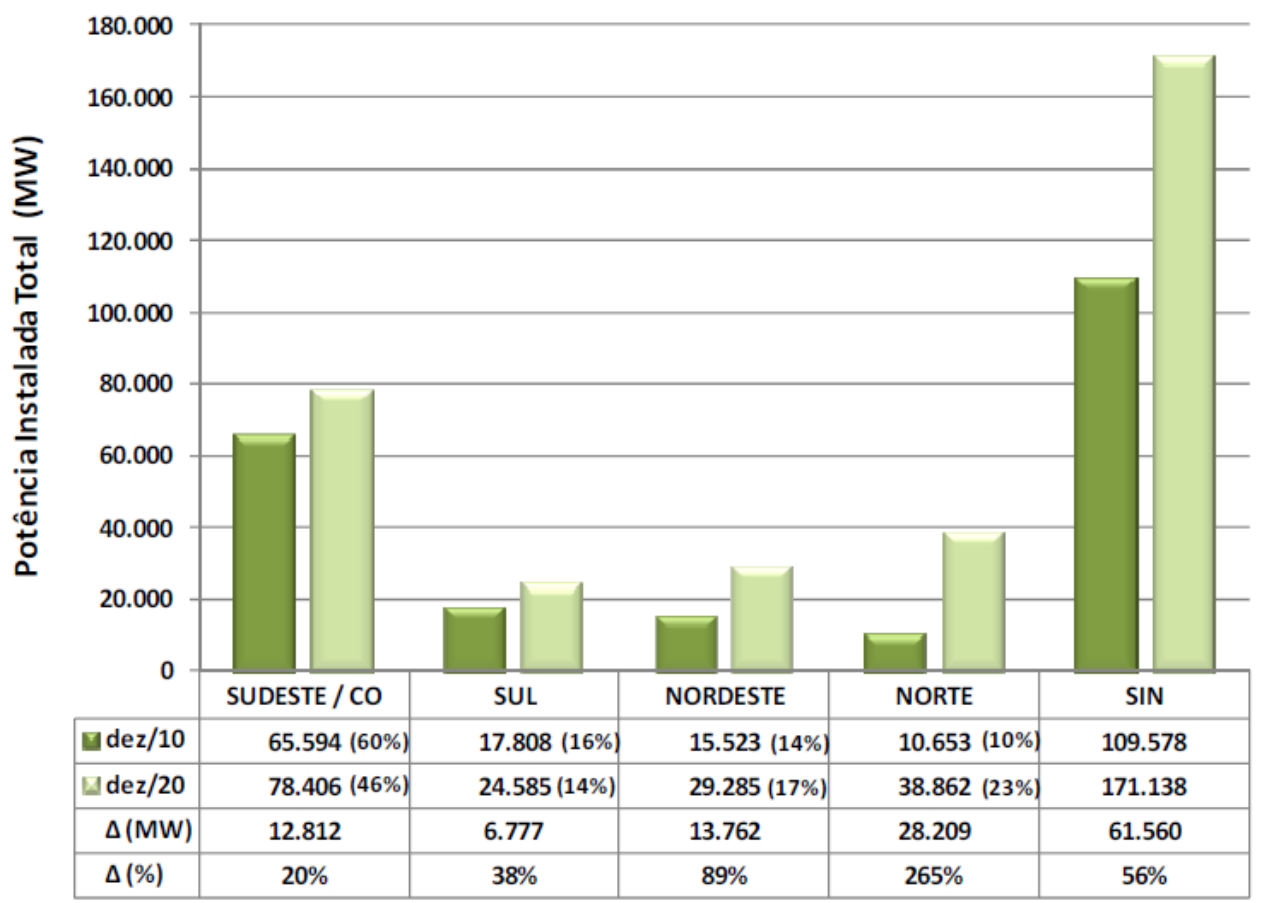

Figura 4.4: Participação Regional na Capacidade Instalada do SIN 


\section{3}

\section{Análise da Operação Frente à Nova Configuração}

O Sistema Interligado Nacional é um sistema hidrotérmico com forte predominância de geração hidráulica, cujas afluências aos reservatórios dependem de precipitações atmosféricas. Para garantir a segurança no atendimento com economicidade são necessários grandes reservatórios de acumulação visando reduzir os riscos associados às incertezas envolvidas nas afluências, ou seja, armazenando água pode-se reduzir os impactos da aleatoriedade das afluências na operação energética. Contudo, a entrada em operação na região Amazônica de usinas com grande capacidade de geração e baixa de regularização provocará, em termos percentuais, uma redução na capacidade de regularização do SIN: a previsão de elevação na capacidade de armazenamento é de apenas $6 \%$, enquanto a capacidade instalada das usinas hidrelétricas tem uma previsão de elevação de 39\%, para o horizonte de 2020. Isso tornará o SIN mais sensível a aleatoriedade das afluências [3].

Para analisar o comportamento do SIN frente a entrada das novas usinas da região Amazônica, foi utilizado o Plano Decenal de Expansão de 2020 (PDE 2020), desenvolvido pela Empresa de Pesquisa Energética (EPE). A justificativa da escolha do PDE 2020 foi por incorporar o horizonte de motorização e operação das novas usinas da bacia Amazônica e considerar a representação dos grandes troncos de interligação.

A Figura 4.5 [3] mostra o horizonte de motorização das novas usinas da região Amazônica representadas por subsistemas equivalentes e a tabela 4.2 apresenta as principais usinas que compõem estes novos subsistemas, com os seus respectivos horizontes de motorização e potência instalada.

Tabela 4.2: Novas Principais Usinas da Região Amazônica

\begin{tabular}{r|r|r|r|r}
\hline & Usina & \multicolumn{2}{|c|}{$\begin{array}{c}\text { Motorização } \\
\text { Inicio }\end{array}$} & $\begin{array}{r}\text { Potência } \\
\text { (MW) }\end{array}$ \\
\hline \multirow{2}{*}{ Acre - Rondônia } & JIRAU & fev/13 & out/17 & 3300 \\
& STO ANTONIO & jan/12 & dez/15 & 3150 \\
\hline Belo Monte & BELO MONTE & mar/16 & jan/19 & 11000 \\
\hline \multirow{3}{*}{ Teles Pires - Tapajós } & COLIDER & jan/15 & $\mathrm{mai} / 15$ & 300 \\
& TELES PIRES & mai/15 & out $/ 15$ & 1820 \\
& S LUIZ TAPAJ & jun/18 & dez/25 & 5919 \\
& S L TAP COMP & dez/17 & mar $/ 18$ & 213 \\
& JATOBA & out/20 & out $/ 25$ & 1226 \\
\hline
\end{tabular}

Devido à forte sazonalidade da região Amazônica, as novas usinas, que têm como característica uma alta capacidade de geração e baixa de 


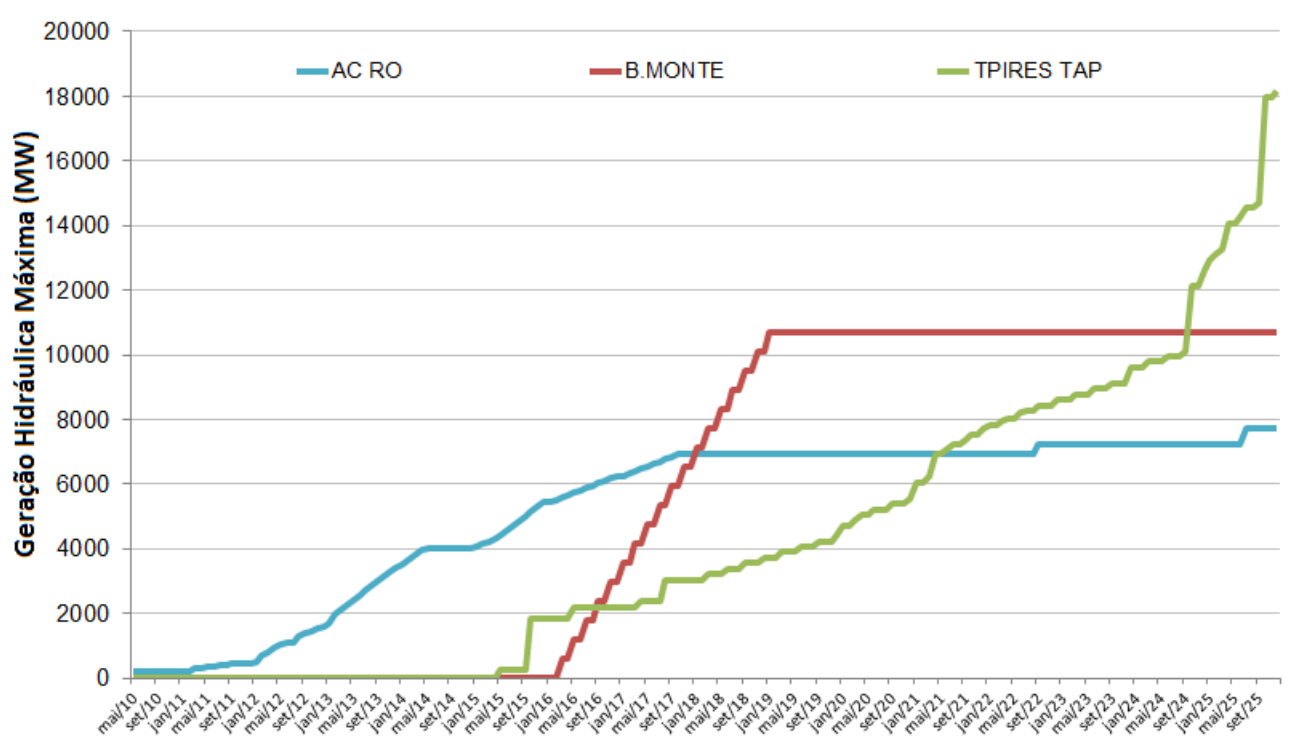

Figura 4.5: Motorização das Novas Usinas da Região Amazônica

regularização, serão capazes de gerar uma grande quantidade de energia no período úmido, e uma baixa quantidade no período seco. Isso porque, com uma baixa capacidade de regularização, elas não terão capacidade de estocar água do período úmido para gerar no período seco, sendo então obrigadas a gerar no período úmido e verter a água excedente que afluir aos reservatórios.

Com vistas a melhor utilizar esta característica hidrológica, a metodologia atual, que minimiza o valor esperado do custo total de operação (custo de geração termoelétrica mais penalidade por não suprimento da demanda), levará as novas usinas da região Amazônica a gerarem o máximo no período úmido, reduzindo a geração de usinas que tenham capacidade de armazenar água, para que no período seco esta água seja usada para gerar energia enquanto as novas usinas da região Amazônica não serão capazes de gerar grande quantidade de energia.

O subsistema que possui os maiores reservatórios de acumulação, e que será capaz de armazenar água durante o período úmido para gerar no período seco é o subsistema Sudeste. Pode-se destacar a importância dos grandes reservatórios instalados nesta região, que representam $71 \%$ do SIN [3]. A metodologia atual tende a elevar o risco dos reservatórios do subsistema Sudeste atingirem níveis baixos no fim do período seco, supondo que com a importação de energia da região Amazônica no período úmido o armazenamento destes reservatórios, em média, possa ser recuperado. Isto pode ser observado na Figura 4.6, que mostra o percentual de séries que levam o armazenamento do subsistema Sudeste a valores abaixo de $10 \%$ da capacidade de armazenamento ao longo do horizonte de estudo e a motorização 
das novas usinas da região Amazônica. Observa-se que, com a motorização das novas usinas há um aumento significativo no número de séries que levam o armazenamento do subsistema Sudeste a valores abaixo de $10 \%$ da capacidade de armazenamento, pulando do patamar de aproximadamente $2 \%$ no início para quase $20 \%$ no final do estudo.

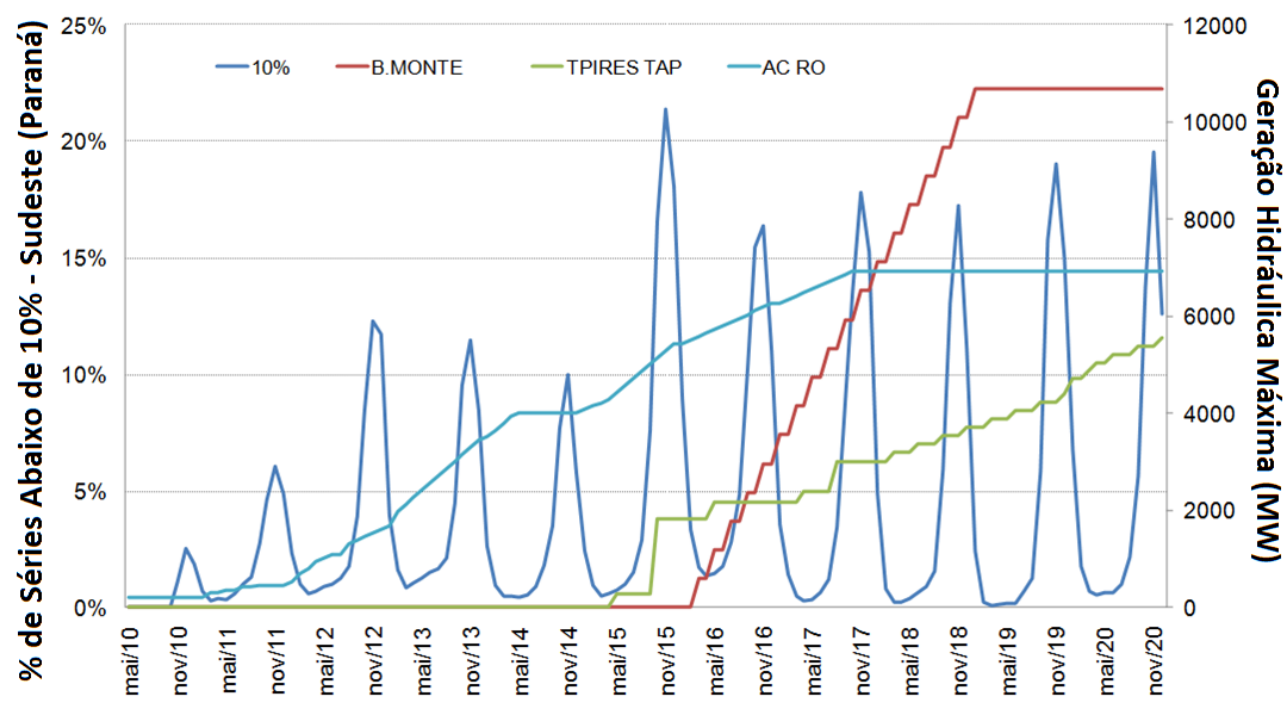

Figura 4.6: Percentual de Séries Abaixo de 10\% do Armazenamento e Motorização das Novas Usinas da Região Amazônica

A Figura 4.7, apresenta a evolução do armazenamento do subsistema Sudeste (bacia do Paraná) para o valor médio das 2000 séries simuladas. Observa-se um aumento da amplitude da variação do armazenamento ao longo do horizonte, provocada pela motorização das novas usinas da região Amazônica, ou seja, os reservatórios do subsistema Sudeste em média tenderam a atingir níveis de armazenamento mas baixos do que atingem na configuração atual do sistema, com a nova configuração do SIN.

A Figura 4.8 apresenta a evolução dos armazenamentos dos subsistemas Sudeste (bacia do Paraná) e "Sudeste menos Paraná"durante o horizonte de estudo. Observa-se que, em média, a otimização manteve o subsistema "Sudeste menos Paraná"com níveis altos de armazenamento, possivelmente para garantir boa altura de queda, enquanto o subsistema Sudeste (bacia do Paraná) teve, em média, uma forte variação da amplitude de armazenamento, para armazenar água durante o período úmido, período no qual as novas usinas da região Amazônica, que possuem baixa capacidade de armazenamento estarão gerando. 
Capítulo 4. Operação do SIN Frente à Entrada de Usinas a Fio D'água de Grande Porte na Região Amazônica

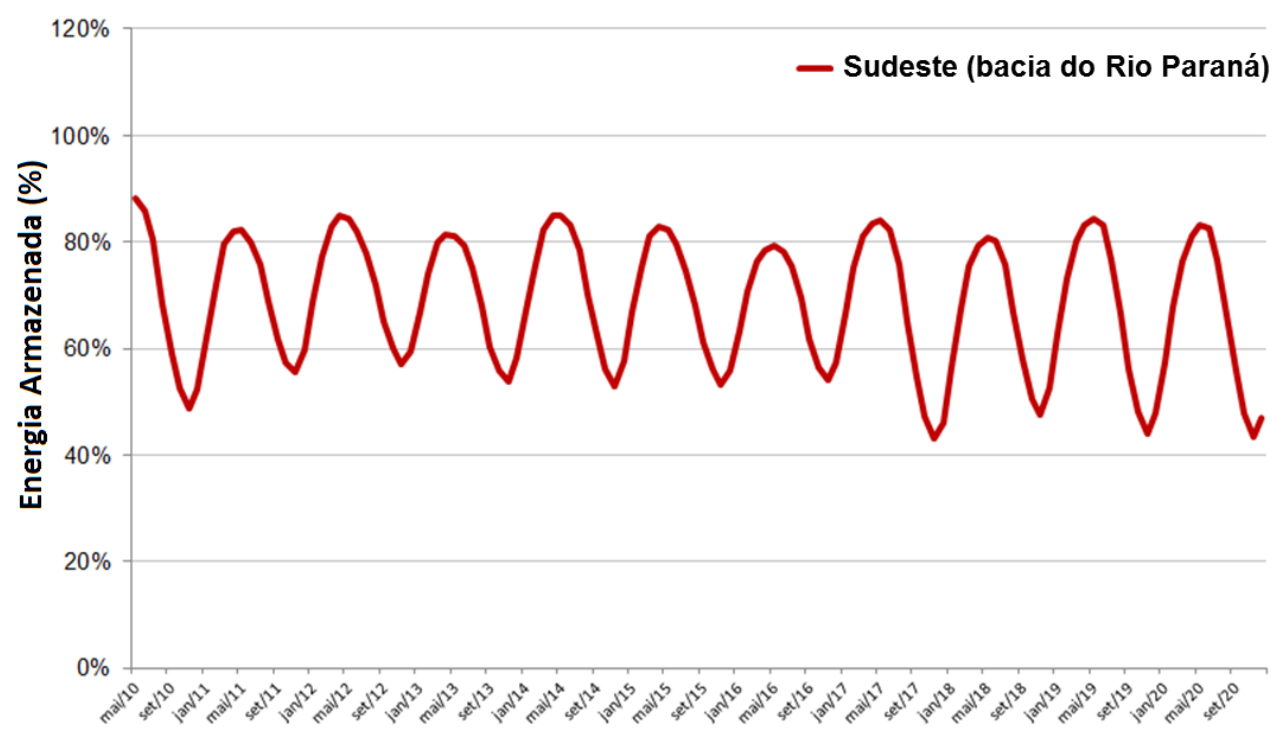

Figura 4.7: Valor Médio das Séries Simuladas para o Sudeste, Bacia do Paraná

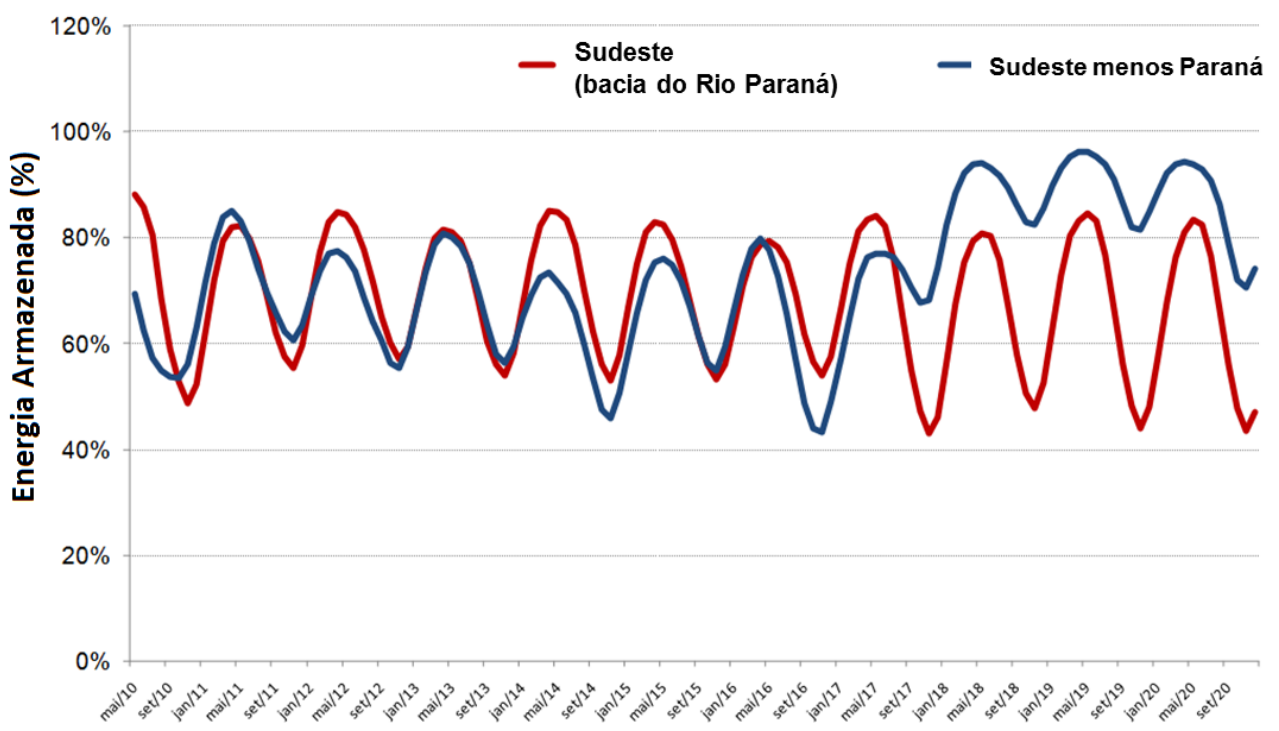

Figura 4.8: Valor Médio das Séries Simuladas para o Sudeste, Bacia do Paraná, e Sudeste, Menos Bacia do Paraná 


\section{Metodologia Proposta para a Determinação dos Níveis Metas}

5.1

\section{Introdução}

Para a definição dos níveis metas é proposto o desenvolvimento de um sistema de apoio à decisão que seja capaz de lidar com objetivos conflitantes como economicidade e segurança, com base teórica, que possa levar em conta informações não modeláveis, sistematizar a participação do decisor na gradação da segurança energética a ser adotada, considerando os custos requeridos, e contornar as possíveis dificuldades apontadas em determinar os níveis metas utilizando a metodologia atual.

A metodologia proposta tem como objetivo definir os níveis metas (níveis mínimos de armazenamento ao final do período seco - final de mês de novembro) através da avaliação de diversas alternativas de possibilidades de armazenamento para os subsistemas Sudeste e Nordeste. Os níveis de armazenamento serão definidos através de um sistema de apoio à decisão com base na segurança energética e economicidade.

Neste trabalho, a segurança energética será abordada através da definição dos níveis mínimos de armazenamento ao final da estação seca que garantam o atendimento até o ano seguinte, considerando a redução da capacidade de regularização e o risco hidrológico. A economicidade será abordada através do custo de geração térmica requerido para alcançar o grau de segurança desejado.

Sendo assim, a segurança energética será aferida pelo risco de déficit e percentual de séries que levam a armazenamentos abaixo de $20 \%$ no ano seguinte (segundo ano do estudo, ano que os níveis metas visam proteger) e a economicidade pelo custo de geração térmica necessária para que o níveis metas sejam atingidos (primeiro ano de estudo).

\section{2}

Sistema de Apoio à Decisão 


\subsection{1}

\section{Definição do Método}

Para escolher o método mais apropriado a ser utilizado na definição dos níveis metas, foi realizada uma revisão bibliográfica dos métodos de apoio multicritério a decisão, e os resultados desta revisão foram apresentados no capítulo 2.

O método escolhido foi o PROMETHEE II (Preference Ranking Organization Method for Enrichment Evaluation), devido a:

- permitir o refinamento da avaliação de cada critério, o que é importante no tratamento diferenciado entre custo e segurança, visto, por exemplo, que pequenas variações de risco de déficit são muito significativas, enquanto pequenas variações de custo podem ser desprezadas. Assim, é fundamental a escolha de um método que seja capaz de tratar de forma diferenciada a avaliação das alternativas em relação a cada critério;

- permitir a ordenação total das alternativas, visto que para a operação do SIN é necessária a definição de uma única alternativa de armazenamento e não um subconjunto de alternativas não dominadas;

- os conceitos e parâmetros envolvidos em sua aplicação podem ser assimilados facilmente pelo decisor, já que fazem parte da sua área de atuação.

\section{2 .2}

\section{Definição dos Critérios}

Este é um importante ponto a ser tratado no desenvolvimento de um sistema de apoio à decisão, e deve envolver especialistas das áreas relacionadas ao problema para que sejam escolhidos os mais relevantes. Neste trabalho, conforme apresentado na seção 5.1, serão utilizados dois grupos de critérios: os relacionados à segurança energética (frequência do não suprimento de energia - percentual de risco de déficit - e percentual de séries que levam o armazenamento abaixo de $20 \%$, para cada subsistema) e a economicidade (custo de geração térmica total para atingir os níveis metas, ou seja, soma dos custos da geração térmica dos subsistemas Sudeste, Sul, Nordeste e Norte).

\section{2 .3}

\section{Definição das Funções de Preferência de Cada Critério}

No método PROMETHEE II, as alternativas são comparadas entre si, em relação a cada critério $(j)$, com o uso de funções de preferência $\left(P_{j}\right)$ que, a partir da verificação da diferença entre as avaliações de duas alternativas 
$\left(\delta_{i k}\right)$, estabelecem um grau de preferência de uma em relação à outra $\left(P_{j}\left(\delta_{i k}\right)\right)$, conforme apresentado no Capítulo 2.

O processo de escolha da função de preferência tem o objetivo de capturar o conhecimento tácito dos decisores e pode ser alterado por estes. Neste trabalho, para o critério de percentual de risco de déficit foi utilizada a função de preferência linear e para os critérios de percentual de séries que levam a armazenamentos abaixo de $20 \%$ e custo para atingir o nível meta foi utilizada a função preferência linear e área linear.

A escolha da função de preferência linear para o critério de percentual de risco de déficit foi devido ao fato de que pequenas variações neste percentual são importantes. Já para os critérios de percentual de séries abaixo de $20 \%$ e custo para atingir o nível meta foi escolhida a função preferência linear e área linear, porque pequenas diferenças podem ser desconsideradas.

A Figura 5.1 apresenta as três funções de preferência utilizadas neste trabalho. Para o critério relacionado ao risco, o limiar de preferência $(p)$ considerado foi 1 (valor absoluto). Para o critério relacionado ao percentual de séries abaixo de 20\%, o limiar de indiferença $(q)$ considerado foi de 0,5 (valor absoluto), e o limiar de preferência $(p)$ de 3 (valor absoluto). Para o critério relacionado ao custo, o limiar de indiferença $(q)$ considerado foi de $0,5 \%$ do custo, e o limiar de preferência $(p)$ de $3 \%$ do custo.
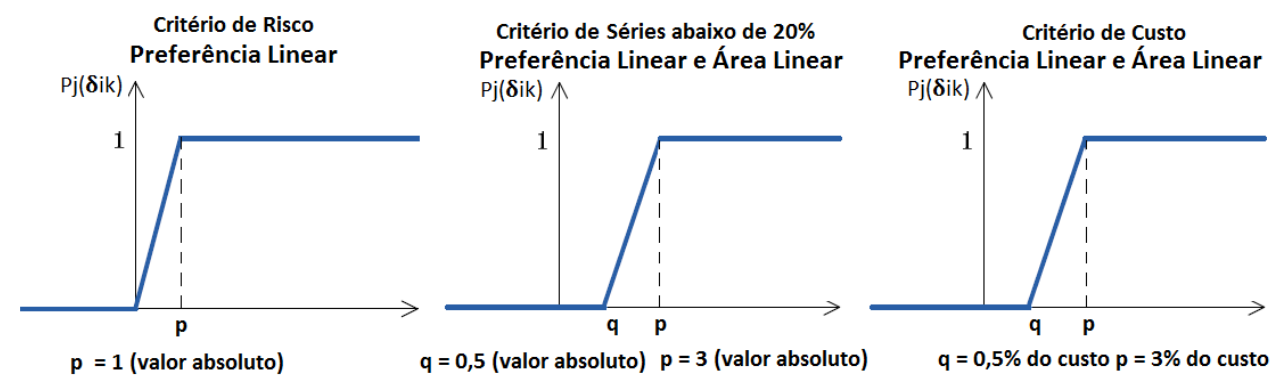

Figura 5.1: Funções de Preferências Utilizadas

\section{2 .4}

\section{Definição dos Pesos}

A escolha dos pesos de cada critério $\left(W_{j}\right)$ deve ser feita em conjunto com os decisores, que poderão atribuir com mais realismo a importância de cada critério e capturar informações conjunturais não quantitativas.

Neste trabalho, foi considerado um total de 14 pesos. A segurança energética foi considerada mais importante que a economicidade, desta forma, os critérios relacionados à segurança energética totalizam 8 pesos, $57.14 \%$ do total e o critério relacionado a economicidade totaliza 6 pesos, $42.86 \%$ do total. 
Os grupos de critérios relacionados à segurança, risco de déficit e percentual de séries que levam o armazenamento a valores abaixo de $20 \%$ foram considerados de mesma importância, então os pesos correspondentes a segurança foram divididos igualmente entre os dois grupos de critérios, 4 pesos correspondendo a $28.57 \%$ para cada um.

Para o grupo de critérios relacionado ao risco de déficit, os pesos foram divididos igualmente para cada subsistema, Sudeste, Sul, Nordeste e Norte, 1 peso, representando $7.14 \%$ do total. Foram definidos pesos iguais em função do percentual de risco de déficit ser igualmente importante nestes quatro subsistemas.

Para o grupo de critérios relacionados ao percentual de séries abaixo de $20 \%$ foi atribuído maior valor para o subsistema Sudeste, com peso igual a 2 , correspondendo a $14.29 \%$ do total, devido à maior capacidade de armazenamento deste subsistema. Para o subsistema Nordeste foi atribuído peso de valor 1 que corresponde a $7.14 \%$ do total, devido a ser o segundo maior subsistema e para os subsistemas Sul e Norte pesos de valor igual a $0.5 \%$ correspondendo a $3.57 \%$ do total.

Em relação ao critério custo, foi atribuído peso de valor 6 , que corresponde a $42.86 \%$ do total, correspondente ao valor total da geração térmica dos quatro subsistemas reunidos em um único critério. Este critério não foi analisado de forma individual para cada subsistema por ser indiferente gerar térmica em um ou outro subsistema, em função do sistema ser interligado. Os valores percentuais dos pesos utilizados neste trabalho são apresentados na Figura 5.2.

\section{3}

\section{Processo de Obtenção dos Dados para o Sistema de Apoio à Decisão}

Os dados utilizados no Sistema de Apoio a Decisão são obtidos através de simulações utilizando o modelo computacional NEWAVE versão 17, sendo composto pelas seguintes etapas:

- definição do grid de alternativas, ou seja, definição das combinações de armazenamento mínimo dos subsistemas Sudeste e Nordeste que serão avaliadas;

- cálculo dos valores correspondentes aos critérios de percentual de risco de déficit e percentual de séries que levam a armazenamento inferior a $20 \%$;

- cálculo dos valores correspondentes ao critério de custo de geração térmica para atingir os níveis metas. 


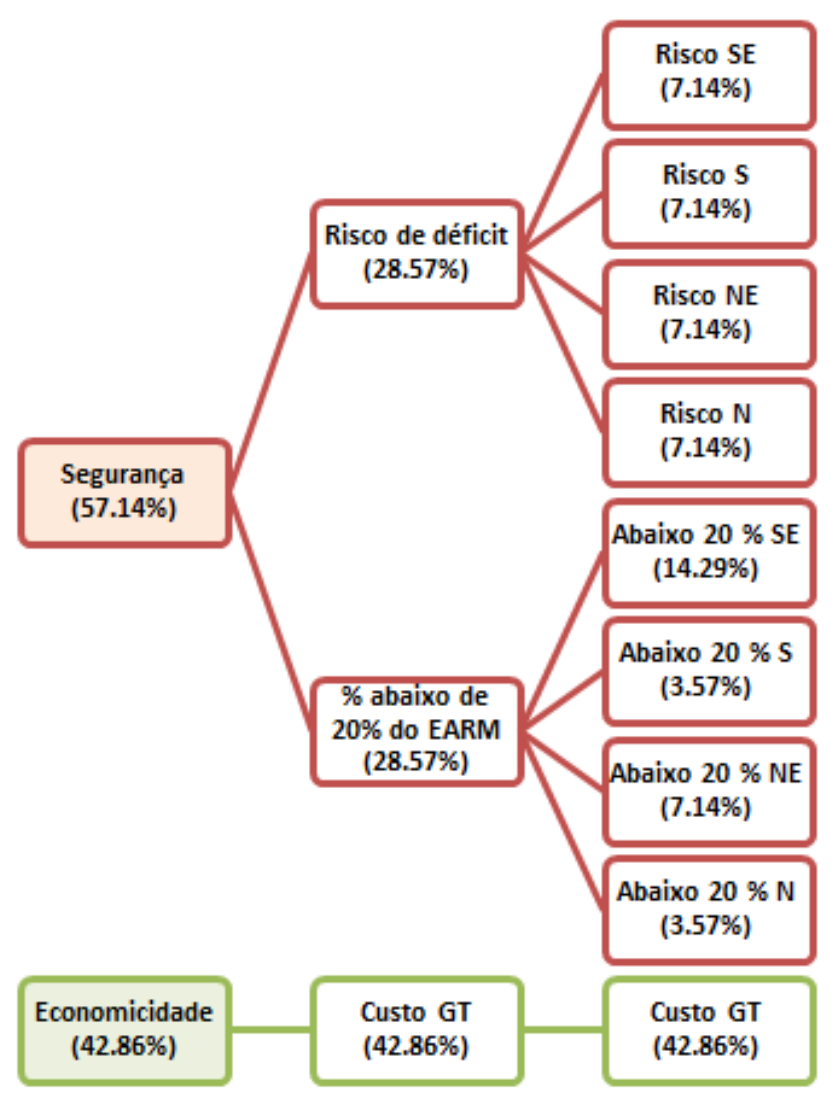

Figura 5.2: Valores Percentuais dos Pesos

\subsection{1 \\ Definição Grid de Alternativas}

As alternativas $(i)$ são definidas pela experiência dos decisores, que optam pelas combinações de armazenamentos para os subsistemas Sudeste e Nordeste que serão avaliadas.

Neste trabalho, foram adotadas combinações de armazenamento dos subsistemas Sudeste e Nordeste partindo do armazenamento mínimo de 20\%, variando de 5 em 5 por cento, até o armazenamento máximo de $50 \%$

Para cada possível alternativa o modelo NEWAVE é utilizado para avaliar a alternativa segundo os critérios escolhidos. De posse das avaliações de cada alternativa, a melhor é escolhida usando o método PROMETHEE II. Após encontrada a solução, é realizada uma segunda etapa, com o objetivo de refinar a solução encontrada, através do estabelecimento de um novo grid de alternativas em torno da solução, variando de 1 em 1 por cento até $2 \%$ para mais e menos do valor encontrado como solução.

Com estes dois passos, é possível cobrir todas as combinações de armazenamentos de 1 em 1 por cento na faixa que vai de 18 a 52 por cento.

Uma possível limitação da metodologia proposta é o grande número 
de alternativas, caso se queira trabalhar com uma faixa maior de níveis de armazenamento ou determinar o nível meta para um número grande de subsistemas. Esta possível limitação pode ser contornada com a eliminação de alternativas através da experiência do decisor, eliminando a priori as alternativas de combinações de armazenamentos que o decisor julga não serem factíveis. Tornando o número de alternativas viável de ser trabalhado.

\subsection{2}

\section{Cálculo dos Valores Correspondentes aos Critérios de Percentual de Risco} e Percentual de Séries com Armazenamento Inferior a 20 Por Cento

O objetivo desta etapa é avaliar as consequências futuras de cada combinação de armazenamento mínimo definida no grid de alternativas.

Para cada alternativa do grid, com o auxílio do modelo NEWAVE utilizando séries sintéticas, são obtidos os dados referentes aos critérios relacionados à segurança energética (percentual de risco de déficit e percentual de séries com armazenamento inferior a 20\%) da seguinte forma:

- executar a simulação final a partir de dezembro do ano para o qual se quer definir os níveis metas, utilizando a estratégia de operação relativa ao PMO de referência;

- o armazenamento inicial é o par correspondente à alternativa a ser avaliada para os subsistemas para os quais se quer definir o nível meta. Para os demais subsistemas considerar o valor médio de armazenamento das 2000 séries sintéticas;

- obter o percentual de risco de déficit e percentual de séries que levam a armazenamentos inferiores a $20 \%$ ao longo do ano seguinte, para cada alternativa.

\subsection{3}

\section{Cálculo dos Valores Correspondentes ao Critério de Custo de Geração Térmica}

O objetivo desta etapa é avaliar o custo de geração térmica necessário para se atingir os níveis de cada combinação de armazenamento mínimo definidas no grid de alternativa.

Para cada alternativa do grid, com o auxílio do modelo NEWAVE utilizando séries sintéticas, são obtidos os dados referentes ao critério relacionado a economicidade (custo de geração térmica), da seguinte forma:

- executar uma política operativa a partir do início do PMO de referência até o final do ano seguinte, sem anos adicionais e com armazenamentos 
fixos no final do período seco do ano seguinte, sendo esses os valores definidos para cada alternativa, para os subsistemas para os quais se deseja definir os níveis metas;

- obter o custo de geração térmica de cada alternativa.

No capítulo seguinte serão apresentados resultados de aplicações da metodologia proposta juntamente com uma análise dos resultados obtidos e testes de sensibilidade. 


\section{Estudos de Casos}

\section{1}

\section{Introdução}

Neste capítulo são apresentados estudos de casos que analisam a aplicabilidade da metodologia proposta. O primeiro estudo é para avaliação da metodologia na condição atual do sistema, e o segundo estudo é para avaliação na condição futura, na qual as novas usinas da região Amazônica estarão totalmente motorizadas.

O primeiro estudo é referente ao cálculo dos níveis metas para o ano de 2012, que tem como caso base o Programa Mensal de Operação (PMO) de dezembro de 2011 e o segundo estudo é referente ao cálculo dos níveis metas para 2013, que tem como caso base um caso fictício de maio de 2012, com as novas UHEs da região Amazônica totalmente motorizadas. As simulações do sistema de apoio a decisão foram realizadas utilizando o software Visual Promethee [55].

\section{2}

\section{Primeiro Estudo de Caso: Condição Atual do Sistema}

Este estudo de caso tem como base o PMO de dezembro de 2011 e o objetivo é estabelecer os níveis metas para novembro de 2012.

A Tabela 6.1 apresenta as variáveis observadas para este estudo, onde as alternativas são representadas pelos pares de energia armazenada (EARM) dos subsistemas Sudeste (SE) e Nordeste (NE) respectivamente. As consequências dos níveis mínimos de armazenamento de cada alternativa (risco de déficit e percentual de séries que levam o armazenamento a valores inferiores a 20\%) são calculados para o ano de 2013 e estão representados para os subsistemas Sudeste, Sul, Nordeste e Norte individualmente. Os valores de custo da geração térmica necessária para atingir os níveis metas especificados são calculados para o ano de 2012 e estão representando o valor de geração térmica total dos subsistemas Sudeste, Sul, Nordeste e Norte. Estes valores foram obtidos conforme descrito no capítulo 5.

Analisando a Tabela 6.1, observa-se que os valores de custo de geração térmica necessária para atingir os níveis metas especificados crescem à medida 
que os níveis de armazenamento desejados para o níveis metas aumentam. Como é de se esperar portanto, as alternativas com menor armazenamento são mais econômicas. Por outro lado, o risco de déficit e o percentual de séries que levam o armazenamento a valores abaixo de $20 \%$ tendem a diminuir com o aumento dos níveis de armazenamento, o que converge ao esperado, pois de fato as alternativas com maior armazenamento são mais seguras.

A Figura 6.1 apresenta os pesos, estabelecidos pelos decisores, para o sistema de apoio à decisão. Os critérios referentes à segurança (risco de déficit e percentual de séries que levam o armazenamento abaixo de 20\%) são representados pelo grupo de cor vermelha e o critério referente à economicidade (custo de geração térmica) pelo grupo de cor verde. A Figura mostra também as funções de preferências e os seus respectivos limiares de preferência e indiferença estabelecidos para cada critério. Estes dados expressam as preferências dos decisores em relação aos critérios selecionados para a definição dos níveis metas e foram estabelecidos conforme apresentado no capítulo 5.

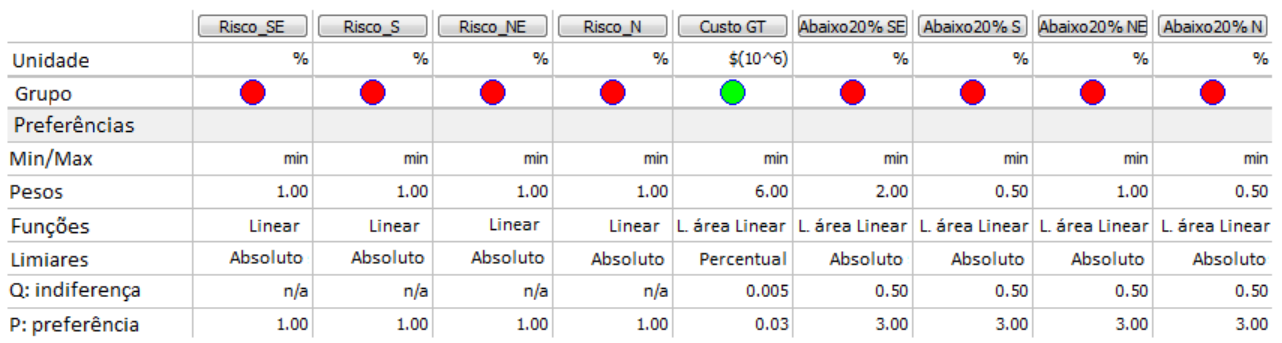

Figura 6.1: Pesos e Limiares Utilizados nos Estudos de Casos

A Tabela 6.2 apresenta a ordem das alternativas obtidas pelo sistema de apoio à decisão, com a aplicação do método PROMETHEE II. São apresentados também os fluxos positivo, negativo e total para cada alternativa. Observase que a melhor alternativa encontrada pelo método (maior fluxo total), em função das preferências dos decisores, foi o valor de energia armazenada de $40 \%$ para o subsistema Sudeste (SE) e 35\% para o subsistema Nordeste (NE).

\subsection{1}

\section{Refinamento da Solução Encontrada}

Após encontrada a solução (40\% para o subsistema Sudeste e 35\% para o subsistema Nordeste) é realizado um novo processamento com o grid de alternativas variando entre as combinações $(S E=38 \%$ e $N E=33 \%)$ de $1 \mathrm{em}$ 1 por cento até $(S E=42 \%$ e $N E=37 \%)$. O objetivo desta etapa é refinar a solução encontrada. A Tabela 6.3 apresenta as variáveis observadas para esta etapa do estudo. 
Tabela 6.1: Variáveis Observadas - Caso: Condição Atual do Sistema

\begin{tabular}{|c|c|c|c|c|c|c|c|c|c|}
\hline $\begin{array}{c}\% \\
\text { EARM } \\
\text { SE - NE }\end{array}$ & $\begin{array}{c}\% \\
\text { Risco } \\
\text { SE }\end{array}$ & $\begin{array}{c}\% \\
\text { Risco } \\
\text { S }\end{array}$ & $\begin{array}{c}\% \\
\text { Risco } \\
\text { NE }\end{array}$ & $\begin{array}{c}\% \\
\text { Risco } \\
\mathbf{N}\end{array}$ & $\begin{array}{c}\text { Custo } \\
\text { GT } \\
\left(\$ 10^{6}\right)\end{array}$ & $\begin{array}{c}\text { \% Séries } \\
\text { abaixo } \\
20 \% \text { SE }\end{array}$ & $\begin{array}{c}\text { \% Séries } \\
\text { abaixo } \\
20 \% \text { S }\end{array}$ & $\begin{array}{l}\text { \% Séries } \\
\text { abaixo } \\
20 \% \text { NE }\end{array}$ & $\begin{array}{c}\text { \% Séries } \\
\text { abaixo } \\
20 \% \text { N }\end{array}$ \\
\hline $20 \%-20 \%$ & 7.55 & 8.20 & 1.05 & 1.75 & 3422.71 & $24.0 \%$ & $45.0 \%$ & $72.4 \%$ & $36.0 \%$ \\
\hline $20 \%-25 \%$ & 7.35 & 8.00 & 0.85 & 1.60 & 3462.93 & $23.9 \%$ & $45.3 \%$ & $69.3 \%$ & $34.3 \%$ \\
\hline $20 \%-30 \%$ & 7.25 & 7.80 & 0.60 & 1.45 & 3497.73 & $23.8 \%$ & $43.8 \%$ & $67.2 \%$ & $33.5 \%$ \\
\hline $20 \%-35 \%$ & 7.15 & 7.75 & 0.50 & 1.30 & 3545.70 & $23.4 \%$ & $44.0 \%$ & $65.3 \%$ & $33.1 \%$ \\
\hline $20 \%-40 \%$ & 7.05 & 7.90 & 0.35 & 1.20 & 3596.99 & $23.2 \%$ & $44.0 \%$ & $63.4 \%$ & $32.6 \%$ \\
\hline $20 \%-45 \%$ & 7.10 & 7.90 & 0.30 & 1.15 & 3654.49 & $23.2 \%$ & $43.8 \%$ & $62.7 \%$ & $31.2 \%$ \\
\hline $20 \%-50 \%$ & 7.00 & 7.90 & 0.25 & 1.20 & 3708.47 & $23.2 \%$ & $45.4 \%$ & $61.0 \%$ & $31.6 \%$ \\
\hline $25 \%-20 \%$ & 5.25 & 6.65 & 0.85 & 1.50 & 3583.80 & $20.3 \%$ & $43.4 \%$ & $71.2 \%$ & $33.5 \%$ \\
\hline $25 \%-25 \%$ & 5.25 & 6.60 & 0.60 & 1.35 & 3633.63 & $19.9 \%$ & $42.3 \%$ & $68.2 \%$ & $32.1 \%$ \\
\hline $25 \%-30 \%$ & 5.10 & 6.60 & 0.55 & 1.15 & 3688.45 & $19.7 \%$ & $42.7 \%$ & $66.2 \%$ & $31.1 \%$ \\
\hline $25 \%-35 \%$ & 5.25 & 6.45 & 0.45 & 1.10 & 3738.28 & $19.5 \%$ & $42.5 \%$ & $64.1 \%$ & $30.0 \%$ \\
\hline $25 \%-40 \%$ & 5.20 & 6.60 & 0.40 & 1.15 & 3794.10 & $19.1 \%$ & $43.3 \%$ & $62.9 \%$ & $30.1 \%$ \\
\hline $25 \%-45 \%$ & 5.15 & 6.30 & 0.20 & 1.10 & 3855.60 & $19.3 \%$ & $42.5 \%$ & $61.4 \%$ & $29.8 \%$ \\
\hline $25 \%-50 \%$ & 5.10 & 6.50 & 0.15 & 1.05 & 3932.21 & $19.1 \%$ & $43.3 \%$ & $59.8 \%$ & $28.5 \%$ \\
\hline $30 \%-20 \%$ & 3.90 & 4.70 & 0.65 & 1.15 & 3777.55 & $16.2 \%$ & $43.1 \%$ & $70.1 \%$ & $31.5 \%$ \\
\hline $30 \%-25 \%$ & 3.75 & 4.80 & 0.55 & 1.05 & 3838.09 & $16.1 \%$ & $42.1 \%$ & $66.9 \%$ & $30.7 \%$ \\
\hline $30 \%-30 \%$ & 3.70 & 4.60 & 0.40 & 0.95 & 3898.27 & $15.9 \%$ & $43.0 \%$ & $64.7 \%$ & $30.4 \%$ \\
\hline $30 \%-35 \%$ & 3.60 & 4.60 & 0.30 & 0.70 & 3955.19 & $15.3 \%$ & $43.1 \%$ & $63.1 \%$ & $29.8 \%$ \\
\hline $30 \%-40 \%$ & 3.55 & 4.40 & 0.20 & 0.75 & 4033.11 & $15.2 \%$ & $41.3 \%$ & $61.8 \%$ & $28.6 \%$ \\
\hline $30 \%-45 \%$ & 3.50 & 4.40 & 0.20 & 0.65 & 4101.90 & $15.0 \%$ & $41.9 \%$ & $60.5 \%$ & $28.5 \%$ \\
\hline $30 \%-50 \%$ & 3.45 & 4.15 & 0.05 & 0.60 & 4187.11 & $14.9 \%$ & $42.6 \%$ & $59.3 \%$ & $27.8 \%$ \\
\hline $35 \%-20 \%$ & 2.65 & 3.95 & 0.30 & 0.70 & 4009.45 & $13.7 \%$ & $42.1 \%$ & $69.5 \%$ & $29.8 \%$ \\
\hline $35 \%-25 \%$ & 2.65 & 3.85 & 0.20 & 0.70 & 4075.09 & $13.4 \%$ & $40.9 \%$ & $66.0 \%$ & $28.7 \%$ \\
\hline $35 \%-30 \%$ & 2.55 & 3.80 & 0.15 & 0.55 & 4134.59 & $12.9 \%$ & $40.2 \%$ & $63.4 \%$ & $28.6 \%$ \\
\hline $35 \%-35 \%$ & 2.60 & 4.05 & 0.20 & 0.50 & 4206.43 & $12.7 \%$ & $41.2 \%$ & $62.0 \%$ & $27.5 \%$ \\
\hline $35 \%-40 \%$ & 2.50 & 4.05 & 0.10 & 0.35 & 4289.97 & $12.6 \%$ & $40.0 \%$ & $60.2 \%$ & $27.1 \%$ \\
\hline $35 \%-45 \%$ & 2.40 & 3.50 & 0.05 & 0.25 & 4383.75 & $12.6 \%$ & $40.3 \%$ & $58.9 \%$ & $26.6 \%$ \\
\hline $35 \%-50 \%$ & 2.50 & 3.10 & 0.05 & 0.20 & 4478.17 & $12.8 \%$ & $40.4 \%$ & $57.5 \%$ & $26.0 \%$ \\
\hline $40 \%-20 \%$ & 1.85 & 2.80 & 0.20 & 0.35 & 4273.81 & $10.6 \%$ & $38.8 \%$ & $67.8 \%$ & $28.3 \%$ \\
\hline $40 \%-25 \%$ & 1.90 & 3.10 & 0.20 & 0.35 & 4347.33 & $10.5 \%$ & $39.4 \%$ & $64.1 \%$ & $26.5 \%$ \\
\hline $40 \%-30 \%$ & 1.70 & 2.85 & 0.20 & 0.45 & 4433.33 & $10.1 \%$ & $38.7 \%$ & $62.1 \%$ & $26.3 \%$ \\
\hline $40 \%-35 \%$ & 1.70 & 2.95 & 0.15 & 0.40 & 4510.18 & $10.2 \%$ & $38.9 \%$ & $60.1 \%$ & $25.7 \%$ \\
\hline $40 \%-40 \%$ & 1.70 & 3.05 & 0.10 & 0.40 & 4603.83 & $10.2 \%$ & $39.5 \%$ & $58.7 \%$ & $24.9 \%$ \\
\hline $40 \%-45 \%$ & 1.70 & 3.25 & 0.10 & 0.40 & 4692.74 & $9.9 \%$ & $39.7 \%$ & $57.9 \%$ & $24.0 \%$ \\
\hline $40 \%-50 \%$ & 1.75 & 2.95 & 0.10 & 0.35 & 4814.26 & $10.1 \%$ & $39.3 \%$ & $56.6 \%$ & $23.4 \%$ \\
\hline $45 \%-20 \%$ & 1.40 & 2.25 & 0.20 & 0.35 & 4589.54 & $8.7 \%$ & $35.6 \%$ & $65.4 \%$ & $27.0 \%$ \\
\hline $45 \%-25 \%$ & 1.40 & 2.50 & 0.25 & 0.50 & 4677.80 & $8.9 \%$ & $36.6 \%$ & $62.2 \%$ & $25.9 \%$ \\
\hline $45 \%-30 \%$ & 1.40 & 2.40 & 0.20 & 0.40 & 4780.04 & $8.5 \%$ & $35.9 \%$ & $60.4 \%$ & $25.5 \%$ \\
\hline $45 \%-35 \%$ & 1.40 & 2.20 & 0.20 & 0.40 & 4870.00 & $8.1 \%$ & $35.3 \%$ & $58.4 \%$ & $24.2 \%$ \\
\hline $45 \%-40 \%$ & 1.40 & 2.35 & 0.20 & 0.40 & 4967.03 & $7.8 \%$ & $35.0 \%$ & $57.0 \%$ & $24.2 \%$ \\
\hline $45 \%-45 \%$ & 1.30 & 2.40 & 0.20 & 0.30 & 5074.57 & $7.6 \%$ & $36.5 \%$ & $56.0 \%$ & $23.8 \%$ \\
\hline $45 \%-50 \%$ & 1.30 & 2.10 & 0.15 & 0.30 & 5198.48 & $7.6 \%$ & $36.6 \%$ & $55.1 \%$ & $22.8 \%$ \\
\hline $50 \%-20 \%$ & 1.15 & 2.20 & 0.20 & 0.35 & 4947.88 & $6.5 \%$ & $33.9 \%$ & $63.1 \%$ & $25.2 \%$ \\
\hline $50 \%-25 \%$ & 1.10 & 1.95 & 0.20 & 0.35 & 5041.93 & $6.3 \%$ & $34.3 \%$ & $60.4 \%$ & $24.5 \%$ \\
\hline $50 \%-30 \%$ & 1.05 & 1.75 & 0.15 & 0.25 & 5162.20 & $6.1 \%$ & $33.9 \%$ & $58.8 \%$ & $23.5 \%$ \\
\hline $50 \%-35 \%$ & 1.00 & 1.65 & 0.15 & 0.30 & 5274.04 & $6.1 \%$ & $34.2 \%$ & $56.6 \%$ & $23.3 \%$ \\
\hline $50 \%-40 \%$ & 0.95 & 1.85 & 0.15 & 0.25 & 5392.38 & $6.1 \%$ & $33.9 \%$ & $55.3 \%$ & $23.4 \%$ \\
\hline $50 \%-45 \%$ & 0.95 & 1.65 & 0.10 & 0.20 & 5531.57 & $5.9 \%$ & $34.1 \%$ & $54.1 \%$ & $22.6 \%$ \\
\hline $50 \%-50 \%$ & 0.95 & 1.60 & 0.10 & 0.15 & 5667.72 & $5.7 \%$ & $34.3 \%$ & $53.3 \%$ & $21.6 \%$ \\
\hline
\end{tabular}


Tabela 6.2: Ordem das Alternativas - Caso: Condição Atual do Sistema

\begin{tabular}{|c|c|c|c|c|}
\hline Ordem & Alternativas & $\phi$ total & $\phi^{+}$ & $\phi^{-}$ \\
\hline 1 & $40 \%-35 \%$ & 0.0542 & 0.4138 & 0.3597 \\
\hline 2 & $40 \%-30 \%$ & 0.0536 & 0.4118 & 0.3582 \\
\hline 3 & $40 \%-20 \%$ & 0.0513 & 0.4175 & 0.3663 \\
\hline 4 & $40 \%-25 \%$ & 0.0502 & 0.4144 & 0.3642 \\
\hline 5 & $35 \%-30 \%$ & 0.0401 & 0.4125 & 0.3724 \\
\hline 6 & $45 \%-35 \%$ & 0.0365 & 0.4030 & 0.3664 \\
\hline 7 & $35 \%-45 \%$ & 0.0353 & 0.4170 & 0.3817 \\
\hline 8 & $40 \%-40 \%$ & 0.0340 & 0.4052 & 0.3711 \\
\hline 9 & $35 \%-40 \%$ & 0.0331 & 0.4109 & 0.3778 \\
\hline 10 & $45 \%-20 \%$ & 0.0307 & 0.4018 & 0.3711 \\
\hline 11 & $35 \%-50 \%$ & 0.0234 & 0.4134 & 0.3901 \\
\hline 12 & $45 \%-30 \%$ & 0.0203 & 0.3936 & 0.3733 \\
\hline 13 & $45 \%-40 \%$ & 0.0174 & 0.3945 & 0.3771 \\
\hline 14 & $35 \%-35 \%$ & 0.0152 & 0.3979 & 0.3827 \\
\hline 15 & $35 \%-25 \%$ & 0.0131 & 0.4012 & 0.3881 \\
\hline 16 & $40 \%-45 \%$ & 0.0131 & 0.3967 & 0.3836 \\
\hline 17 & $50 \%-30 \%$ & 0.0129 & 0.4034 & 0.3905 \\
\hline 18 & $30 \%-40 \%$ & 0.0118 & 0.3977 & 0.3859 \\
\hline 19 & $50 \%-25 \%$ & 0.0115 & 0.3944 & 0.3829 \\
\hline 20 & $30 \%-35 \%$ & 0.0101 & 0.3999 & 0.3898 \\
\hline 21 & $45 \%-25 \%$ & 0.0081 & 0.3882 & 0.3801 \\
\hline 22 & $50 \%-35 \%$ & 0.0072 & 0.4065 & 0.3993 \\
\hline 23 & $45 \%-45 \%$ & -0.0003 & 0.3906 & 0.3909 \\
\hline 24 & $30 \%-45 \%$ & -0.0007 & 0.3895 & 0.3903 \\
\hline 25 & $35 \%-20 \%$ & -0.0041 & 0.3952 & 0.3993 \\
\hline 26 & $50 \%-45 \%$ & -0.0047 & 0.4139 & 0.4186 \\
\hline 27 & $50 \%-20 \%$ & -0.0055 & 0.3841 & 0.3896 \\
\hline 28 & $40 \%-50 \%$ & -0.0061 & 0.3913 & 0.3974 \\
\hline 29 & $50 \%-40 \%$ & -0.0062 & 0.4058 & 0.4120 \\
\hline 30 & $25 \%-35 \%$ & -0.0067 & 0.4010 & 0.4077 \\
\hline 31 & $30 \%-50 \%$ & -0.0078 & 0.3909 & 0.3987 \\
\hline 32 & $50 \%-50 \%$ & -0.0089 & 0.4177 & 0.4267 \\
\hline 33 & $25 \%-25 \%$ & -0.0125 & 0.4119 & 0.4245 \\
\hline 34 & $30 \%-30 \%$ & -0.0128 & 0.3970 & 0.4097 \\
\hline 35 & $25 \%-30 \%$ & -0.0137 & 0.4030 & 0.4167 \\
\hline 36 & $20 \%-40 \%$ & -0.0150 & 0.4007 & 0.4158 \\
\hline 37 & $30 \%-25 \%$ & -0.0160 & 0.4037 & 0.4196 \\
\hline 38 & $45 \%-50 \%$ & -0.0162 & 0.3886 & 0.4048 \\
\hline 39 & $30 \%-20 \%$ & -0.0232 & 0.4067 & 0.4299 \\
\hline 40 & $20 \%-35 \%$ & -0.0244 & 0.4080 & 0.4324 \\
\hline 41 & $25 \%-45 \%$ & -0.0256 & 0.3869 & 0.4126 \\
\hline 42 & $20 \%-45 \%$ & -0.0282 & 0.3875 & 0.4157 \\
\hline 43 & $20 \%-30 \%$ & -0.0292 & 0.4144 & 0.4437 \\
\hline 44 & $25 \%-40 \%$ & -0.0338 & 0.3866 & 0.4204 \\
\hline 45 & $25 \%-20 \%$ & -0.0354 & 0.4182 & 0.4536 \\
\hline 46 & $25 \%-50 \%$ & -0.0397 & 0.3814 & 0.4211 \\
\hline 47 & $20 \%-50 \%$ & -0.0527 & 0.3801 & 0.4328 \\
\hline 48 & $20 \%-25 \%$ & -0.0646 & 0.4141 & 0.4787 \\
\hline 49 & $20 \%-20 \%$ & -0.0888 & 0.4190 & 0.5078 \\
\hline
\end{tabular}


Tabela 6.3: Variáveis Observadas para a Etapa de Refinamento da Solução Caso: Condição Atual do Sistema

\begin{tabular}{|c|c|c|c|c|c|c|c|c|c|}
\hline $\begin{array}{c}\% \\
\text { EARM } \\
\text { SE - NE }\end{array}$ & $\begin{array}{c}\% \\
\text { Risco } \\
\text { SE }\end{array}$ & $\begin{array}{c}\% \\
\text { Risco } \\
\text { S }\end{array}$ & $\begin{array}{c}\% \\
\text { Risco } \\
\text { NE }\end{array}$ & $\begin{array}{c}\% \\
\text { Risco } \\
\text { N }\end{array}$ & $\begin{array}{c}\text { Custo } \\
\text { GT } \\
\left(\$ 10^{6}\right)\end{array}$ & $\begin{array}{l}\text { \% Séries } \\
\text { abaixo } \\
20 \% \text { SE }\end{array}$ & $\begin{array}{c}\text { \% Séries } \\
\text { abaixo } \\
20 \% \text { S }\end{array}$ & $\begin{array}{c}\text { \% Séries } \\
\text { abaixo } \\
20 \% \text { NE }\end{array}$ & $\begin{array}{c}\text { \% Séries } \\
\text { abaixo } \\
20 \% \mathrm{~N}\end{array}$ \\
\hline $38 \%-33 \%$ & 2.20 & 3.35 & 0.20 & 0.40 & 4350.99 & $11.3 \%$ & $39.5 \%$ & $61.6 \%$ & $27.1 \%$ \\
\hline $38 \%-34 \%$ & 2.20 & 3.20 & 0.15 & 0.50 & 4374.69 & $11.3 \%$ & $39.9 \%$ & $61.2 \%$ & $26.6 \%$ \\
\hline $38 \%-35 \%$ & 2.20 & 3.20 & 0.15 & 0.50 & 4385.19 & $11.3 \%$ & $39.7 \%$ & $60.8 \%$ & $26.7 \%$ \\
\hline $38 \%-36 \%$ & 2.15 & 3.10 & 0.10 & 0.50 & 4408.04 & $11.2 \%$ & $39.5 \%$ & $60.2 \%$ & $26.7 \%$ \\
\hline $38 \%-37 \%$ & 2.10 & 3.15 & 0.10 & 0.35 & 4419.26 & $11.3 \%$ & $39.6 \%$ & $60.2 \%$ & $26.4 \%$ \\
\hline $39 \%-33 \%$ & 1.95 & 2.95 & 0.15 & 0.50 & 4410.50 & $10.7 \%$ & $38.9 \%$ & $61.1 \%$ & $26.4 \%$ \\
\hline $39 \%-34 \%$ & 1.90 & 2.90 & 0.15 & 0.50 & 4430.86 & $10.8 \%$ & $39.1 \%$ & $60.8 \%$ & $26.0 \%$ \\
\hline $39 \%-35 \%$ & 1.90 & 2.90 & 0.10 & 0.45 & 4448.73 & $10.5 \%$ & $39.1 \%$ & $60.5 \%$ & $26.0 \%$ \\
\hline $39 \%-36 \%$ & 1.95 & 2.90 & 0.10 & 0.45 & 4467.57 & $10.8 \%$ & $38.5 \%$ & $60.2 \%$ & $25.7 \%$ \\
\hline $39 \%-37 \%$ & 1.95 & 2.90 & 0.10 & 0.45 & 4480.05 & $10.8 \%$ & $39.0 \%$ & $59.9 \%$ & $25.4 \%$ \\
\hline $40 \%-33 \%$ & 1.65 & 2.90 & 0.15 & 0.45 & 4478.04 & $10.2 \%$ & $38.5 \%$ & $60.9 \%$ & $26.0 \%$ \\
\hline $40 \%-34 \%$ & 1.65 & 2.95 & 0.15 & 0.40 & 4494.92 & $10.2 \%$ & $38.8 \%$ & $60.4 \%$ & $25.4 \%$ \\
\hline $40 \%-35 \%$ & 1.70 & 2.95 & 0.15 & 0.40 & 4510.18 & $10.2 \%$ & $38.9 \%$ & $60.1 \%$ & $25.7 \%$ \\
\hline $40 \%-36 \%$ & 1.70 & 2.90 & 0.15 & 0.40 & 4531.19 & $10.1 \%$ & $39.0 \%$ & $59.5 \%$ & $25.6 \%$ \\
\hline $40 \%-37 \%$ & 1.70 & 2.95 & 0.15 & 0.40 & 4555.48 & $10.0 \%$ & $38.9 \%$ & $59.4 \%$ & $25.0 \%$ \\
\hline $41 \%-33 \%$ & 1.65 & 3.25 & 0.25 & 0.50 & 4548.54 & $9.8 \%$ & $38.5 \%$ & $60.3 \%$ & $25.8 \%$ \\
\hline $41 \%-34 \%$ & 1.60 & 3.10 & 0.25 & 0.45 & 4566.69 & $9.6 \%$ & $38.9 \%$ & $60.0 \%$ & $25.2 \%$ \\
\hline $41 \%-35 \%$ & 1.60 & 3.05 & 0.25 & 0.50 & 4580.52 & $9.5 \%$ & $38.6 \%$ & $59.8 \%$ & $24.9 \%$ \\
\hline $41 \%-36 \%$ & 1.60 & 3.15 & 0.25 & 0.50 & 4598.18 & $9.4 \%$ & $38.9 \%$ & $59.2 \%$ & $25.3 \%$ \\
\hline $41 \%-37 \%$ & 1.60 & 3.20 & 0.25 & 0.50 & 4613.55 & $9.3 \%$ & $39.6 \%$ & $58.9 \%$ & $25.2 \%$ \\
\hline $42 \%-33 \%$ & 1.60 & 2.85 & 0.20 & 0.45 & 4610.17 & $9.6 \%$ & $38.0 \%$ & $60.1 \%$ & $25.9 \%$ \\
\hline $42 \%-34 \%$ & 1.60 & 3.00 & 0.20 & 0.45 & 4622.67 & $9.5 \%$ & $37.6 \%$ & $59.8 \%$ & $25.6 \%$ \\
\hline $42 \%-35 \%$ & 1.60 & 3.05 & 0.20 & 0.45 & 4645.20 & $9.4 \%$ & $37.8 \%$ & $59.6 \%$ & $25.3 \%$ \\
\hline $42 \%-36 \%$ & 1.60 & 3.05 & 0.20 & 0.50 & 4664.64 & $9.4 \%$ & $37.8 \%$ & $59.0 \%$ & $25.2 \%$ \\
\hline $42 \%-37 \%$ & 1.60 & 3.10 & 0.20 & 0.50 & 4680.38 & $9.3 \%$ & $38.4 \%$ & $58.9 \%$ & $25.3 \%$ \\
\hline
\end{tabular}

Os limiares e pesos utilizados nesta segunda etapa são os mesmos utilizados na primeira etapa do estudo, apresentados na Figura 6.1, e a ordem das alternativas obtida pelo sistema de apoio à decisão é apresentada na Tabela 6.4 .

A melhor alternativa encontrada foi o armazenamento de $39 \%$ para o Sudeste e $33 \%$ para o Nordeste. Portanto, estes valores são os níveis metas estabelecidos pela metodologia proposta para o mês de novembro do ano de 2012 .

\section{3}

\section{Segundo Estudo de Caso: Novas Usinas Motorizadas}

Este estudo de caso tem como base um caso fictício de maio de 2012, com as UHEs da região Amazônica totalmente motorizadas, e o objetivo é estabelecer os níveis metas para novembro de 2013. A Tabela 6.5 apresenta as variáveis observadas para este estudo. Os valores de risco de déficit e percentual de séries que levam a armazenamentos abaixo de $20 \%$ correspondem ao ano de 2014 e os valores de custo da geração térmica necessária para atingir os níveis metas especificados ao ano de 2013. Estes valores, assim como o estudo de caso anterior, foram obtidos conforme descrito no capítulo 5 . 
Tabela 6.4: Ordem das Alternativas para a Etapa de Refinamento da Solução - Caso: Condição Atual do Sistema

\begin{tabular}{c|c|c|c|c}
\hline Ordem & Alternativas & $\phi$ total & $\phi^{+}$ & $\phi^{-}$ \\
\hline $\mathbf{1}$ & $\mathbf{3 9 \% - 3 3 \%}$ & $\mathbf{0 . 1 9 3 7}$ & $\mathbf{0 . 2 7 7 3}$ & $\mathbf{0 . 0 8 3 6}$ \\
\hline 2 & $38 \%-33 \%$ & 0.1882 & 0.3469 & 0.1587 \\
\hline 3 & $38 \%-34 \%$ & 0.1725 & 0.3096 & 0.1371 \\
\hline 4 & $39 \%-34 \%$ & 0.1701 & 0.2538 & 0.0837 \\
\hline 5 & $38 \%-35 \%$ & 0.1630 & 0.2931 & 0.1301 \\
\hline 6 & $38 \%-36 \%$ & 0.1599 & 0.2714 & 0.1115 \\
\hline 7 & $39 \%-35 \%$ & 0.1551 & 0.2377 & 0.0826 \\
\hline 8 & $38 \%-37 \%$ & 0.1495 & 0.2642 & 0.1147 \\
\hline 9 & $40 \%-33 \%$ & 0.1108 & 0.2118 & 0.1009 \\
\hline 10 & $39 \%-36 \%$ & 0.1032 & 0.2119 & 0.1087 \\
\hline 11 & $40 \%-34 \%$ & 0.0784 & 0.1906 & 0.1122 \\
\hline 12 & $39 \%-37 \%$ & 0.0766 & 0.1976 & 0.1209 \\
\hline 13 & $40 \%-35 \%$ & 0.0352 & 0.1678 & 0.1327 \\
\hline 14 & $40 \%-36 \%$ & -0.0098 & 0.1482 & 0.1580 \\
\hline 15 & $40 \%-37 \%$ & -0.0667 & 0.1238 & 0.1905 \\
\hline 16 & $41 \%-33 \%$ & -0.0874 & 0.1145 & 0.2019 \\
\hline 17 & $41 \%-34 \%$ & -0.0996 & 0.1078 & 0.2074 \\
\hline 18 & $41 \%-35 \%$ & -0.1159 & 0.1043 & 0.2202 \\
\hline 19 & $41 \%-36 \%$ & -0.1501 & 0.0973 & 0.2474 \\
\hline 20 & $42 \%-33 \%$ & -0.1663 & 0.0892 & 0.2555 \\
\hline 21 & $41 \%-37 \%$ & -0.1764 & 0.0992 & 0.2757 \\
\hline 22 & $42 \%-34 \%$ & -0.1797 & 0.0894 & 0.2692 \\
\hline 23 & $42 \%-35 \%$ & -0.2141 & 0.0841 & 0.2982 \\
\hline 24 & $42 \%-36 \%$ & -0.2319 & 0.0945 & 0.3263 \\
\hline 25 & $42 \%-37 \%$ & -0.2582 & 0.0921 & 0.3503 \\
\hline & & & &
\end{tabular}

Analisando a Tabela 6.5, observa-se que, como é de se esperar e conforme observado no estudo de caso anterior, as alternativas com menor armazenamento são mais econômicas e as alternativas com maior armazenamento são mais seguras.

Os limiares e pesos, estabelecidos pelos decisores, utilizados na análise deste caso são os mesmos utilizados para o estudo de caso 1, apresentados na Figura 6.1.

A Tabela 6.6 apresenta a ordem das alternativas obtidas pelo sistema de apoio à decisão, com a aplicação do método PROMETHEE II. São apresentados também os fluxos positivo, negativo e total para cada alternativa. Observa-se que a melhor alternativa encontrada, em função das preferências dos decisores (maior fluxo total), foi o valor de energia armazenada de $40 \%$ para o subsistema Sudeste e $20 \%$ para o subsistema Nordeste. 
Tabela 6.5: Variáveis Observadas - Caso: Novas Usinas Motorizadas

\begin{tabular}{|c|c|c|c|c|c|c|c|c|c|}
\hline $\begin{array}{c}\% \\
\text { EARM } \\
\text { SE - NE }\end{array}$ & $\begin{array}{c}\% \\
\text { Risco } \\
\text { SE }\end{array}$ & $\begin{array}{c}\% \\
\text { Risco } \\
\text { S }\end{array}$ & $\begin{array}{c}\% \\
\text { Risco } \\
\text { NE }\end{array}$ & $\begin{array}{c}\% \\
\text { Risco } \\
\text { N }\end{array}$ & $\begin{array}{c}\text { Custo } \\
\text { GT } \\
\left(\$ 10^{6}\right)\end{array}$ & $\begin{array}{l}\text { \% Séries } \\
\text { abaixo } \\
20 \% \text { SE }\end{array}$ & $\begin{array}{c}\text { \% Séries } \\
\text { abaixo } \\
20 \% \mathrm{~S}\end{array}$ & $\begin{array}{c}\text { \% Séries } \\
\text { abaixo } \\
20 \% \text { NE }\end{array}$ & $\begin{array}{c}\text { \% Séries } \\
\text { abaixo } \\
20 \% \text { N }\end{array}$ \\
\hline $20 \%-20 \%$ & 4.40 & 4.00 & 1.45 & 2.50 & 16805.91 & $18.7 \%$ & $68.5 \%$ & $34.8 \%$ & $40.3 \%$ \\
\hline $20 \%-25 \%$ & 4.25 & 4.10 & 1.40 & 2.40 & 17844.02 & $18.0 \%$ & $68.6 \%$ & $33.0 \%$ & $39.8 \%$ \\
\hline $20 \%-30 \%$ & 4.05 & 3.85 & 1.35 & 2.30 & 17524.52 & $17.6 \%$ & $68.5 \%$ & $31.6 \%$ & $39.0 \%$ \\
\hline $20 \%-35 \%$ & 4.00 & 3.75 & 1.20 & 2.20 & 17999.24 & $17.2 \%$ & $67.6 \%$ & $30.3 \%$ & $38.9 \%$ \\
\hline $20 \%-40 \%$ & 3.90 & 3.75 & 0.90 & 2.05 & 18526.72 & $16.9 \%$ & $68.7 \%$ & $27.4 \%$ & $39.5 \%$ \\
\hline $20 \%-45 \%$ & 3.85 & 3.55 & 0.85 & 1.90 & 19099.18 & $16.8 \%$ & $68.3 \%$ & $25.4 \%$ & $39.1 \%$ \\
\hline $20 \%-50 \%$ & 3.70 & 3.25 & 0.65 & 2.25 & 19689.40 & $16.8 \%$ & $69.5 \%$ & $22.5 \%$ & $39.4 \%$ \\
\hline $25 \%-20 \%$ & 3.80 & 3.25 & 1.35 & 1.95 & 17586.03 & $15.4 \%$ & $67.2 \%$ & $34.4 \%$ & $38.5 \%$ \\
\hline $25 \%-25 \%$ & 3.80 & 3.10 & 1.25 & 1.95 & 17938.73 & $15.0 \%$ & $67.2 \%$ & $32.4 \%$ & $38.8 \%$ \\
\hline $25 \%-30 \%$ & 3.65 & 3.20 & 1.10 & 1.95 & 18330.98 & $14.6 \%$ & $67.8 \%$ & $30.4 \%$ & $37.8 \%$ \\
\hline $25 \%-35 \%$ & 3.40 & 3.10 & 1.00 & 1.80 & 18780.45 & $14.6 \%$ & $67.8 \%$ & $28.9 \%$ & $38.5 \%$ \\
\hline $25 \%-40 \%$ & 3.45 & 2.85 & 0.90 & 1.40 & 19282.60 & $14.6 \%$ & $67.8 \%$ & $27.1 \%$ & $37.7 \%$ \\
\hline $25 \%-45 \%$ & 3.35 & 2.95 & 0.75 & 1.20 & 22056.51 & $13.9 \%$ & $67.1 \%$ & $23.4 \%$ & $37.5 \%$ \\
\hline $25 \%-50 \%$ & 3.20 & 2.70 & 0.55 & 1.35 & 20420.05 & $13.5 \%$ & $67.0 \%$ & $21.3 \%$ & $37.3 \%$ \\
\hline $30 \%-20 \%$ & 2.95 & 2.75 & 1.20 & 1.35 & 18522.48 & $12.8 \%$ & $65.3 \%$ & $33.3 \%$ & $37.9 \%$ \\
\hline $30 \%-25 \%$ & 2.95 & 2.50 & 1.05 & 1.25 & 18907.14 & $12.5 \%$ & $65.7 \%$ & $29.8 \%$ & $37.4 \%$ \\
\hline $30 \%-30 \%$ & 2.70 & 2.40 & 0.85 & 1.30 & 20111.68 & $12.2 \%$ & $65.9 \%$ & $28.1 \%$ & $36.6 \%$ \\
\hline $30 \%-35 \%$ & 2.65 & 2.25 & 0.70 & 1.25 & 19750.64 & $11.8 \%$ & $65.5 \%$ & $27.5 \%$ & $36.0 \%$ \\
\hline $30 \%-40 \%$ & 2.60 & 2.20 & 0.60 & 0.90 & 20229.03 & $11.4 \%$ & $66.0 \%$ & $25.2 \%$ & $35.9 \%$ \\
\hline $30 \%-45 \%$ & 2.35 & 2.20 & 0.55 & 1.25 & 22012.24 & $11.4 \%$ & $66.0 \%$ & $24.0 \%$ & $36.3 \%$ \\
\hline $30 \%-50 \%$ & 2.40 & 2.05 & 0.45 & 1.25 & 21262.09 & $11.4 \%$ & $64.9 \%$ & $20.8 \%$ & $35.8 \%$ \\
\hline $35 \%-20 \%$ & 2.30 & 2.00 & 0.90 & 1.00 & 20157.30 & $10.4 \%$ & $65.5 \%$ & $31.7 \%$ & $37.0 \%$ \\
\hline $35 \%-25 \%$ & 2.10 & 1.80 & 0.80 & 1.05 & 20645.48 & $9.8 \%$ & $66.0 \%$ & $30.4 \%$ & $36.8 \%$ \\
\hline $35 \%-30 \%$ & 2.10 & 1.75 & 0.65 & 1.00 & 20387.08 & $9.5 \%$ & $66.1 \%$ & $29.2 \%$ & $36.1 \%$ \\
\hline $35 \%-35 \%$ & 2.10 & 1.45 & 0.60 & 0.95 & 20802.90 & $9.0 \%$ & $66.9 \%$ & $26.9 \%$ & $35.3 \%$ \\
\hline $35 \%-40 \%$ & 1.95 & 1.35 & 0.55 & 0.95 & 21240.70 & $9.0 \%$ & $66.4 \%$ & $24.5 \%$ & $35.3 \%$ \\
\hline $35 \%-45 \%$ & 1.75 & 1.40 & 0.45 & 0.90 & 21695.66 & $8.8 \%$ & $66.3 \%$ & $22.1 \%$ & $35.8 \%$ \\
\hline $35 \%-50 \%$ & 1.75 & 1.30 & 0.45 & 1.00 & 22167.96 & $9.0 \%$ & $65.4 \%$ & $19.8 \%$ & $35.8 \%$ \\
\hline $40 \%-20 \%$ & 1.75 & 1.25 & 0.75 & 0.85 & 20801.24 & $8.6 \%$ & $64.5 \%$ & $30.4 \%$ & $35.5 \%$ \\
\hline $40 \%-25 \%$ & 1.55 & 1.20 & 0.70 & 0.75 & 21168.39 & $8.3 \%$ & $64.3 \%$ & $29.4 \%$ & $35.3 \%$ \\
\hline $40 \%-30 \%$ & 1.50 & 1.30 & 0.65 & 0.75 & 21525.15 & $8.0 \%$ & $65.2 \%$ & $27.2 \%$ & $35.5 \%$ \\
\hline $40 \%-35 \%$ & 1.60 & 1.25 & 0.55 & 0.70 & 21906.51 & $7.8 \%$ & $65.6 \%$ & $25.4 \%$ & $35.2 \%$ \\
\hline $40 \%-40 \%$ & 1.50 & 1.10 & 0.45 & 0.60 & 22290.82 & $7.5 \%$ & $65.1 \%$ & $24.6 \%$ & $35.1 \%$ \\
\hline $40 \%-45 \%$ & 1.50 & 0.90 & 0.40 & 0.70 & 22700.50 & $7.2 \%$ & $65.2 \%$ & $22.7 \%$ & $35.3 \%$ \\
\hline $40 \%-50 \%$ & 1.35 & 0.95 & 0.40 & 0.70 & 23116.47 & $7.1 \%$ & $64.3 \%$ & $19.7 \%$ & $34.9 \%$ \\
\hline $45 \%-20 \%$ & 1.40 & 0.85 & 0.70 & 0.75 & 21942.67 & $6.9 \%$ & $60.7 \%$ & $29.0 \%$ & $35.1 \%$ \\
\hline $45 \%-25 \%$ & 1.35 & 0.85 & 0.70 & 0.65 & 22306.29 & $6.6 \%$ & $61.7 \%$ & $27.6 \%$ & $35.2 \%$ \\
\hline $45 \%-30 \%$ & 1.30 & 0.85 & 0.50 & 0.60 & 23360.89 & $6.2 \%$ & $62.4 \%$ & $26.5 \%$ & $35.4 \%$ \\
\hline $45 \%-35 \%$ & 1.20 & 0.80 & 0.50 & 0.50 & 22978.11 & $6.0 \%$ & $61.5 \%$ & $24.2 \%$ & $35.3 \%$ \\
\hline $45 \%-40 \%$ & 1.15 & 0.85 & 0.45 & 0.40 & 23295.00 & $5.9 \%$ & $62.6 \%$ & $22.6 \%$ & $34.7 \%$ \\
\hline $45 \%-45 \%$ & 1.15 & 0.75 & 0.50 & 0.50 & 24844.75 & $5.7 \%$ & $63.4 \%$ & $20.9 \%$ & $34.6 \%$ \\
\hline $45 \%-50 \%$ & 1.15 & 0.70 & 0.35 & 0.50 & 24006.28 & $5.5 \%$ & $63.6 \%$ & $18.5 \%$ & $34.1 \%$ \\
\hline $50 \%-20 \%$ & 1.15 & 0.70 & 0.70 & 0.55 & 23089.77 & $5.6 \%$ & $59.7 \%$ & $28.8 \%$ & $33.3 \%$ \\
\hline $50 \%-25 \%$ & 1.15 & 0.70 & 0.60 & 0.50 & 23374.90 & $5.2 \%$ & $60.0 \%$ & $27.3 \%$ & $33.3 \%$ \\
\hline $50 \%-30 \%$ & 1.10 & 0.70 & 0.50 & 0.50 & 24412.07 & $5.0 \%$ & $60.2 \%$ & $25.0 \%$ & $33.7 \%$ \\
\hline $50 \%-35 \%$ & 1.05 & 0.65 & 0.50 & 0.50 & 23942.62 & $4.8 \%$ & $61.6 \%$ & $23.7 \%$ & $33.4 \%$ \\
\hline $50 \%-40 \%$ & 1.00 & 0.60 & 0.40 & 0.40 & 24236.79 & $4.7 \%$ & $61.3 \%$ & $21.8 \%$ & $32.8 \%$ \\
\hline $50 \%-45 \%$ & 0.95 & 0.50 & 0.35 & 0.35 & 25691.58 & $4.5 \%$ & $61.5 \%$ & $20.0 \%$ & $33.0 \%$ \\
\hline $50 \%-50 \%$ & 0.95 & 0.55 & 0.35 & 0.30 & 24818.39 & $4.2 \%$ & $60.1 \%$ & $19.1 \%$ & $32.5 \%$ \\
\hline
\end{tabular}


Tabela 6.6: Ordem das Alternativas - Caso: Novas Usinas Motorizadas

\begin{tabular}{|c|c|c|c|c|}
\hline Ordem & Alternativas & $\phi$ total & $\phi^{+}$ & $\phi^{-}$ \\
\hline 1 & $40 \%-20 \%$ & 0.0977 & 0.4173 & 0.3196 \\
\hline 2 & $30 \%-40 \%$ & 0.0908 & 0.4249 & 0.3340 \\
\hline 3 & $40 \%-25 \%$ & 0.0901 & 0.4099 & 0.3198 \\
\hline 4 & $35 \%-30 \%$ & 0.0864 & 0.4142 & 0.3278 \\
\hline 5 & $35 \%-35 \%$ & 0.0843 & 0.4127 & 0.3283 \\
\hline 6 & $30 \%-35 \%$ & 0.0826 & 0.4343 & 0.3517 \\
\hline 7 & $35 \%-40 \%$ & 0.0805 & 0.4103 & 0.3298 \\
\hline 8 & $40 \%-30 \%$ & 0.0685 & 0.3949 & 0.3264 \\
\hline 9 & $45 \%-20 \%$ & 0.0655 & 0.3870 & 0.3215 \\
\hline 10 & $30 \%-25 \%$ & 0.0632 & 0.4305 & 0.3673 \\
\hline 11 & $35 \%-45 \%$ & 0.0559 & 0.3926 & 0.3367 \\
\hline 12 & $45 \%-25 \%$ & 0.0533 & 0.3855 & 0.3321 \\
\hline 13 & $40 \%-40 \%$ & 0.0454 & 0.3821 & 0.3367 \\
\hline 14 & $30 \%-20 \%$ & 0.0437 & 0.4330 & 0.3892 \\
\hline 15 & $45 \%-40 \%$ & 0.0428 & 0.3923 & 0.3495 \\
\hline 16 & $40 \%-35 \%$ & 0.0413 & 0.3745 & 0.3332 \\
\hline 17 & $45 \%-35 \%$ & 0.0398 & 0.3872 & 0.3474 \\
\hline 18 & $35 \%-20 \%$ & 0.0331 & 0.4021 & 0.3691 \\
\hline 19 & $50 \%-50 \%$ & 0.0212 & 0.4249 & 0.4036 \\
\hline 20 & $50 \%-40 \%$ & 0.0174 & 0.4042 & 0.3868 \\
\hline 21 & $35 \%-50 \%$ & 0.0141 & 0.3706 & 0.3565 \\
\hline 22 & $40 \%-45 \%$ & 0.0138 & 0.3740 & 0.3603 \\
\hline 23 & $35 \%-25 \%$ & 0.0128 & 0.3848 & 0.3720 \\
\hline 24 & $30 \%-50 \%$ & 0.0116 & 0.3966 & 0.3850 \\
\hline 25 & $50 \%-25 \%$ & 0.0090 & 0.3786 & 0.3697 \\
\hline 26 & $40 \%-50 \%$ & 0.0081 & 0.3694 & 0.3613 \\
\hline 27 & $45 \%-50 \%$ & 0.0057 & 0.3903 & 0.3846 \\
\hline 28 & $50 \%-20 \%$ & 0.0006 & 0.3707 & 0.3701 \\
\hline 29 & $30 \%-30 \%$ & -0.0033 & 0.3856 & 0.3890 \\
\hline 30 & $50 \%-35 \%$ & -0.0041 & 0.3843 & 0.3884 \\
\hline 31 & $25 \%-20 \%$ & -0.0043 & 0.4252 & 0.4295 \\
\hline 32 & $25 \%-25 \%$ & -0.0104 & 0.4140 & 0.4243 \\
\hline 33 & $25 \%-50 \%$ & -0.0117 & 0.3824 & 0.3940 \\
\hline 34 & $25 \%-30 \%$ & -0.0189 & 0.4033 & 0.4222 \\
\hline 35 & $25 \%-40 \%$ & -0.0193 & 0.3944 & 0.4137 \\
\hline 36 & $50 \%-45 \%$ & -0.0290 & 0.4017 & 0.4307 \\
\hline 37 & $25 \%-35 \%$ & -0.0349 & 0.3897 & 0.4246 \\
\hline 38 & $45 \%-30 \%$ & -0.0350 & 0.3462 & 0.3813 \\
\hline 39 & $50 \%-30 \%$ & -0.0533 & 0.3560 & 0.4093 \\
\hline 40 & $20 \%-30 \%$ & -0.0567 & 0.4103 & 0.4669 \\
\hline 41 & $20 \%-35 \%$ & -0.0586 & 0.3933 & 0.4519 \\
\hline 42 & $20 \%-40 \%$ & -0.0683 & 0.3811 & 0.4494 \\
\hline 43 & $20 \%-20 \%$ & -0.0715 & 0.4289 & 0.5004 \\
\hline 44 & $45 \%-45 \%$ & $\begin{array}{l}-0.0814 \\
\end{array}$ & 0.3416 & 0.4230 \\
\hline 45 & $20 \%-45 \%$ & -0.0827 & 0.3733 & 0.4560 \\
\hline 46 & $20 \%-50 \%$ & -0.1000 & 0.3685 & 0.4685 \\
\hline 47 & $20 \%-25 \%$ & -0.1135 & 0.3863 & 0.4998 \\
\hline 48 & $30 \%-45 \%$ & -0.1481 & 0.3016 & 0.4498 \\
\hline 49 & $25 \%-45 \%$ & -0.2740 & 0.2418 & 0.5158 \\
\hline
\end{tabular}




\subsection{1}

\section{Refinamento da Solução Encontrada}

Após encontrada a solução (40\% para o subsistema Sudeste e 20\% para o subsistema Nordeste) é realizado um novo processamento com o grid de alternativas variando entre as combinações $(S E=38 \%$ e $N E=18 \%)$ de 1 em 1 por cento até $(S E=42 \%$ e $N E=22 \%$ ). A Tabela 6.7 apresenta as variáveis observadas para esta etapa do estudo.

Tabela 6.7: Variáveis Observadas para a Etapa de Refinamento da Solução Caso: Novas Usinas Motorizadas

\begin{tabular}{|c|c|c|c|c|c|c|c|c|c|}
\hline $\begin{array}{c}\% \\
\text { EARM } \\
\text { SE - NE }\end{array}$ & $\begin{array}{c}\% \\
\text { Risco } \\
\text { SE }\end{array}$ & $\begin{array}{c}\% \\
\text { Risco } \\
\text { S }\end{array}$ & $\begin{array}{c}\% \\
\text { Risco } \\
\text { NE }\end{array}$ & $\begin{array}{c}\% \\
\text { Risco } \\
\text { N }\end{array}$ & $\begin{array}{c}\text { Custo } \\
\text { GT } \\
\left(\$ 10^{6}\right)\end{array}$ & $\begin{array}{c}\% \text { Séries } \\
\text { abaixo } \\
20 \% \text { SE }\end{array}$ & $\begin{array}{c}\text { \% Séries } \\
\text { abaixo } \\
20 \% \mathrm{~S}\end{array}$ & $\begin{array}{c}\text { \% Séries } \\
\text { abaixo } \\
20 \% \text { NE }\end{array}$ & $\begin{array}{c}\text { \% Séries } \\
\text { abaixo } \\
20 \% \mathrm{~N}\end{array}$ \\
\hline $38 \%-18 \%$ & 1.95 & 1.65 & 0.90 & 0.95 & 20171.81 & $9.4 \%$ & $64.8 \%$ & $31.6 \%$ & $35.8 \%$ \\
\hline $38 \%-19 \%$ & 1.95 & 1.60 & 0.80 & 0.90 & 20253.41 & $9.3 \%$ & $64.8 \%$ & $31.2 \%$ & $35.9 \%$ \\
\hline $38 \%-20 \%$ & 1.95 & 1.45 & 0.75 & 0.90 & 20330.73 & $9.2 \%$ & $65.1 \%$ & $30.9 \%$ & $35.9 \%$ \\
\hline $38 \%-21 \%$ & 1.90 & 1.35 & 0.80 & 1.00 & 20385.52 & $9.2 \%$ & $65.2 \%$ & $30.7 \%$ & $35.8 \%$ \\
\hline $38 \%-22 \%$ & 2.00 & 1.35 & 0.75 & 0.85 & 20479.17 & $9.1 \%$ & $65.4 \%$ & $30.2 \%$ & $35.6 \%$ \\
\hline $39 \%-18 \%$ & 1.95 & 1.35 & 0.85 & 0.80 & 20423.64 & $8.9 \%$ & $64.6 \%$ & $31.1 \%$ & $35.3 \%$ \\
\hline $39 \%-19 \%$ & 1.95 & 1.40 & 0.80 & 0.70 & 20493.25 & $9.0 \%$ & $64.8 \%$ & $31.2 \%$ & $35.0 \%$ \\
\hline $39 \%-20 \%$ & 2.00 & 1.35 & 0.75 & 0.75 & 20556.56 & $8.9 \%$ & $65.0 \%$ & $30.9 \%$ & $35.6 \%$ \\
\hline $39 \%-21 \%$ & 1.90 & 1.30 & 0.85 & 0.80 & 20634.90 & $8.9 \%$ & $65.2 \%$ & $29.8 \%$ & $35.4 \%$ \\
\hline $39 \%-22 \%$ & 1.80 & 1.30 & 0.80 & 0.80 & 20709.92 & $9.0 \%$ & $65.3 \%$ & $29.6 \%$ & $35.6 \%$ \\
\hline $40 \%-18 \%$ & 1.85 & 1.30 & 0.90 & 0.85 & 20652.28 & $8.8 \%$ & $64.1 \%$ & $30.9 \%$ & $35.3 \%$ \\
\hline $40 \%-19 \%$ & 1.85 & 1.30 & 0.80 & 0.80 & 20728.15 & $8.7 \%$ & $64.1 \%$ & $30.6 \%$ & $35.3 \%$ \\
\hline $40 \%-20 \%$ & 1.75 & 1.25 & 0.75 & 0.85 & 20801.24 & $8.6 \%$ & $64.5 \%$ & $30.4 \%$ & $35.5 \%$ \\
\hline $40 \%-21 \%$ & 1.75 & 1.30 & 0.70 & 0.85 & 20870.13 & $8.4 \%$ & $64.3 \%$ & $29.9 \%$ & $35.3 \%$ \\
\hline $40 \%-22 \%$ & 1.65 & 1.30 & 0.70 & 0.80 & 20943.70 & $8.4 \%$ & $64.2 \%$ & $29.8 \%$ & $35.3 \%$ \\
\hline $41 \%-18 \%$ & 1.65 & 1.30 & 0.85 & 0.75 & 20889.53 & $8.3 \%$ & $63.3 \%$ & $30.7 \%$ & $35.3 \%$ \\
\hline $41 \%-19 \%$ & 1.65 & 1.25 & 0.80 & 0.75 & 20970.23 & $8.3 \%$ & $63.0 \%$ & $30.7 \%$ & $35.5 \%$ \\
\hline $41 \%-20 \%$ & 1.60 & 1.25 & 0.75 & 0.80 & 21032.41 & $8.2 \%$ & $63.2 \%$ & $30.4 \%$ & $35.3 \%$ \\
\hline $41 \%-21 \%$ & 1.50 & 1.20 & 0.75 & 0.80 & 21118.49 & $8.3 \%$ & $63.1 \%$ & $30.2 \%$ & $35.8 \%$ \\
\hline $41 \%-22 \%$ & 1.50 & 1.15 & 0.75 & 0.80 & 21161.71 & $8.2 \%$ & $63.4 \%$ & $29.9 \%$ & $35.6 \%$ \\
\hline $42 \%-18 \%$ & 1.50 & 1.15 & 0.85 & 0.80 & 21137.87 & $8.1 \%$ & $62.5 \%$ & $31.1 \%$ & $35.5 \%$ \\
\hline $42 \%-19 \%$ & 1.45 & 1.15 & 0.80 & 0.80 & 21200.79 & $8.0 \%$ & $62.8 \%$ & $30.6 \%$ & $35.7 \%$ \\
\hline $42 \%-20 \%$ & 1.50 & 1.15 & 0.75 & 0.65 & 21269.15 & $7.9 \%$ & $62.5 \%$ & $29.8 \%$ & $35.4 \%$ \\
\hline $42 \%-21 \%$ & 1.55 & 1.15 & 0.75 & 0.65 & 21328.34 & $7.9 \%$ & $62.7 \%$ & $29.7 \%$ & $35.3 \%$ \\
\hline $42 \%-22 \%$ & 1.55 & 1.15 & 0.75 & 0.60 & 21408.02 & $7.9 \%$ & $62.8 \%$ & $29.5 \%$ & $35.1 \%$ \\
\hline
\end{tabular}

Os limiares e pesos utilizados são os mesmos utilizados na primeira etapa do estudo, apresentados na Figura 6.1, e a ordem das alternativas obtida pelo sistema de apoio à decisão é apresentado na Tabela 6.8.

A melhor alternativa encontrada foi o armazenamento de $38 \%$ para o Sudeste e $18 \%$ para o Nordeste. Portanto, estes valores são os níveis metas estabelecidos para o mês de novembro do ano de 2013, considerando as novas usinas da região Amazônica totalmente motorizadas.

\section{4}

\section{Análise de Sensibilidade}

Para analisar a sensibilidade da metodologia são propostos os seguintes testes: 
Tabela 6.8: Ordem das Alternativas para a Etapa de Refinamento da Solução - Caso: Novas Usinas Motorizadas

\begin{tabular}{|c|c|c|c|c|}
\hline Ordem & Alternativas & $\phi$ total & $\phi^{+}$ & $\phi^{-}$ \\
\hline 1 & $38 \%-18 \%$ & 0.2123 & 0.3245 & 0.1121 \\
\hline 2 & $38 \%-19 \%$ & 0.2088 & 0.2957 & 0.0868 \\
\hline 3 & $38 \%-20 \%$ & 0.1962 & 0.2683 & 0.0721 \\
\hline 4 & $38 \%-21 \%$ & 0.1736 & 0.2463 & 0.0726 \\
\hline 5 & $39 \%-18 \%$ & 0.1722 & 0.2326 & 0.0604 \\
\hline 6 & $38 \%-22 \%$ & 0.1481 & 0.2171 & 0.0690 \\
\hline 7 & $39 \%-19 \%$ & 0.1431 & 0.2142 & 0.0711 \\
\hline 8 & $39 \%-20 \%$ & 0.1116 & 0.1868 & 0.0752 \\
\hline 9 & $39 \%-21 \%$ & 0.0787 & 0.1628 & 0.0840 \\
\hline 10 & $40 \%-18 \%$ & 0.0626 & 0.1493 & 0.0867 \\
\hline 11 & $39 \%-22 \%$ & 0.0448 & 0.1431 & 0.0983 \\
\hline 12 & $40 \%-19 \%$ & 0.0300 & 0.1241 & 0.0941 \\
\hline 13 & $40 \%-20 \%$ & -0.0065 & 0.1047 & 0.1112 \\
\hline 14 & $40 \%-21 \%$ & -0.0408 & 0.0922 & 0.1330 \\
\hline 15 & $41 \%-18 \%$ & -0.0461 & 0.0908 & 0.1369 \\
\hline 16 & $40 \%-22 \%$ & -0.0714 & 0.0815 & 0.1529 \\
\hline 17 & $41 \%-19 \%$ & -0.0831 & 0.0778 & 0.1609 \\
\hline 18 & $41 \%-20 \%$ & -0.1133 & 0.0667 & 0.1800 \\
\hline 19 & $41 \%-21 \%$ & -0.1458 & 0.0636 & 0.2094 \\
\hline 20 & $42 \%-18 \%$ & -0.1576 & 0.0705 & 0.2281 \\
\hline 21 & $41 \%-22 \%$ & -0.1576 & 0.0661 & 0.2237 \\
\hline 22 & $42 \%-20 \%$ & -0.1693 & 0.0905 & 0.2598 \\
\hline 23 & $42 \%-19 \%$ & -0.1723 & 0.0700 & 0.2423 \\
\hline 24 & $42 \%-21 \%$ & -0.1965 & 0.0871 & 0.2836 \\
\hline 25 & $42 \%-22 \%$ & $\begin{array}{l}-0.2218 \\
\end{array}$ & 0.0910 & 0.3128 \\
\hline
\end{tabular}

- O primeiro teste é para analisar a coerência da metodologia ao avaliar diferentes alternativas em relação aos critérios.

- O segundo teste é para analisar a estabilidade da solução em relação a variações nos pesos estabelecidos, o que pode minimizar a insegurança do decisor com relação à sensibilidade da solução em relação a pequenas variações nos pesos.

- O terceiro teste é para analisar a sensibilidade dos resultados em função de variações nos pesos.

- Por último, uma análise da solução estabelecida pela metodologia em relação a Curva de Pareto.

A análise de sensibilidade será realizada tendo como base o segundo estudo de caso: Novas Usinas Motorizadas. 


\subsection{1 \\ Análise de Coerência da Metodologia ao Avaliar Diferentes Alternativas em Relação aos Critérios}

Para analisar a coerência da metodologia proposta em avaliar diferentes alternativas em relação aos critérios, foram selecionadas as alternativas de menor (Sudeste 20\% e Nordeste 20\%) e maior (Sudeste 50\% e Nordeste 50\%) armazenamento e analisada a avaliação destas alternativas em função dos critérios considerados utilizando componentes principais [56, 57].

Os critérios e alternativas formam um plano multidimensional, onde cada critério representa um eixo e as alternativas pontos em relação a estes eixos. Com a analise de componentes principais é possível representar todos os critérios em um plano bidimensional, onde cada critério é representado por uma linha e as alternativas por uma teia sobre os critérios. Os critérios que apresentam covariância positiva são representados por linhas orientadas aproximadamente na mesma direção. Os critérios que apresentam covariância negativa são representados por linhas orientadas em direções opostas. As circunferências representam curvas de nível e os valores crescem do centro para fora. O ponto onde a teia toca a linha representa a avaliação da alternativa em relação ao critério $[56,57]$.

A Figura 6.2 apresenta os resultados desta análise, onde se observa que a alternativa de menor armazenamento apresenta uma ótima avaliação para o critério relacionado à economicidade (custo de geração térmica). Conforme esperado, por se tratar de uma alternativa de baixo armazenamento, não foi necessário a geração de muita energia de fonte térmica para atingir estes níveis de armazenamento. Foram obtidas avaliações ruins para os critérios relacionados à segurança (percentual de séries que levam o armazenamento a valores abaixo de $20 \%$ e risco de déficit). Conforme esperado, os baixos níveis de armazenamento levaram a maiores riscos de déficit e maiores percentuais de séries que levam a armazenamento abaixo de $20 \%$. Já a análise da alternativa de maior armazenamento apresentou uma avaliação ruim para o critério relacionado à economicidade. Conforme esperado, por ter sido necessário mais geração de energia de fonte térmica para poupar geração hidráulica e atingir os altos níveis de armazenamento estabelecidos, e uma ótima avaliação para os critérios relacionados a segurança. Conforme esperado, os armazenamentos em níveis mais elevados reduziram os riscos de déficit e percentuais de séries que levam a armazenamento abaixo de 20\%. Em resumo, os resultados são coerentes na avaliação das alternativas em função dos critérios.

Analisando a avaliação da alternativa definida como solução pelo sistema de apoio à decisão, com base nos pesos estabelecidos pelos decisores $(57.14 \%$ 
Sudeste $20 \%$ e Nordeste $20 \%$

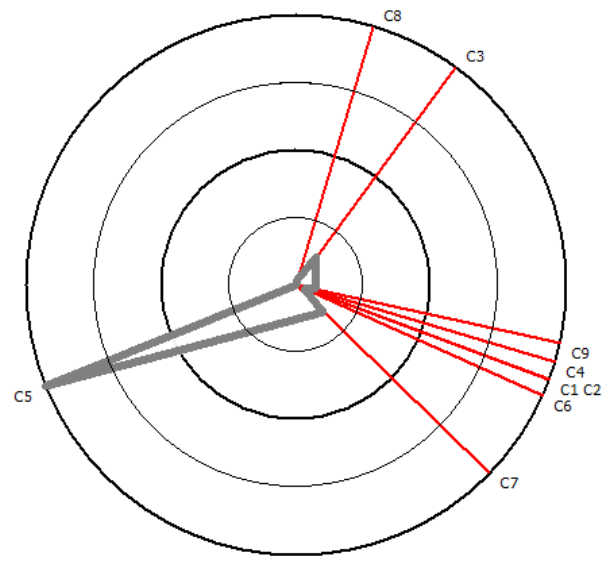

Sudeste $50 \%$ e Nordeste $50 \%$

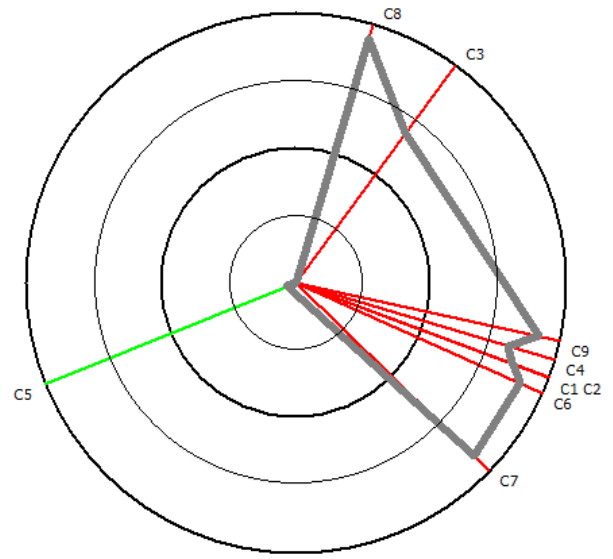

$C 1=\%$ de risco do SE; $C 2=\%$ de risco do $\mathrm{S} ; C 3=\%$ de risco do $\mathrm{NE}$

$C 4=\%$ de risco do N; $C 5=\%$ custo $\mathrm{GT} ; C 6=\%$ abaixo de $20 \% \mathrm{SE}$

$C 7=\%$ abaixo de $20 \%$ S; $C 8=\%$ abaixo de $20 \%$ NE; $C 9=\%$ abaixo de $20 \%$ N

Figura 6.2: Avaliações das Alternativas de Maior e Menor Armazenamento Caso: Novas Usinas Motorizadas

para segurança e $42.86 \%$ para economicidade), observa-se que a solução selecionada apresenta um melhor compromisso em relação a segurança e economicidade, ou seja, a solução apresenta uma boa avaliação tanto para os critérios relacionados a segurança como para o critério relacionado a economicidade, conforme apresentado na Figura 6.3.

\subsection{2}

\section{Análise da Estabilidade da Solução em Relação a Variações nos Pesos Estabelecidos}

Para avaliar a estabilidade da solução selecionada em função dos pesos estabelecidos pelos decisores, foi realizada a análise apresentada na Figura 6.4, onde se observam os intervalos em que os pesos podem ser variados, um de cada vez, sem que se altere a melhor alternativa definida pela metodologia.

Para avaliar a estabilidade da solução na etapa de aumento da precisão em função dos pesos estabelecidos pelos decisores, foi realizada a mesma análise da etapa anterior. Os resultados são apresentados na Figura 6.5.

Os resultados obtidos com as análises de estabilidade realizadas para as duas etapas indicam estabilidade da solução encontrada pela metodologia em relação a pequenas variações nos pesos estabelecidos pelos decisores na primeira etapa e a variações mais significativas na segunda etapa. Na segunda etapa, o grid de alternativas varia de $1 \%$ em $1 \%$ em torno da solução encontrada, com isto a avaliação das alternativas em relação aos critérios se tornam mais próximas, em alguns casos até igual, provocando maiores faixas de estabilidade 
Sudeste $40 \%$ e Nordeste $20 \%$

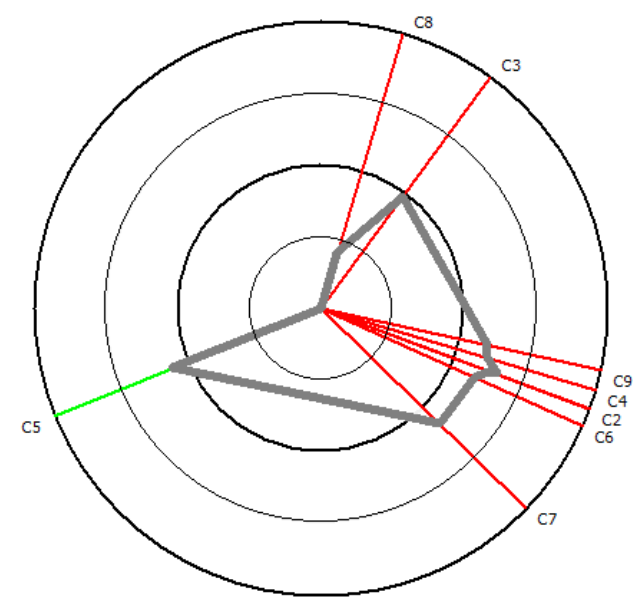

$C 1=\%$ de risco do $\mathrm{SE} ; C 2=\%$ de risco do $\mathrm{S} ; C 3=\%$ de risco do $\mathrm{NE}$

$C 4=\%$ de risco do N; $C 5=\%$ custo $\mathrm{GT} ; C 6=\%$ abaixo de $20 \% \mathrm{SE}$

$C 7=\%$ abaixo de $20 \% \mathrm{~S}$; $C 8=\%$ abaixo de $20 \% \mathrm{NE}$; $C 9=\%$ abaixo de $20 \% \mathrm{~N}$

Figura 6.3: Avaliação da Melhor Alternativa - Caso: Novas Usinas Motorizadas

da solução.

\subsection{3}

\section{Análise da Sensibilidade dos Resultados em Função de Variações nos Pesos}

Para analisar a sensibilidade dos resultados em função de variações nos pesos, foi realizado um teste, variando os pesos dos critérios relacionados a segurança de forma decrescente e os pesos dos critérios relacionados a economicidade de forma crescente. Os resultados são apresentados na Tabela 6.9. Observa-se que, para valores baixos de pesos para os critérios relacionados a economicidade e valores altos de pesos para os critérios relacionados a segurança, o modelo seleciona como resultado, conforme esperado, a alternativa de maior valor de armazenamento. À medida que os valores de pesos para os critérios relacionados a economicidade aumentam e os valores de pesos relacionados a segurança diminuem, o modelo seleciona como resultado, conforme esperado, alternativas de armazenamento cada vez menores.

\subsection{4}

\section{Análise da Solução Estabelecida pela Metodologia em Relação a Curva de Pareto}

Por último, foi desenhada a Curva de Pareto das alternativas em relação aos grupos de critérios relacionados à segurança e à economicidade. O eixo horizontal representa o grupo de critérios relacionados à segurança (risco de déficit e percentual de séries que levam o armazenamento a valores abaixo de 


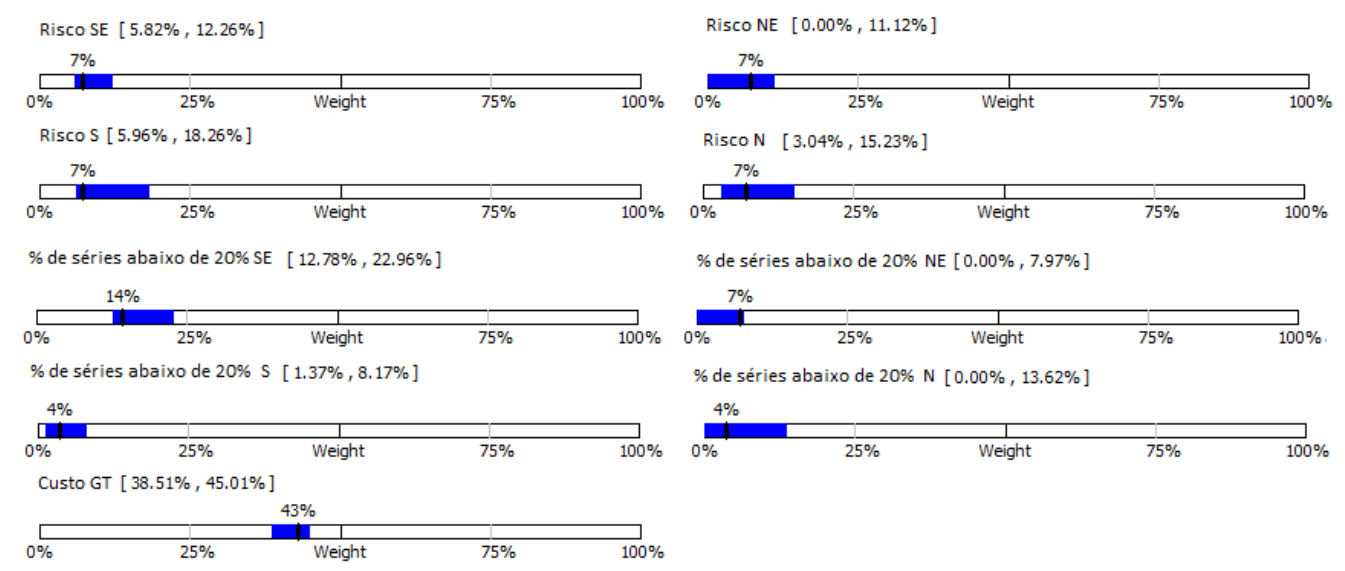

Figura 6.4: Intervalos de Confiança para Variação dos Pesos sem Alteração da Melhor Alternativa - Caso: Novas Usinas Motorizadas

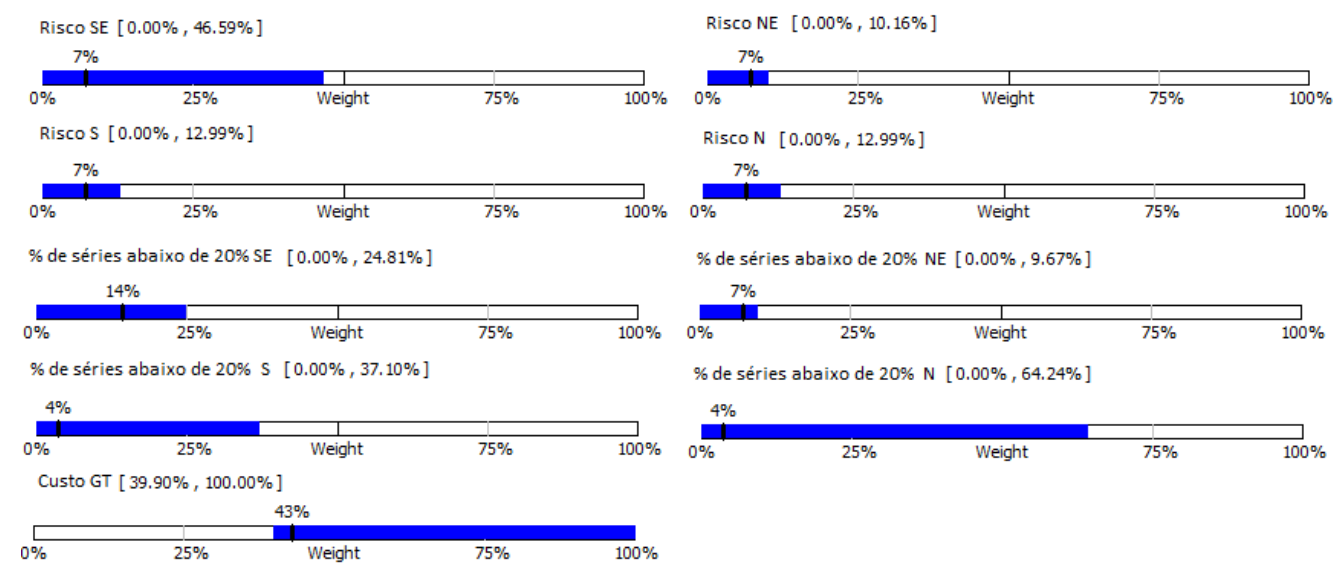

Figura 6.5: Intervalos de Confiança para Variação dos Pesos sem Alteração da Melhor Alternativa para a Etapa de Refinamento da Solução - Caso: Novas Usinas Motorizadas

Tabela 6.9: Resultados em Relação a Variação dos Pesos - Caso: Novas Usinas Motorizadas

\begin{tabular}{r|r||r}
\hline \multicolumn{2}{c||}{$\begin{array}{r}\text { Pesos Definidos } \\
\text { Segurança }\end{array}$} & $\begin{array}{r}\text { Solução Encontrada } \\
\text { Energia Armazenada }\end{array}$ \\
\hline $100 \%$ & $0 \%$ & $50 \%-50 \%$ \\
\hline $70 \%$ & $30 \%$ & $50 \%-50 \%$ \\
\hline $60 \%$ & $40 \%$ & $40 \%-20 \%$ \\
\hline $50 \%$ & $50 \%$ & $30 \%-25 \%$ \\
\hline $40 \%$ & $60 \%$ & $25 \%-20 \%$ \\
\hline $30 \%$ & $70 \%$ & $20 \%-20 \%$ \\
\hline $0 \%$ & $100 \%$ & $20 \%-20 \%$ \\
\hline
\end{tabular}


20\%); as melhores alternativas em relação a segurança (níveis metas altos) estão localizadas à esquerda e as piores (níveis metas baixos) estão localizadas à direita. $\mathrm{O}$ eixo vertical representa o critério relacionado à economicidade (custo de geração térmica para atingir os níveis metas). As alternativas mais econômicas (níveis metas baixos) estão localizadas na parte superior da figura e as mais caras na parte inferior da figura (níveis metas altos).

A Curva de Pareto é representada pela linha de cor vermelha e as alternativas que compõem esta linha são as alternativas não dominadas, que representam as melhores alternativas de solução para o problema.

A Figura 6.6 apresenta a Curva de Pareto para a primeira etapa do Estudo de Caso: Novas Usinas Motorizadas, no qual a solução encontrada pelo método proposto foi a de $S E=40 \%$ e $N E=20 \%$, sendo esta solução uma das que compõe a Curva de Pareto. A Figura 6.7 apresenta a Curva de Pareto para a segunda etapa do estudo, e a solução encontrada pelo método proposto foi a de $(S E=38 \%$ e $N E=18 \%)$, sendo esta solução uma das que compõe a Curva de Pareto. Os resultados mostram que as soluções encontradas pela metodologia proposta nas duas etapas não são soluções dominadas, o que comprova a eficiência da metodologia proposta.

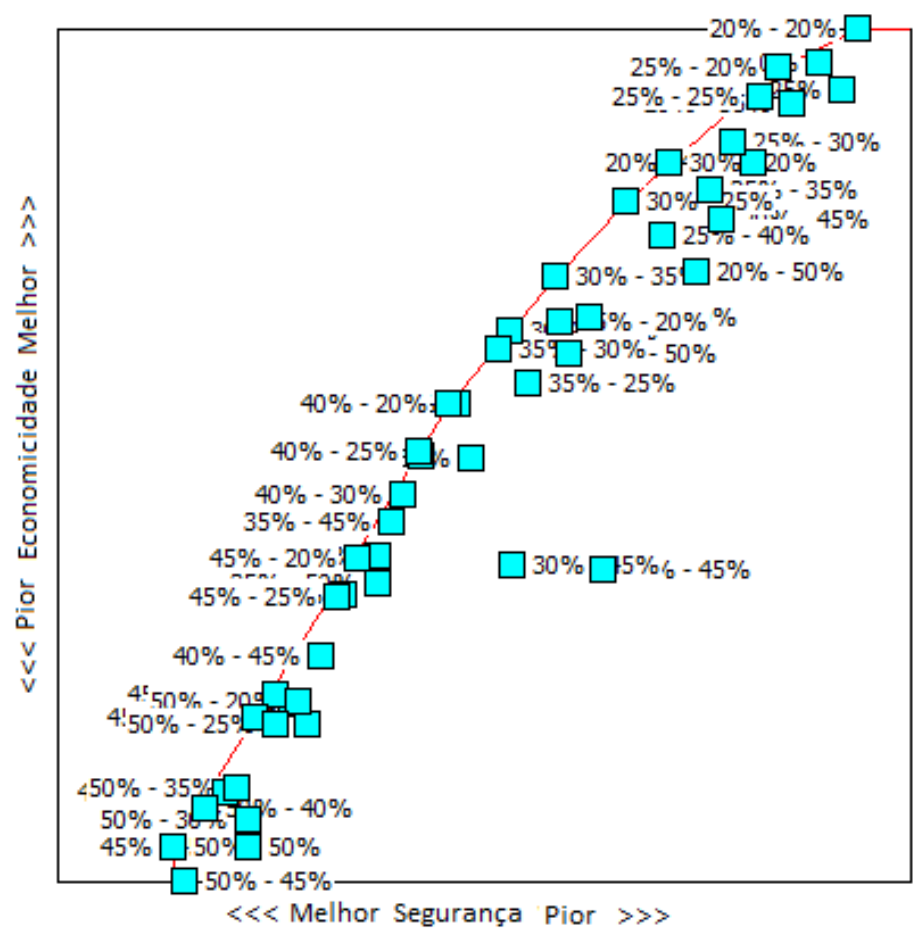

Figura 6.6: Curva de Pareto da Etapa 1 - Caso: Novas Usinas Motorizadas 


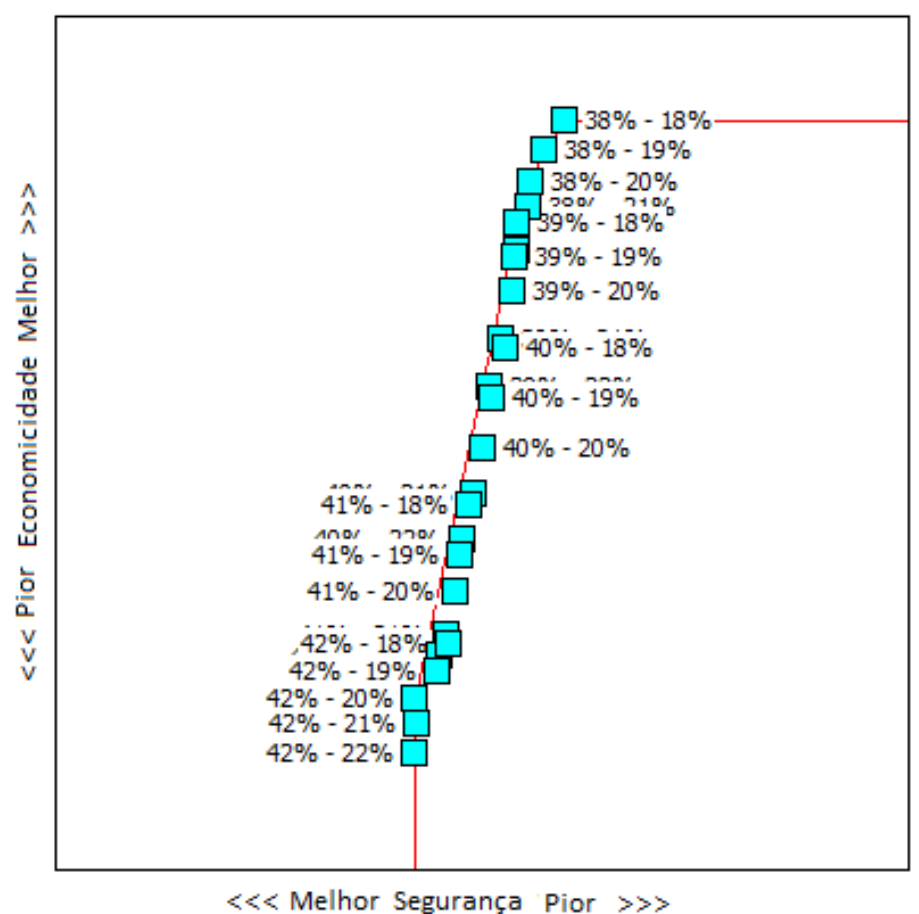

Figura 6.7: Curva de Pareto da Etapa 2 - Caso: Novas Usinas Motorizadas 


\section{Conclusões e Trabalhos Futuros}

\section{1}

\section{Conclusões}

O planejamento da operação do Sistema Interligado Nacional Brasileiro (SIN) é realizado por uma cadeia de modelos de otimização cujo critério é a minimização do valor esperado do custo total de operação em todo o período de planejamento. Entretanto, o racionamento de energia ocorrido em meados de 2001 tornou evidente a necessidade de discussão e revisão do critério de otimização, neutro ao risco, implementado até então. Consequentemente, o desenvolvimento de uma formulação capaz de incorporar aspectos de segurança à otimização econômica se tornou necessário.

A entrada de grandes usinas a fio d'água na região Amazônica, a necessidade de desenvolvimento de uma modelagem que possibilite a consideração de múltiplos objetivos e a necessidade de assegurar a sistematização do processo decisório foram os principais motivadores para a realização deste trabalho, cujo foco é a proposta de uma nova modelagem para a definição dos níveis metas para o problema de planejamento da operação.

Para a definição dos níveis metas é proposto um sistema de apoio à decisão que avalia um conjunto de alternativas de possibilidades de armazenamento para os subsistemas Sudeste/Centro-Oeste e Nordeste. O sistema proposto utiliza o método PROMETHEE II para classificar as alternativas com base nas preferências dos decisores em relação a critérios relacionados à segurança energética (percentual de risco de déficit e percentual de séries que levam o armazenamento abaixo de 20\%) e economicidade (custo de geração térmica para atingir os níveis metas).

Para avaliação da metodologia proposta foram realizados estudos de casos com a condição atual e futura, novas usinas da região Amazônica totalmente motorizadas. O sistema foi testado para verificar a coerência dos resultados e a estabilidade da solução em função de variações nos pesos estabelecidos pelos decisores. Os resultados obtidos se mostraram satisfatórios.

As principais contribuições deste trabalho, através da metodologia proposta, em relação à metodologia atualmente utilizada para a determinação dos níveis metas foram a sistematização da tomada de decisão mantendo a repro- 
dutibilidade; a não necessidade de estabelecimento prévio de série hidrológica crítica; a não necessidade de definição de premissas de intercâmbio; e a possibilidade de tratamento de outras condicionantes que não são possíveis na metodologia atual, tais como o custo para alcançar os níveis metas.

\section{2}

\section{Trabalhos Futuros}

Recomenda-se, como extensão deste trabalho, a consideração de outros critérios no sistema de apoio à decisão, tais como o atendimento à demanda de ponta e a consideração de falhas dos grandes troncos de interligação entre a região Amazônica e o subsistema Sudeste/Centro-Oeste.

Outra recomendação importante de extensão deste trabalho é a inclusão no critério econômico do impacto do custo operativo do ano seguinte em relação ao níveis de armazenamentos estabelecidos pelos níveis metas.

Outra recomendação é a consideração, no cálculo dos valores correspondentes aos critérios de percentual de risco e percentual de séries com armazenamento inferior a $20 \%$, do crescimento da participação de fontes renováveis, como por exemplo a energia eólica.

Enfim, recomenda-se, em complementação a este trabalho, estudos adicionais de sensibilidade em relação aos parâmetros ajustáveis pelo decisor, como por exemplo, a definição das funções de preferência de cada critério e os limiares de preferência e indiferença. 


\section{Referências Bibliográficas}

[1] "ONS - Operador Nacional do Sistema Elétrico." http://www.ons.org.br/historico/geracao_energia.aspx, acesso em fevereiro de 2013.

[2] M. T. Tolmasquim, Novo Modelo do Setor Elétrico Brasileiro. EPE Brasília - DF: Synergia, 2011.

[3] EPE - Plano Decenal de Expansão de Energia 2020, 2011.

[4] ONS - NT 50/2010 Metodologia de Segurança Operativa - Níveis Metas de Armazenamento, 2010.

[5] A. S. Kligerman, Um Sistema de Apoio à Decisão Bicritério para o Planejamento da Operação Energética. PhD thesis, UFF, Niterói, 2009.

[6] J. N. Clímaco, C. H. Antunes, and M. J. G. Alves, Programação Linear Multiobjectivo: do Modelo de Programação Linear Clássico à Consideração Explícita de Várias Funções Objetivo. Universidade de Coimbra, 2003.

[7] L. F. A. M. Gomes, M. C. G. Araya, and C. Carignano, Tomada de Decisões em Cenários Complexos. Thomson, 2004.

[8] L. F. A. M. Gomes, C. F. S. Gomes, and A. T. Almeida, Tomada de Decisão Gerencial um Enfoque Multicritério. Editora Atlas, 2002.

[9] R. Keeney and H. Raiffa, Decision With Multiple Objectives: Preferences and Value Trade-offs. John Wiley \& Sons, 1976.

[10] W. Edwards, "Smarts and Smarter: improved simple methods for multiatribute utility measurement," Organizational Behavior and Human Decision Processes, 1994.

[11] M. R. L. Júnior, "Análise multiatributo com tratamento da incerteza: aplicação do método Interval Smart/Swing Weighting à escolha de fornecedores de serviços de TI," Master's thesis, Ibmec, Rio de Janeiro, 2008.

[12] C. B. e Costa and J. Vansnick, "Macbeth: an interactive path towards the construction of cardinal value function," International Transactions in Operational Research, 1994. 
[13] M. C. C. Chaves, T. G. Ramos, T. D. Barros, and J. C. C. B. S. Mello, "Uso integrado de dois métodos de apoio à decisão multicritério: Vip analysis e macbeth," Proc. 8th Power System Computation Cont., 2009.

[14] T. L. Saaty, The Analytic Hierarchy Process. McGraw-Hill, 1980.

[15] P. Vincke, Multicriteria Decision-Aid. John Wiley \& Sons, 1992.

[16] V. Belton, T. J. Stewart, and C. Carignano, Multiple Criteria Decision Analysis. Kluwer Academic Publishers, 2003.

[17] J. Buchanan, P. Sheppard, and D. V. Lamsade, "Project ranking using electre iii," International Transactions in Operational Research, 1999.

[18] J. P. Brans and P. Vincke, "A preference ranking organisation method," Management Science, 1985.

[19] B. Mareschal, "Weight stability intervals in multicriteria decision aid," European Journal of Operational Research, 1988.

[20] J. P. Brans, P. Vincke, and B. Mareschal, "How to select and how to rank projects: the PROMETHEE method," European Journal of Operational Research, 1986.

[21] R. Benayoun, J. Montgolfier, J. Tergny, and O. Larichev, "Linear programming with multiple objective functions: Step Method," Mathematical Programming, 1971.

[22] S. Zionts and J. Wallenius, "An interactive programming method for solving the multiple criteria problem," Management Science, 1976.

[23] J. N. Clímaco and C. H. Antunes, "Trimap - an interactive tricriteria linear programming package," Foundations of Control Engineering, 1987.

[24] N. Mladineo, J. Margeta, J. P. Brans, and B. Mareschal, "Multicriteria ranking of alternative locations for small scale hydro plants," European Journal of Operational Research, 1987.

[25] J. P. Brans, "Ethics and decision," European Journal of Operational Research, 2002.

[26] J. Meza, M. Yildirim, and A. Masud, "A model for the multiperiod multiobjective power generation expansion planning," IEEE Transactions on Power Systems, 2007. 
[27] C. A. V. Cavalcante and A. T. Almeida, "A multi-criteria decisionaiding model using PROMETHEE III for preventive maintenance planning under uncertain conditions," Journal of Quality in Maintenance Engineering, 2007.

[28] A. Albadvi, S. K. Chaharsooghi, and A. Esfahanipour, "Decision making in stock trading: an application of PROMETHEE," European Journal of Operational Research, 2007.

[29] H. L. Ferreira, "Modelos multicritério de localização de transformadores reservas no contexto de planejamento de manutenção," Master's thesis, UFPE, Pernambuco, 2009.

[30] A. C. Passos, "Definição de um índice de qualidade para distribuidoras de energia elétrica utilizando o apoio multicritério à decisão e análise de séries temporais," Master's thesis, PUC, Rio De Janeiro, 2010.

[31] K. Brucker, C. Macharis, and A. Verbeke, "Multi-criteria analysis and the resolution of sustainable development dilemmas: a stakeholder management," European Journal of Operational Research, 2012.

[32] M. Abedi, S. Torabi, G. Norouzi, M. Hamzeh, and G. Elyasi, "PROMETHEE II: a knowledge driven method for copper exploration," Computers e Geoscience, 2012.

[33] F. M. C. de Souza, Procedimentos para a Aplicação da Teoria da Decisão. PhD thesis, UFPE, Pernambuco, 2007.

[34] V. S. Duarte, Teoria da Decisão Aplicada ao Planejamento da Operação do Sistema Hidrotérmico Brasileiro. PhD thesis, UFRJ, Rio de Janeiro, 2012.

[35] E. L. Silva, Formação de Preços em Mercado de Energia Elétrica. Editora Sagra Luzzatto, 2001.

[36] L. A. M. Fortunato, Introdução ao Planejamento da Expansão e Operação de Sistemas de Produção de Energia Elétrica. Editora Universitária EDUFF, 1990.

[37] A. L. M. Marcato, Representação Híbrida de Sistemas Equivalentes e Individualizados para o Planejamento da Operação de Médio Prazo de Sistemas de Potência de Grande Porte. PhD thesis, PUC, Rio de Janeiro, 2002. 
[38] ONS - Plano da Operação Energética 2012/2016, 2012.

[39] L. A. Terry, M. V. F. Pereira, T. A. A. Neto, L. F. C. A. Silva, and P. R. H. Sales, "Coordinating the energy generation of the brazilian national hydrothermal electrical generating system," Interfaces 16: 1638, 1986.

[40] M. V. Pereira, "Optimal scheduling of hydrothermal systems," IFAC International Symposium on Planning and Operation of Electric Energy Systems, 1985.

[41] ANEEL - Resolução 351: autoriza o funcionamento do ONS, 1998.

[42] Presidência da República - Lei no 9.648: criação do ONS, 1998.

[43] CEPEL - Manual do usuário do programa NEWAVE versão 17, 2012.

[44] CEPEL - Manual do usuário do programa DECOMP versão 18, 2012.

[45] R. V. Slyke and R. J.-B. Wets, "L-shaped linear programs with application to optimal control and stochastic programming," SIAM Journal on Applied Mathematics, 1969.

[46] CEPEL - Manual do usuário do programa DESSEM-PAT versão 5.1, 2009.

[47] ONS - Incorporação da Curva de Aversão a Risco no Cálculo da Política Operativa, 2002.

[48] "ONS - Operador Nacional do Sistema Elétrico." http://www.ons.org.br/historico/energia_armazenada.aspx, acesso em fevereiro de 2013.

[49] ONS - Processo Histórico da Representação de Aversão a Risco na PDDE, 2011.

[50] ONS - NT 065/2011 Procedimentos Operativos de Curto Prazo, 2011.

[51] "ANA - Agência Nacional de Águas." http://www2.ana.gov.br/Paginas/portais/bacias/amazonica.aspx, acesso em abril de 2013.

[52] "ONS - Operador Nacional do Sistema Elétrico." http://www.ons.org.br/conheca_sistema/mapas_sin.aspx, acesso em janeiro de 2013. 
[53] J. Kelman, E. A. de Santana, J. C. D. Saraiva, J. G. S. de Menezes Senna, and R. D. Rufino, Atlas de Energia Elétrica do Brasil $3^{a}$ edição. Brasília - DF: Brasília Aneel, 2008.

[54] EPE - Plano Nacional de Energia 2030, 2007.

[55] "Visual PROMETHEE." http://www.promethee-gaia.net/, acesso em julho de 2012.

[56] B. Mareschal and J. P. Brans, "Geometrical representations for MCDA," European Journal of Operational Research, 1988.

[57] J. P. Brans and B. Mareschal, "The promcalc \& gaia decision support system for multicriteria decision aid," Decision Support Systems, 1994. 